\section{orm}

1.

14:

OAK RIDGE

NATIONAL

LABORATORY

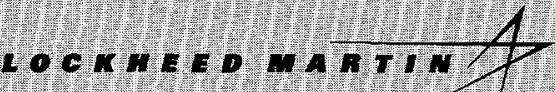
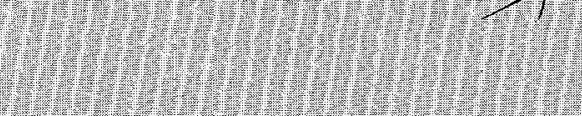

$$
\sqrt{2}
$$

(3)

WWACED ANO OPERATED BY

LOCKHEED MARTN ENERGY RESEARCH CORPORATION FOAT THE UNTED STATES DEPARTMENT OF ENERGY

\title{
Development of a Tritium Extruder for ITER Pellet Injection
}

\author{
P. W. Fisher \\ M. J. Gouge
}

\section{RECEIVED \\ OCT 291998 \\ O OTI}


This report has been reproduced directly from the best available copy.

Available to DOE and DOE contractors from the Office of Scientific and Technical Information, P.O. Box 62, Oak Ridge, TN 37831; prices available from (423) 576-8401, FTS 626-8401.

Available to the public from the National Technical Information Service, U.S. Department of Commerce, 5285 Port Royal Rd., Springfield, VA 22161.

This report was prepared as an account of work sponsored by an agency of the United States Government. Neither the United States Government nor any agency thereof, nor any of their employees, makes any warranty, express or implied, or assumes any legal liability or responsibility for the accuracy, completeness, or usefulness of any information, apparatus, product, or process disclosed, or represents that its use would not infringe privately owned rights. Reference herein to any specific commercial product, process, or service by trade name, trademark, manufacturer, or otherwise, does not necessarily constitute or imply its endorsement, recommendation, or favoring by the United States Government or any agency thereof. The views and opinions of authors expressed herein do not necessarily state or reflect those of the United States Government or any agency thereof. 


\section{DISCLAIMER}

Portions of this document may be illegible in electronic image products. Images are produced from the best available original document. 
ITER/US/98/IV-FV-05

ORNL/TM-13637

\title{
DEVELOPMENT OF A TRITIUM EXTRUDER FOR ITER PELLET INJECTION
}

\author{
P. W. Fisher \\ M. J. Gouge
}

Manuscript Completed: May 1, 1998

Date Published: September 1998

Prepared by

OAK RIDGE NATIONAL LABORATORY

Oak Ridge, Tennessee 37831 managed by

LOCKHEED MARTIN ENERGY RESEARCH CORP.

for the

U.S. DEPARTMENT OF ENERGY

under contract DE-AC05-96OR22464 
Page Intentionally Blank 


\section{CONTENTS}

\section{Page}

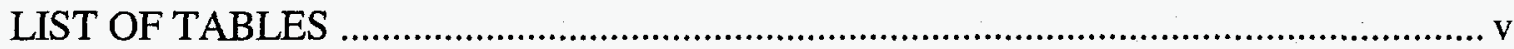

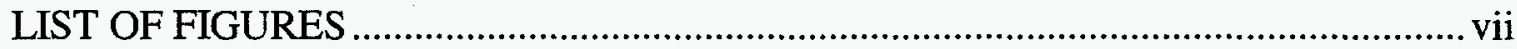

ACKNOWLEDGMENTS AND GENERAL DISCLAIMER ..................................... ix

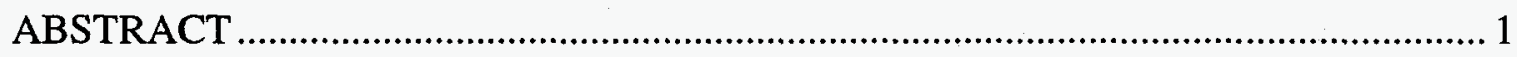

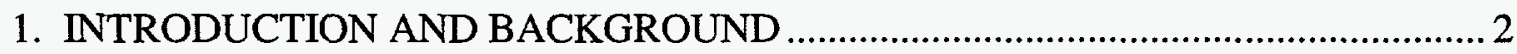

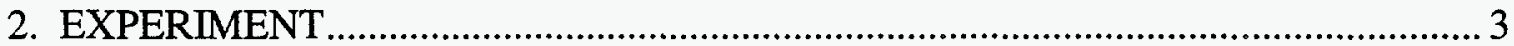

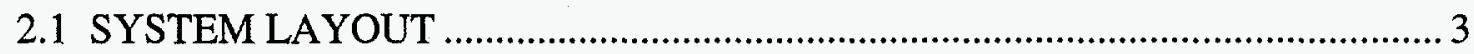

2.2 SYSTEM HARDWARE ....................................................................... 3

2.2.1 Repeating Pneumatic Injector (RPI) Assembly ..................................... 3

2.2.2 Liquid Helium Cooling System and ${ }^{3} \mathrm{He}$ separator................................. 5

2.2.3 Pellet Diagnostic Line ..................................................................... 5

2.2.4 Gas Ballast Tank ............................................................................ 5

2.2.5 Valve Manifold, Piping, and Fittings ................................................ 6

2.2.5.1 Valves and valve manifold .................................................. 6

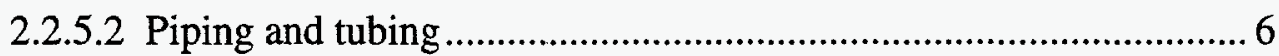

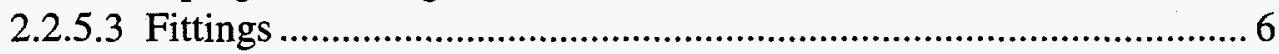

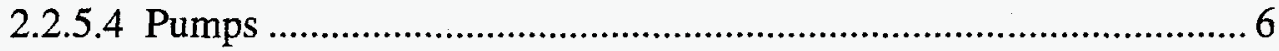

2.2.5.5 Overpressure protection ........................................................... 7

2.2.6 Secondary Confinement ................................................................... 7

2.2.7 Flow Diagram.................................................................................. 7

2.2.8 Instrumentation, Control and Data Acquisition ....................................... 8

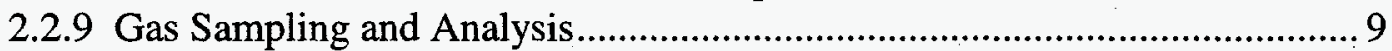

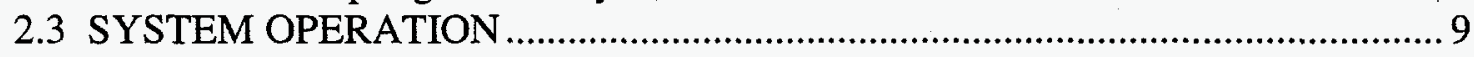

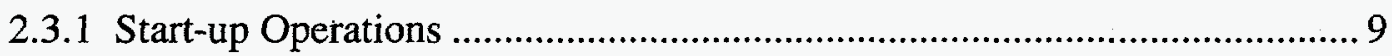

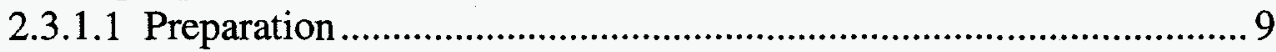

2.3.1.2 Glovebox and tritium alarm systems status ............................. 10

2.3.1.3 Valve manifold \& injection line purging and pumpdown ............ 10

2.3.1.4 Cooldown......................................................................... 10

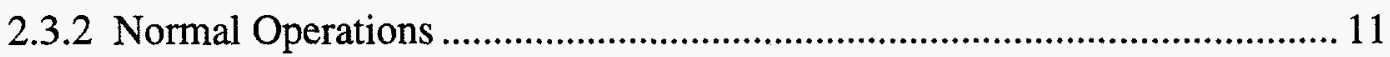

2.3.2.1 Feed gas preparation ......................................................... 11

2.3.2.2 Extruder plug formation ........................................................ 12

2.3.2.3 Extrusion, pellet formation, and firing ................................. 12

2.3.2.4 Gas recovery modes ...................................................... 13

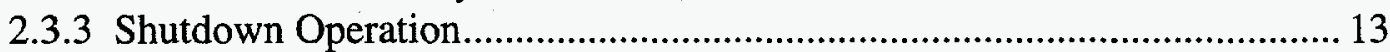

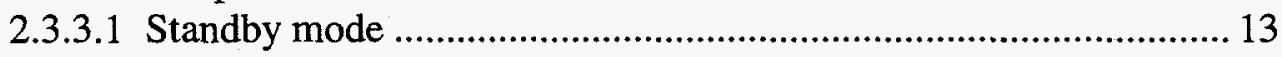

2.3.3.2 Warmup mode ............................................................... 14

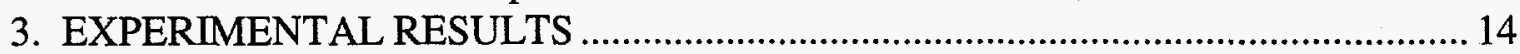

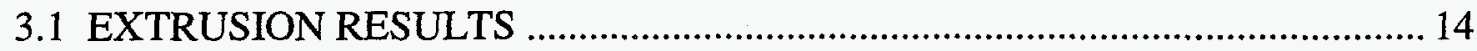

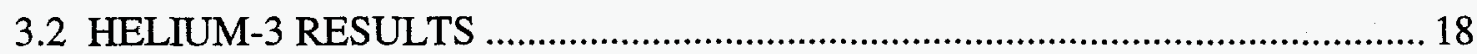

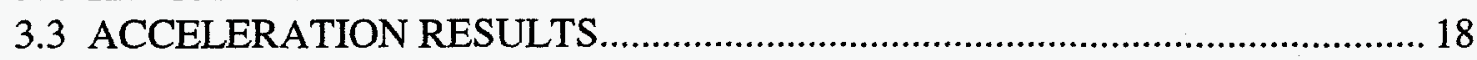

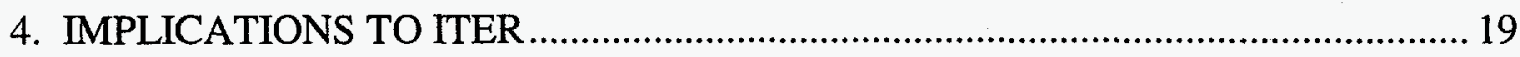

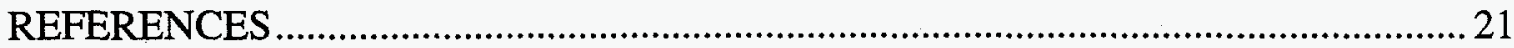


Appendix I. TRITIUM SYSTEMS TEST ASSEMBLY TEST PLAN........................59

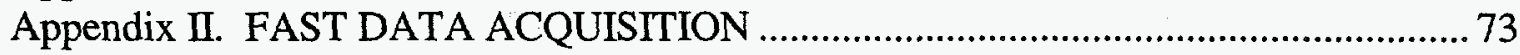

Appendix III. SUMMARY OF TPOP-II RUNS ................................................. 83 


\section{LIST OF TABLES}

Table

Page

3.1 TPOP-II tritium utilization at TSTA

23

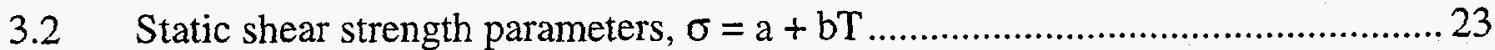

3.3 Dynamic shear strength...

23

3.4 Helium-3 separation data . 24 
Page Intentionally Blank 


\section{LIST OF FIGURES}

Figure

Page

2.1 Layout of the TPOP-II experimental apparatus 25

2.2

Photograph of the TPOP-II experimental installed in the TSTA facility .....26

2.3

2.4

Diagram of the repeating pneumatic injector assembly...

TPOP-II guard vacuum enclosure

Extruder mechanism

Pellet cutting and chambering mechanism

.30

2.7

Helium-3 separator

TPOP-I pellet diagnostic line.

Process flow diagram.

Feed gas supply manifold

Feed gas storage manifold

Interfaces between pellet injector and TSTA system .

TPOP-II control and data acquisition system ....

Volume and tritium inventory in extruder as a function of distance

from the nozzle, including the volume of the nozzle.

Cross section of TPOP-II extruder showing distance above nozzle

in centimeters

A tritium extrusion at various times

A tritium extrusion taken with less illumination

A D-T extrusion darkening with time; fresh extrusion (left) and $41 \mathrm{~s}$ later (right)

Extruder force versus position for $\mathrm{D}_{2}, \mathrm{D}-\mathrm{T}$, and $\mathrm{T}_{2}$ at comparable conditions, $0.15 \mathrm{~cm} / \mathrm{s}$ ram speed and $13 \mathrm{~K}$.

3.7 Extruder force versus position for $\mathrm{D}_{2}$ and $\mathrm{T}_{2}$ at comparable conditions, $0.27 \mathrm{~cm} / \mathrm{s}$ ram speed and $13.5 \mathrm{~K}$

3.8 Relative extrusion forces of $\mathrm{T}_{2}$ and $\mathrm{DT}$ with respect to $\mathrm{D}_{2}$ at several conditions.

3.9 Two consecutive tritium extrusions at $14.1 \mathrm{~K}$ and $1.11 \mathrm{~cm} / \mathrm{s} \mathrm{ram}$ speed. Run 1216, left peak, is a large charge of tritium and Run 1217, right peak, is the second run utilizing the relatively small remaining portion of material.

3.10 Best fit for deuterium extrusions of peak force versus peak force location and cryostat temperature

3.11 Best fit for D-T extrusions of peak force versus peak force location and cryostat temperature

3.12 Best fit for tritium extrusions of peak force versus peak force location and cryostat temperature

3.13 Shear strength as a function of temperature for solid hydrogen isotopes .....52 
3.14 Shot 1222 data with in which the fit to linear portion of curve extrapolates to the nozzle. Excursion of data above linear fit at right is due to the extrusion hitting the bottom of the cryostat

3.15 Shot 1126 data. Here the linear fit does not extrapolate to the end of the nozzle and flow is considered to be in the transition zone between static

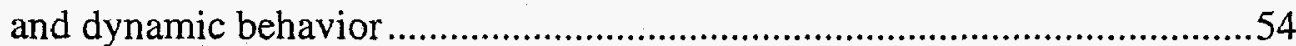

3.16 Photograph of TPOP-II deuterium pellet measuring $7 \mathrm{~mm}$ in diameter by $11 \mathrm{~mm}$ long and traveling at $1 \mathrm{~km} / \mathrm{s}$ 55

3.17 Photograph of a sequence of TPOP-II deuterium pellets at a repetition rate of $0.5 \mathrm{~Hz}$ and traveling at $1.1 \mathrm{~km} / \mathrm{s}$

3.18 Photograph of (a) an extrusion of pure tritium and (b) a pure tritium pellet in flight at the second photo station ………….......................................57

3.19 Tritium pellet speed as a function of deuterium supply pressure .58 


\section{ACKNOWLEDGMENTS AND GENERAL DISCLAIMER}

This report is an account of work assigned to the U.S. Home Team under Task Agreement No. T230 within the Agreement among the European Atomic Energy Community, the Government of Japan, the Government of the Russian Federation, and the Government of the United States of America on Cooperation in the Engineering Design Activities for the International Thermonuclear Experimental Reactor ("ITER EDA Agreement") under the auspices of the International Atomic Agency (IAEA). The report has not been reviewed by the ITER Publications Office.

This report is an account of work undertaken within the framework of the ITER EDA Agreement. Neither the ITER Director, the Parties to the ITER Agreement, the U.S. DOE, the U.S. Home Team Leader, the U.S. Home Team, the IAEA or any agency thereof, or any of their employees, makes any warranty, express or implied, or assumes any legal liability or responsibility for the accuracy, completeness, or usefulness of any information, apparatus, product, or process disclosed, or represents that its use would not infringe privately owned rights. Reference herein to any specific commercial product, process, or service by trade name, trademark, manufacturer, or otherwise, does not necessarily constitute or imply its endorsement, recommendation, or favoring by the parties to the ITER EDA Agreement, the IAEA or any agency thereof.

The views and opinions of authors expressed herein do not necessarily state or reflect those of the ITER Director, the Parties to the ITER Agreement, the U.S. DOE, the U.S. Home Team Leader, the U.S. Home Team, the IAEA or any agency thereof.

Research was performed by Oak Ridge National Laboratory managed by Lockheed Martin Energy Research Corp. for the U.S. Department of Energy under contract DE-AC05-96OR22464. 
Page Intentionally Blank 


\title{
DEVELOPMENT OF A TRITIUM EXTRUDER FOR ITER PELLET INJECTION
}

\author{
Final Report \\ P. W. Fisher \\ M. J. Gouge
}

\begin{abstract}
As part of the International Thermonuclear Experimental Reactor (ITER) plasma fueling development program, Oak Ridge National Laboratory (ORNL) has fabricated a pellet injection system to test the mechanical and thermal properties of extruded tritium. Hydrogenic pellets will be used in ITER to sustain the fusion power in the plasma core and may be crucial in reducing first-wall tritium inventories by a process of "isotopic fueling" in which tritium-rich pellets fuel the burning plasma core and deuterium gas fuels the edge. This repeating single-stage pneumatic pellet injector, called the TritiumProof-of-Principle Phase II (TPOP-II) Pellet Injector, has a piston-driven mechanical extruder and is designed to extrude and accelerate hydrogenic pellets sized for the ITER device. The TPOP-II program has the following development goals: evaluate the feasibility of extruding tritium and deuterium-tritium (D-T) mixtures for use in future pellet injection systems; determine the mechanical and thermal properties of tritium and D-T extrusions; integrate, test, and evaluate the extruder in a repeating, single-stage light gas gun that is sized for the ITER application (pellet diameter $\sim 7$ to $8 \mathrm{~mm}$ ); evaluate options for recycling propellant and extruder exhaust gas; and evaluate operability and reliability of ITER prototypical fueling systems in an environment of significant tritium inventory that requires secondary and room containment systems.

In tests with deuterium feed at ORNL, up to 13 pellets per extrusion have been extruded at rates up to $1 \mathrm{~Hz}$ and accelerated to speeds of 1.0 to $1.1 \mathrm{~km} / \mathrm{s}$, using hydrogen propellant gas at a supply pressure of 65 bar. Initially, deuterium pellets $7.5 \mathrm{~mm}$ in diameter and $11 \mathrm{~mm}$ in length were produced-the largest cryogenic pellets produced by the fusion program to date. These pellets represent about a $10 \%$ density perturbation to ITER. Subsequently, the extruder nozzle was modified to produce pellets that are almost 7.5-mm right circular cylinders. Tritium and D-T pellets have been produced in experiments at the Los Alamos National Laboratory Tritium Systems Test Assembly. About $38 \mathrm{~g}$ of Tritium have been utilized in the experiment. The tritium was received in eight batches, six from product containers and two from the Isotope Separation System. Two types of runs were made: those in which the material was only extruded and those in which pellets were produced and fired with deuterium propellant. A total of $36 \mathrm{~T}_{2}$ runs and $28 \mathrm{D}-\mathrm{T}$ runs have been made. A total of 36 pure tritium runs and $28 \mathrm{D}-\mathrm{T}$ mixture runs were made. Extrusion experiments indicate that both $\mathrm{T} 2$ and D-T will require higher extrusion forces than $\mathrm{D} 2$ by about a factor of two.
\end{abstract}




\section{INTRODUCTION AND BACKGROUND}

An earlier Oak Ridge National Laboratory (ORNL) tritium pellet injector experiment (1988-1989) ${ }^{1-3}$ operated at the Tritium Systems Test Assembly (TSTA) established the basic scientific feasibility of production and pneumatic acceleration of tritium pellets for fueling future fusion reactors. This earlier experiment, Tritium-Proof-of-Principle Phase I (TPOP-I), used a single-stage, light gas gun in which a single 4-mm-diam pellet was frozen in-situ in the barrel and accelerated with high-pressure hydrogen gas. Over $100 \mathrm{kCi}(\sim 10 \mathrm{~g})$ of tritium was processed through the experiment without incident during the entire lifetime of the project. In Phase II of this experiment, the pipe gun has been replaced with a repeating pneumatic pellet injector (RPI), which was developed by Combs, Milora, and Foust at ORNL. ${ }^{4}$ The specific embodiment of this gun is similar to the design of the injector used on the Joint European Torus ${ }^{5,6}$ and recently installed on the DIII-D tokamak experiment at General Atomics. ${ }^{7}$ These extruder-based guns have been used to fuel fusion experiments with deuterium and hydrogen pellet streams ranging from $1.8-\mathrm{mm}$-diam at $10 \mathrm{~Hz}$ to $6-\mathrm{mm}$-diam at $1 \mathrm{~Hz}$. The extrusion feed technique is quite general and has also been used in centrifugal pellet injectors. The Tritium-Proof-ofPrinciple Phase II (TPOP-II) gun is designed to produce 8-mm-diam pellets as prototypes for those that will be used to fuel the International Thermonuclear Experimental Reactor (ITER) device. Unlike TPOP-I, which was a single-shot device, the new gun is able to produce streams of more than ten pellets at frequencies up to $1 \mathrm{~Hz}$. A TPOP- $I$ run could require as much as $50 \mathrm{kCi}(\sim 5 \mathrm{~g})$ of tritium for a single fill of the extruder.

ITER requires pellet fueling to replenish burned-up fuel in the plasma, to control plasma density and burn rate, to establish a flow of hydrogenic ions in the scrape-off layer to reduce impurities and helium ash concentrations in the core of the plasma, and to influence gas composition in the plasma edge. This latter point is important to the development of the concept of isotopic fueling. ${ }^{8}$ In this concept, pellets of high-tritium concentration would be delivered beyond the scrape-off layer for plasma fueling, and gas of high-deuterium concentration would be delivered into the scrape-off layer to control the density and composition of the diverter region. The high concentration of deuterium next to the wall would translate into lower tritium concentration in the wall and would significantly reduce $(\sim 50 \%)$ the tritium inventory in the wall, which could approach several kilograms. Therefore, pellets with a broad range of tritium concentration are being evaluated in these experiments. Fueling requirements for ITER have been specified ${ }^{9}$ and call for the use of up to 10-mm-diam deuterium-tritium (D-T) pellets at about $1 \mathrm{~Hz}$. These pellets would represent about a $10 \%$ perturbation in the plasma density if the entire mass is deposited in the core. A conservative approach has been adopted here; the largest anticipated pellets are being produced so that issues related to volumetric heat generation due to decay heat from tritium in both the extruder and pellets can be evaluated.

Physical properties of solid tritium that would facilitate the design and operation of

an extruder for tritium are not known. In the course of TPOP-I experiments, ${ }^{10}$ data from break-away pressure measurements of deuterium and tritium pellets indicate that the shear strength for tritium may be about twice that of deuterium, at a temperature of about $10 \mathrm{~K}$. These numbers indicate that one might expect to encounter about twice the extrusion forces for tritium as are encountered for deuterium for a given extruder nozzle design. The actual behavior of tritium during the extrusion, punching, and acceleration 
processes must be tested to gain any confidence in the use of extruder-based pellet injectors for ITER. Because of this lack of information, it was decided to utilize the successful RPI technology with few changes to get a direct comparison of tritium with the extensive deuterium extruder database. The goals of the TPOP-II program are to determine the feasibility and conditions under which tritium and D-T mixtures can be extruded, to determine the mechanical and thermal properties of tritium and D-T extrusions, to extrude and accelerate ITER-relevant pellets in a repeating mode, to evaluate options for recycling extruder and pellet exhaust, and to evaluate the RPI design in an environment having significant tritium inventory, secondary containment, and interfaces with other tritium processing systems.

\section{EXPERIMENT}

\subsection{SYSTEM LAYOUT}

Fig. 2.1 shows a layout of the TPOP-II experimental apparatus. The repeating pneumatic injector (RPI), guard vacuum enclosure, the injection line, and the gas handling system are housed in a glovebox for tritium containment. This is the same glovebox as was used in the original TPOP experiment. A glovebox extension has been added above one end of the TPOP glovebox to contain the tritium extruder, which is too tall to fit in the original glovebox. This extension plus the weight of the extruder and guard vacuum box surrounding the RPI require the strengthening of the TPOP glovebox support structure. Shown below the glovebox is a secondarily contained, $\sim 600$ liter ballast volume to maintain pressure in the injection line below 30 mbar ( 22 torr) during pellet production runs. With very few exceptions (noted below), tritium-wetted surfaces are all metal (usually stainless steel). All interfaces between the glovebox and TSTA (tritium, deuterium, nitrogen, helium, electrical, control, vacuum connections, etc.) are through panels in the top of the glovebox. Cajon VCR fittings are used for all external gas connections in these panels. This is shown in Fig. 2.2 which is a photograph of the apparatus installed at TSTA. Operation of the entire experiment is controlled remotely from the console at the left in Fig. 2.2. High-speed data acquisition is accomplished through CAMAC digitizer modules connected to a MicroVAX II computer.

\subsection{SYSTEM HARDWARE}

\subsubsection{Repeating Pneumatic Injector (RPI) Assembly}

Fig. 2.3 is a diagram of the TPOP-II repeating pneumatic injector (RPI) assembly, which is housed in a guard vacuum chamber. This guard vacuum chamber consists of a welded box frame structure with separate plates for the four sides and top; the guard vacuum assembly is shown in Fig. 2.4. Principal RPI components include the extruder mechanism with two copper cryostats, the pellet cutting and chambering "cookie cutter" mechanism with adjacent copper cryostat, the gun barrel, the ${ }^{3} \mathrm{He}$ separator which removes the ${ }^{3} \mathrm{He}$ byproduct from the tritium radioactive decay from the incoming tritium supply gas stream. 
The extruder mechanism shown in Fig. 2.5 freezes input gas into a column of hydrogenic solid in a batch process for use at a later time. Extruders are generally capable of moving solid material at a sufficiently high rate of speed to provide a "real time" pellet feed system. The apparatus shown is an example of a repeating pneumatic injector that is capable of delivering $4 \mathrm{~mm}$ diameter pellets continuously at rates of up to $5 \mathrm{~Hz}$. For TPOP Phase II, the pellets will be larger $(\sim 8 \mathrm{~mm}$ diameter $)$ and the expected repetition rate is about $1 \mathrm{~Hz}$ max. A similar extrusion system developed for the JET tokamak ${ }^{5}$ features three extruder units of $2.7 \mathrm{~mm}, 4 \mathrm{~mm}$ and $6 \mathrm{~mm}$ capability in a common vacuum enclosure. These deuterium extruders have proven very reliable during the five years they were in operation at JET. ${ }^{6}$ The extruder section consists of a liquid reservoir positioned above a cylindrical freezing chamber which is fitted at its outlet with a tapered brass extrusion nozzle. A motor-driven screw press activates a Vespel piston that moves vertically inside the cylindrical bore of the freezing chamber where the solid hydrogenic charge is located. The extruder assembly has two cryostats; each is a $7.62 \mathrm{~cm}$ long by $7.94 \mathrm{~cm}$ diameter block of oxygen-free, high-conductivity (OFHC) copper that has 0.406 - by $0.406-\mathrm{cm}$ square cooling channels with a spiral pitch machined into it. A $50-\mathrm{W}$ Nichrome heater is wrapped around and epoxied to the perimeter of each cryostat for temperature control. The extrusion nozzle which terminates just above the chambering mechanism position provides a smooth transition from the $10.5 \mathrm{~mm}$ cylindrical extruder bore to a rectangular cross section whose length $(9.5 \mathrm{~mm})$ is larger than the punch tube diameter and whose width $(5.5 \mathrm{~mm})$ determines the length of the pellet. Present deuterium extruders typically operate at $\sim 14 \mathrm{~K}$ where the shear strength of the ice is sufficiently low enough to prevent excessive piston forces at high extrusion rates.

The pellet cutting and chambering mechanism is shown in Fig. 2.6. As the extruder feeds a continuous supply of solid deuterium (or tritium) to the gun assembly, a reciprocating electromagnetically-driven, breech-side cutting mechanism (punch tube) forms and chambers cylindrical pellets from the extrusion. The chambering mechanism contains a single cryostat, the main body of which is also a $7.62 \mathrm{~cm}$ long by $7.62 \mathrm{~cm}$ diameter block of OFHC copper that has $0.406-$ by $0.406-\mathrm{cm}$ square cooling channels with a spiral pitch machined into it. Above this main body is an integral OFHC extension which houses the chambering mechanism and the top surface of which connects to the extruder nozzle.

Tritium and D-T pellets are accelerated in the gun barrel to high velocities with controlled amounts of compressed deuterium gas delivered by a fast electromagnetic propellant valve. This valve is a fast solenoid valve $(<1$-ms opening time) developed at ORNL, which has operated at pressures up to $20.6 \mathrm{MPa}$ (3000 psi). ${ }^{11}$ It is all-metal except for the Vespel stem tip and Vespel o-ring body seal. A mini-Conflat-type seal is used for the main valve body connection to the pellet chambering mechanism. Breech pressure is measured with a quartz piezoelectric transducer (PCB 105B12, 0 to $2000 \mathrm{psi}$ ). The gun barrel is a continuous 7.7-mm- $\mathrm{m}, 1.25-\mathrm{m}$-long $(\mathrm{L} / \mathrm{D}=160)$ stainless steel tube with a wall thickness of $0.89 \mathrm{~mm}(0.035 \mathrm{in}$.). A Cajon VCR fitting attached to the muzzle end of the barrel forms an all-metal sealed interface with the injection line. At the breech end of the barrel, an indium-sealed flange bolts to the gun cryostat. The barrel assembly penetrates through a flange assembly on the front cover of the guard vacuum box. This flange assembly includes a bellows subassembly with a Cajon Ultra-Torr fitting on one end. A sleeve on the barrel OD forms a seal with this fitting, providing a vacuum tight connection. The entire barrel assembly can be removed from the system by disassembling these 
few mechanical joints, which are easily remade, without disturbing any other parts of the system.

\subsubsection{Liquid Helium Cooling System and ${ }^{3}$ He separator}

Liquid helium enters and exits the guard vacuum chamber through two vacuuminsulated, o-ring sealed, bayonet fittings (Linde-type) on the front plate. The liquid helium supply is split into four parallel cooling paths inside the guard vacuum box (the two extruder cryostats, the gun cryostat and the ${ }^{3} \mathrm{He}$ separator) each with a flow control (throttle) valve. These four parallel paths finally combine and are then discharged through the exhaust bayonet fitting. The ${ }^{3} \mathrm{He}$ separator is basically a small copper counterflow heat exchanger. A diagram is shown in Fig. 2.7. Helium coolant passes through the 1.27-cm-ID central cooling channel, which has a spiral baffle to enhance heat transfer. Tritium is cryopumped into the external finned surfaces, which have a large volume $\left(139 \mathrm{~cm}^{3}\right)$ to keep the ${ }^{3} \mathrm{He}$ pressure low during filling and a wide entry region to prevent obstruction by condensed tritium.

\subsubsection{Pellet Diagnostic Line}

The pellet diagnostic line (used in TPOP Phase I) shown in Fig. 2.8 provides several means for measuring pellet velocity and photographing pellets. The two diagnostic stations shown, which are $78 \mathrm{~cm}$ apart, are essentially identical; each has a velocity gate and a photographic station. Pellets are viewed through Ceramaseal sapphire windows with a $2.54-\mathrm{cm}(1-\mathrm{in}$.) clear viewing diameter. The windows are mounted on $7-\mathrm{cm}-\mathrm{OD}$ (2.75-in-OD) Conflat flanges and have a working pressure range from high vacuum to 2.1 $\mathrm{MPa}$ (300 psi). The velocity gates use $1-\mathrm{mm}$ optical fibers to form light beams that, when interrupted, indicate the presence of a pellet. Ensing-Bickford radiation-hard and hard-clad silica fiber cables are used. The fibers are terminated outside the vacuum system and light passes in and out of the system through sapphire windows. The gate valve in the pellet line (PV1 in Fig. 2.8) separates the gun from the injection line vacuum system and is open during operations. This pneumatically actuated (with spring closing), all-metal gate valve (VAT Series 48) has DN 16 CF (Mini-Conflat) flanges. At the end of the pellet line, a piezoelectric shock transducer (PCB 305A03) is mounted on the outside of a 7-cm Conflat flange to detect the time at which the pellet reaches the end of the diagnostic line. The multiple light gates and impact signals from the shock transducer allow independent measurement of the pellet speed.

\subsubsection{Gas Ballast Tank}

A $600 \mathrm{~L}$ gas ballast tank with secondary confinement is positioned below the glovebox (see Figs. 2.1 and 2.2). This tank receives the pellet feed and propellant gas from a single extruder run (8-10 pellets) and keeps the injection line pressure at or below about 30 mbar ( 22 torr). The tank is directly connected to the second diagnostic station in the pellet injection line via a $6.98 \mathrm{~cm}(2.75)$ inch Conflat seal. The secondary confinement tank and glovebox communicate with each other. The secondary confinement tank is connected to the glovebox through a $10.16 \mathrm{~cm}$ (4 inch) connection and nitrogen cover gas flows from the far end of the tank to the glovebox where it is monitored. 


\subsubsection{Valve Manifold, Piping, and Fittings}

\subsubsection{Valves and valve manifold}

All the process valves that contact tritium are either all-metal VAT vacuum valves with Conflat fittings or Nupro HB or BK series bellows-sealed valves with Vespel (polyimide) stem tips and VCR fittings. The Teflon-coated bellows-to-body gasket on the original Nupro valves were replaced with a silver-coated gasket for tritium service. Pneumatic valves are actuated by solenoid valves located in the glovebox; these valves vent into the glovebox. All VAT valves have position-indicating switches.

The two valve manifolds are constructed entirely of stainless steel with welded, silver-soldered, or Cajon VCR joints. Shutoff valves are pneumatically actuated, normally closed valves (Nupro BK series) with Vespel stem tips. Valve positions are determined by reading pressure switches (Whitman-P119) attached to each valve's pneumatic supply line. Each manifold has a motor control valve (MCV1 and MCV2) for metering gas delivery and for use as a pressure control element. These control valves are all metal with stepper motor drive (MKS Type 245). Pressures are indicated locally with absolutepressure, variable-reluctance transducers (Validyne AP10) with AND-10050 pressure fittings sealed with Natorq silver-plated metal boss seals.

\subsubsection{Piping and tubing}

All piping that contacts tritium or potentially contaminated gas is type 304 or 316 stainless steel tubing except for the cryostats and ${ }^{3} \mathrm{He}$ separator which are made of copper. Diameter of the major process tubing is $6.35 \mathrm{~mm}(.25 \mathrm{inch})$. Vacuum piping is $1.27 \mathrm{~cm}\left(.5^{\prime \prime}\right)$ to $5.08 \mathrm{~cm}\left(2.0^{\prime \prime}\right)$ in diameter. A flexible connection made with a welded stainless steel bellows is used in the extruder mechanism.

\subsubsection{Fittings}

Most of the process connections utilize VCR fittings with nickel gaskets. Conflat flanges with copper gaskets are used in some places. VCR unions, tees and crosses are used to connect tube to tube. No organic gaskets are used on system piping potentially wetted by tritium or D-T.

\subsubsection{Pumps}

A diaphragm pump, a scroll pump, and a turbo-molecular pump are installed in the system. None have oil or organic materials that contact tritium. The turbo-molecular pump evacuates the guard vacuum chamber which does not normally see tritium. All the pumps are located inside of secondary containment. The system's internal vacuum pump is a Normetex $15-\mathrm{m}^{3} / \mathrm{h}$ all-metal scroll pump, backed by a Normetex two-stage, all-metal diaphragm pump with a maximum discharge pressure of $100 \mathrm{kPa}(1 \mathrm{~atm})$. These pumps are outfitted with Conflat flanges for tritium service. The Normetex scroll pump evacuates the valve manifold, transfers pure hydrogen isotopes between the valve manifolds, the extruder and the ${ }^{3} \mathrm{He}$ separator and assists in transfer of D-T from TPOP-II to TSTA. 


\subsubsection{Overpressure protection}

Aluminum bursting disks are provided for overpressure protection of nodes that could receive high-pressure gas or trap cryogenically condensed gas; these disks are vented to the $\sim 600$ liter gas ballast tank, not to the glovebox, to ensure tritium containment in case of failure. Reverse buckling rupture disks (BS\&B Safety Systems RF-90), mounted in nominal 2.54-cm (1-in.) safety heads (RB-7FS) modified by adding VCR fittings, were used for this purpose. Bursting disk assemblies have the same leak tightness requirements to surroundings as all other process elements. Leak tightness through disks is tested by process measurements. Burst disk pressures are set as follows: BD1, BD2, and BD4 (extruder and fill node) are 35 psid and BD3 ( ${ }^{3} \mathrm{He}$ separator) is 90 psid.

\subsubsection{Secondary Confinement}

The glovebox used in Phase I was made of aluminum with Lexan windows; it had an internal volume of $\sim 3 \mathrm{~m}^{3}$. For Phase $I$ an additional glovebox was added to the top side of the rear portion of the existing glovebox as shown in Fig. 2.1 and 2.2 to house the extruder drive assembly. This new aluminum glovebox is dual-sided with removable end panels, Lexan windows and standard gloveports. It has a skylight opening on top and bottom. The two gloveboxes are connected using an adapter flange that interfaces between two skylight openings. The existing glovebox support structure was modified to support the new gravity loads of this glovebox extension and the extruder/gun mechanism. Internal subassemblies are attached to the glovebox with Unistrut channels that are welded to the floor and ceiling of the glovebox.

\subsubsection{Flow Diagram}

A process flow diagram is shown in Fig. 2.9. The gate valve in the pellet line (PV1) is described in Section 2.2.3. The pellet gas valve (PV2) is a Nupro HB series bellows valve and admits gas (deuterium, D-T, or tritium) to the upper liquid reservoir cryostat. Valves PV3-PV5 and PV7-PV20 are located on two pellet feed gas (tritium) manifolds, shown in Figs. 2.10 and 2.11. The manifold in Fig. 2.10 supplies pellet feed gas to the gun and tritium to the ${ }^{3} \mathrm{He}$ separator, receives feed gas (both tritium and auxiliary gas) from external sources, and serves as a gas sampling location. The manifold in Fig. 2.11 provides 12.5 liters of storage for the pellet feed gas and internal pumping and vacuum interfaces for the feed gas system. Valve PV21, located near the scroll pump, is a pneumatically actuated, spring-closing, all-metal, right-angle valve (VAT Series 37) with DN-16-CF (Mini-Conflat) flanges. This valve establishes flow between the manifolds and the external vacuum system via the pellet diagnostic line. As discussed above, the system's internal vacuum pump is a Normetex $15-\mathrm{m}^{3} / \mathrm{h}$ all-metal scroll pump, backed by a Normetex two-stage, all-metal diaphragm pump. All components in the propellant gas feed system are rated for pressures at or above the maximum operating pressure of 100 bar (1450 psi). A three-way solenoid valve SV1 located outside the glovebox (not shown in Fig. 2.9) separates the propellant supply line from the experiment. This valve limits the maximum propellant gas volume that can be released to the glovebox to $100 \mathrm{~cm}^{3}$ which is not enough to cause an overpressure hazard. Valves SV1 and SV2 are solenoid valves (Circle Seal SV20 series) with position-indicating switches. A snubber in the line 
after each of these valves limits the flow rate of high-pressure gas. Propellant gas pressure is measured with a 0- to 240 bar (0- to 3500-psi) pressure transducer (PE8, Dynisco Series 800 ). Supply pressure is measured outside the glovebox at $100 \mathrm{cc}$ volume with a 345 bar (5000-psi) full-scale, calibrated Bourdon tube gage (Pressure Products).

\subsubsection{Instrumentation, Control and Data Acquisition}

Three separate computer systems are involved in TPOP operation. The TSTA master data acquisition computer (MDAC) controls all of the functions of TSTA systems shown in Fig. 2.12 (LIO, TP1, SEC, etc.) including tritium monitoring, glovebox pressure, and glovebox purging. The TPOP process control system, presently an NCR-PC8 personal computer (PC/AT) using a program called THE FIX from Intellution, controls all systems in the TPOP glovebox. The TPOP experiment is operated in the TSTA facility in close coordination with a TSTA operator who controls all TSTA systems through MDAC while the TPOP experiment is running. A MicroVAX II computer is used to generate control signals which operate the gun during firing and for high-speed data acquisition. Fig. 2.13 is a block diagram of the TPOP control and data acquisition system. All routine operations inside the glovebox are controlled by equipment outside the glovebox. In general, the operator works only with the equipment shown along the bottom row in Fig. 2.13. Controls for this equipment (with the exception of the MicroVAX II input/output) are located on the front panel of the control console in Fig. 2.2. Valves in the experiment can be controlled either through a manual control panel or through the process control computer (but not through both simultaneously). THE FIX controls all digital and analog input and output functions through an Analog Devices micro-Mac-4000 unit. The PC/AT also operates the Lakeshore DRC-91C cryogenic temperature controllers from THE FIX through an IEEE-488 bus using a program written in the $\mathrm{C}$ language especially for this purpose. All cryogenic temperatures are measured with silicon diodes (Lakeshore DT-470-CU-12). Another C program records the number of times each valve is operated, the number of times the pump is operated, and the total time of pump operation for reliability studies. These data are recorded even if the system is being operated from the manual control panel. THE FIX is configured to allow the operator to see and control the entire process in manual mode from the PC/AT, see and control the extruder and ${ }^{3} \mathrm{He}$ separator temperatures, read and trend analog inputs (temperatures, pressures, etc.), and execute the program that is required to automatically run the system. All normal operations, such as tritium transfer to the glovebox, ${ }^{3} \mathrm{He}$ separation, extruder filling, etc., are carried out automatically by these programs. These programs were verified during the TPOP-I experiment in 1988-89. New programming for TPOP-II will be verified with deuterium feed before commencing tritium operation. Pressures in the system are controlled by MKS- 245 pressure controllers. The setpoint pressures for these controllers comes from the PC/AT, and the control-point pressures come directly from the digital panel meter gage readouts.

Signals from the light gates, shock transducers, pressure elements, temperature controllers, and the force washer are digitized by the CAMAC system. Light gates are digitized at a rate of $500 \mathrm{kHz}$ and other signals are digitized at $20 \mathrm{kHz}$. The Micro VAX II computer collects fast transient data from the CAMAC modules, provides the trigger for the pellet chambering mechanism and the fast propellant valve that accelerates 
the pellet, and collects a snapshot of all analog data values just before each shot. After the runs are completed, programs are run to plot the transient. Velocities may be calculated from the resulting time-of-flight information for three segments of the pellet path: between the first and second light gates, between the first light gate and the first indication of shock at the end of the diagnostic line, and between the second light gate and the first indication of shock. Pellet images are recorded on VHS videotape by Panasonic AG1950 video recorders using Panasonic WV-CD51 charge-coupled device (CCD) cameras. Images are back lighted by light from totally-enclosed Laser Science VSL-DYE class III-b lasers with Coumarin 481 dye, located outside the glovebox. Each 3-ns flash from a laser is carried through 1-mm optical fiber to a photo station, where it "freezes" the image of the pellet in flight. The hydrogenic extrudate is also viewed with a CCD camera in natural lighting and the image is recorded on VHS videotape by a Panasonic AG-1950 video recorder. The extrudate is viewed through windows on each side of the gun cryostat and guard vacuum box.

\subsubsection{Gas Sampling and Analysis}

Tritium analysis are performed by TSTA personnel using a mass spectrometer for ${ }^{3} \mathrm{He}$ and Raman spectrometer for hydrogen isotopes. Mass spectrometer analysis are done off-line on samples collected in gas cylinders at port " $S$ " inside the glovebox. The RAMAN spectrometer is piped directly to the TPOP-II tritium feed and exhaust lines.

\subsection{SYSTEM OPERATION}

The TPOP-II is operated from the TPOP process control computer except for the primary utility valves, breakers and some process component isolation valves. Hands-on operation is needed to pumpdown and purge system components, cooldown, conduct gas analysis and reset the extruder for the next run. Major modes in the normal sequence of operations are: preparation, glovebox verification, purging and pumpdown, cooldown, extruder operation and shutdown.

\subsubsection{Start-up Operations}

\subsubsection{Preparation}

Before any equipment was operated in the TSTA facility the following documents were written and approved: 
Title

System Design Description TPOP Pellet Injector

Phase II Tritium Extruder for ITER

Test Plan Deuterium Operation of the TPOP-II

Fuel Injection System

Test Plan Tritium Leak Checking of the TPOP-II

Fuel Injection System

Test Plan Tritium Operation of the TPOP-II Fuel

Injection System
TSTA Number

TTA-SDD-110-02

TTA-TP-TPOP-02

TTA-TP-TPOP-04

TTA-TP-TPOP-05

These documents cover all aspects of TPOP-II operation, interfaces with the TSTA system, safety analysis (FMEA in SDD), personnel training requirements, installation procedures, tritium leak testing procedures, and experimental procedures for extruded pellet runs. Operators are required to read and understand these documents before working on the experiment. They are also required to complete LANL and TSTA specific training. The tritium operations test plan is included for reference as Appendix I of this report.

\subsubsection{Glovebox and tritium alarm systems status}

The proper operation of the glovebox pressure control system and glovebox tritium and oxygen monitoring systems are verified periodically by TSTA staff in accordance with TSTA procedures.

\subsubsection{Valve manifold \& injection line purging and pumpdown}

High-pressure nitrogen for the pneumatic supply are checked to ensure it is operating at the correct setpoint. The valve manifold including auxiliary and propellant gas supplies, injection line and ballast tank are pumped down and/or purged prior to initial operation.

\subsubsection{Cooldown}

The TPOP-II guard vacuum system is evacuated before a run by the turbo-molecular pump and is then isolated from the TWT system when the guard vacuum box is at the proper vacuum for cooldown. There are three extruder cryostats; an upper extruder cryostat, a lower extruder cryostat and a gun cryostat and a ${ }^{3} \mathrm{He}$ separator. The three extruder cryostats and the ${ }^{3} \mathrm{He}$ separator cryostat are cooled down to operating temperatures which range from $5-30 \mathrm{~K}$. The cryostats are cooled by pressurized helium liquid or vapor that flows from an external 500- or 1000- liter dewar through a helium transfer line which penetrates the glovebox from above and is connected to the front face of the guard vacuum box through a custom bayonet fittings. There is a manual valve in this helium 
transfer line. There are four motor controlled needle valves (MCV3-MCV6) in the helium flow path. The needle valves regulate the flow of the helium through the cryostats and the ${ }^{3} \mathrm{He}$ separator. The amount of helium diverted from the main extruder flow path to the ${ }^{3} \mathrm{He}$ separator is controlled by MCV6. The position of the four needle valves is controlled manually at the control panel to optimize cryostat temperatures for the hydrogen isotope being used as feed gas and to minimize liquid helium consumption.

\subsubsection{Normal Operations}

\subsubsection{Feed gas preparation}

Tritium is transferred to the TPOP-II experiment in batches from product containers (PCs) or during TSTA loop runs it may be transfered directly from the Isotope Separation Syster (ISS). Usually one to two PCs will be required for a week long operation (about 2-3 pure tritium extrusion runs per PC). Before a transfer, TSTA operators mount a PC of tritium in the LIO glovebox and establishes a flow path to the TPOP-II glovebox. A program named T2FLL is then run from THE FIX on the TPOP PC/AT. This program measures the pressure in tritium line, calculates an intermediate fill pressure based on the final desired fill pressure (entered by the operator), and transfers tritium from the PC until the intermediate pressure is reached. The flow path is shown in Fig. 2.14. The scroll pump draws tritium into the storage reservoir through PV8, MCV1, PV14, PV15, PV20, and PV18. When the intermediate setpoint is reached, T2FILL stops the flow of tritium by closing MCV1 and the program ends. When T2FILL ends, the TSTA operator shuts the hand valve on the PC in LIO. The TPOP operator then starts a program called T2FILL2. This program transfers all the remaining tritium from the line into the 15 liter storage reservoir by again opening MCV1 until the line is empty. The program then closes the valves and de-energizes the pumps.

Helium obtained directly from the ISS is very pure and does not require any further processing before use. However, tritium obtained from PCs must be processed to remove ${ }^{3} \mathrm{He}$ (which ranged from $3 \%$ to $16 \%$ during TPOP-I experiments). Helium must be removed from the tritium before it can be used to produce extruded pellets. To do this the TSTA operator establishes a vacuum exhaust route through TP1 to some destination which can accept helium, e.g. an empty PC in the LIO glovebox. The ${ }^{3} \mathrm{He}$ separator is cooled to $<12 \mathrm{~K}$. If the gas is to be analyzed, a sample cylinder is attached to the sample port and evacuated, then rinsed with deuterium and evacuated several times to remove all traces of helium from the previous sample. Program HE3-SEP is then run to carry out the separation. This program establishes a flow path between the storage reservoir and the ${ }^{3}$ He separator by opening valves PV5, PV11, and PV18, as shown in Fig. 2.15. The temperature in the separator will rise slightly (to $>20 \mathrm{~K}$ ) as the separator condensed the feed gas; afterwards it will be returned to $12 \mathrm{~K}$ (typically within $30 \mathrm{~s}$ ), the vacuum system is opened to the other side of the separator (by opening PV3) to draw off ${ }^{3} \mathrm{He}$ and lower the separator pressure to allow transfer of the remaining tritium from the reservoir. At this point the separator is isolated from the feed reservoir by closing PV5. The separator is then heated to $15 \mathrm{~K}$ and the ${ }^{3} \mathrm{He}$ is swept out to the vacuum with a small amount of tritium (tritium vapor pressure $=4$ torr at $15 \mathrm{~K}$ ) for a period of $4 \mathrm{~min}$. Low ${ }^{3} \mathrm{He}$ levels can not be obtained if the separator is operated at lower temperatures $(<15 \mathrm{~K})$ during this 
period, either because of flow limitations from the separator or because of cryotrapping of ${ }^{3} \mathrm{He}$ in the solid tritium. Helium is pumped out of the system through PV3, PV16, PV15, and PV10 to the exhaust line to TP1. At this point PV3 and PV5 are closed to isolate the separator from the system. The balance of the system (excluding the separator), including both reservoirs and all lines, is carefully rinsed with deuterium and evacuated to TP1 to remove all traces of residual ${ }^{3} \mathrm{He}$. Flow from the separator is then routed to the storage reservoir through the scroll pump, and the tritium is transferred by heating the separator. Typically, more than $95 \%$ of the initial tritium charge is recovered for use in pellet production after the separation. At this point a sample is taken for analysis by mass spectroscopy.

To prepare a gas mixture of deuterium and tritium, the desired amount of tritium is transferred into the glovebox, treated to remove ${ }^{3} \mathrm{He}$, and stored in the reservoir. The desired amount of deuterium is then admitted from the auxiliary gas line into the feed volume, and a program named MIXGAS is run. This program circulates the gas in a loop through both reservoirs by using the scroll pump, interrupting the flow several times so that all the gas accumulates in one reservoir to help promote mixing. Samples of this gas may be analyzed by the RAMAN spectrometer.

\subsubsection{Extruder plug formation}

A plug must be formed in the nozzle of the extruder before gun operation can commence. A special punch controller has been provided which can engage and hold the punch in place with minimum current to block the escape of gas from the gun. This unit is interlocked to the extruder drive so that the drive can't be operated with the punch engaged. The temperature of the lower cryostat (TE3) is allowed to fall to less than $10 \mathrm{~K}$ for this operation and temperatures of the top and middle cryostats (TE1 and TE2) are set at $14 \mathrm{~K}$ and $23 \mathrm{~K}$ respectively (for deuterium). Gas is admitted to the extruder through PV2, PV4, and MCV2 at a controlled pressure starting at 100 torr and gradually increasing to reservoir pressure. After the system has come to equilibrium, the punch will be extracted and the extruder motor will be run at a low speed to compact the solidified material. The extrudate can be observed through the windows in the lower cryostat. The Normetex pumps may be used to increase the feed gas pressure to the extruder if necessary.

\subsubsection{Extrusion, pellet formation, and firing}

The temperature of the three extruder cryostats is verified to be in the proper range for the isotope being extruded:

\begin{tabular}{|c|c|c|c|}
\hline & Deuterium & $\mathrm{D}-\mathrm{T}$ & Tritium \\
\hline Upper extruder cryostat & $23 \mathrm{~K}$ & $\overline{23 \mathrm{~K}}$ & $23 \mathrm{~K}$ \\
\hline Lower extruder cryostat & $14 \mathrm{~K}$ & $13 \mathrm{~K}$ & $13 \mathrm{~K}$ \\
\hline Gun cryostat & $14 \mathrm{~K}$ & $13 \mathrm{~K}$ & $13 \mathrm{~K}$ \\
\hline
\end{tabular}

Feed gas is supplied to the extruder at constant pressure, using a batch procedure called CONSTPRES. For each run, the operator enters the desired pressure and starts the program. Extruder filling is considered complete when the upper cryostat is filled with 
liquid by coming into equilibrium with the feed gas pressure. Actual extrusion is initiated by a batch procedure called EXTRUDE run from THE FIX software on the TPOP-II process control computer. This program starts the extruder drive motor in the down (extrude) direction and sends a delayed digital signal to the MicroVAX computer which initiates a pre-programmed pellet firing sequence (total number of pellets, repetition rate specified in advance) by sending signals to the pellet chambering mechanism power supply and propellant valve power supply via CAMAC timing modules. Details of the fast data acquisition system are given in Appendix II. The normal propellant gas was hydrogen for runs made at ORNL and deuterium for runs made at TSTA. In parallel, the CAMAC digitizing modules record the data (pellet chambering mechanism shock transducer, propellant valve downstream pressure, two injection line light gates, and target plate shock transducer, etc.) and prepares for the next shot. Data may later be transferred to ORNL over ethernet or by storing files on TK50 tapes. Plots of the CAMAC digitizer data may be made using a program named SPLOT. Hard copies of all of this information have been placed in notebooks with photographs of the pellets.

There are several safety interlocks on the extruder that stop the extruder drive motor. There is a force washer (A. L. Design, Inc. ALD-W-20), which is set at $4445 \mathrm{nt}$ (1000 pounds), and temperature interlocks for the three cryostats set at $10 \mathrm{~K}$. Also there are upper and lower limit switches on the extruder drive path to prevent piston travel outside predetermined limits.

\subsubsection{Gas recovery modes}

\subsection{Injection line/gas ballast tank gas recovery}

After an extruder run in which pellets are extruded and accelerated, there will be of order 10,000-20,000 mbar-liter (7,500-15,000 torr-liter) of pellet feed gas (deuterium, D-T or tritium) and propellant gas (deuterium) in the injection line/gas ballast tank. This will result in a vacuum of $20-30$ mbar (22 torr) in these systems. Prior to the next run, this gas will be transferred to an empty PC or to a metal getter bed to get the injection line vacuum back to a level of order 1-2 mbar (0.7-1.5 torr). A fraction of this gas inventory could be recycled as pellet feed gas to the extruder for the next run if the isotope mix is of interest.

\subsection{Extruder exhaust gas recovery}

For runs in which the extruder is run without producing and accelerating pellets (i.e. no propellant gas is added to system) it was beneficial to recycle the exhaust extruder gas back to the extruder for the next run. This process allowed multiple extrusion runs to be made with gas on known composition.

\subsubsection{Shutdown Operation}

\subsubsection{Standby mode}

There is no hydrogenic feed material in the extruder. The guard vacuum box and all manifold and piping systems are at normal vacuum and the liquid helium inlet valve is 
manually shut to conserve helium in the dewar. The cryostat temperatures are allowed to slowly drift upward. This mode will be used for long (of order $>30 \mathrm{~min}$ ) delays after cooldown is complete while performing auxiliary tasks such as transferring tritium from a new PC. Glovebox pressure control and monitoring systems remain functional.

\subsubsection{Warmup mode}

All hydrogenic gases are transferred from the extruder, interior piping and the injection line to either the valve manifold storage reservoirs, empty (waste) PC's or metal getter beds. The liquid helium inlet valve is shut and the cryostat temperatures are allowed to slowly drift upward. The guard vacuum remains isolated from the PEV until the cryostat temperatures are in the $30-40 \mathrm{~K}$ range to determine if there has been any hydrogenic gas leakage. If leakage is below acceptable limits, the guard vacuum pumping system is opened to the PEV. Glovebox pressure control and monitoring systems remain functional.

\section{EXPERIMENTAL RESULTS}

Appendix III shows a summary of the TPOP-II experimental runs. There have been basically five experimental campaigns, the first at ORNL involved only deuterium and the balance at TSTA all involved tritium as well as deuterium. The first campaign was made during fabrication of the gun at $O R L^{13}$. These runs were made to assure gun performance before shipment to TSTA. As such there was not a great deal of emphasis placed on data acquisition, indeed the data acquisition system itself was one of those items being developed during this period. Some modifications to the equipment and operating procedure were made during this period which are reflected in the way the gun was operated at TSTA. Prior to the first campaign at TSTA, the TPOP-I system was brought out of storage and refitted with the TPOP-П 8-mm RPI extruder based gun. During the period $8 / 31 / 95$ to $9 / 28 / 95$ the system was first operated with $\mathrm{D}_{2}$ to prove its integrity and to establish some basis for comparison with later $\mathrm{T}_{2}$ runs. The system was then secured for $T_{2}$ operations and tritium leak tested. Following this, the first $T_{2}$ runs were made with $\mathrm{T}_{2}$ drawn from PCs. This completed the second campaign ${ }^{14}$. The third campaign (4/23/96 to $4 / 25 / 96)$ was made over six months later using tritium from PCs. The fourth campaign (8/15/96 to 8/16/96) was made about four months later during a TSTA loop run. This campaign was not as productive as it could have been because the data acquisition programs were not working properly at the start and the campaign and work was terminated prematurely when the TSTA loop developed a leak. The fifth and final campaign was conducted over a year later $(9 / 16 / 97$ to $9 / 19 / 97)$ utilized tritium from

PCs. This campaign was devoted exclusively to making extrusion runs for the purpose of characterizing the properties of solid $\mathrm{T}_{2}$ and $\mathrm{D}-\mathrm{T}$.

\subsection{EXTRUSION RESULTS}

Extruder operation was constrained by the availability of $T_{2}$. Tritium utilization during all phases of the TPOP experiment is summarized in Table 3.1. About $38 \mathrm{~g}$ of $\mathrm{T}_{2}$ 
have been processed through the TPOP system. As can be seen, the amount of $T_{2}$ transferred to the experiment increased with time as the experience and confidence level increased. Early transfers were about $2.7 \mathrm{~g}$ and the largest transfer made during the loop run directly from the Isotope Separation System (ISS) was 4.6g. Figure 3.1 shows a plot of the extruder inventory as a function of fill level above the nozzle (the nozzle itself contains about $1 \mathrm{~g}$ of $\mathrm{T}_{2}$ ). Inventories of $2.7 \mathrm{~g}$ and $4.6 \mathrm{~g}$ correspond to levels of $6.2 \mathrm{~cm}$ and $13.1 \mathrm{~cm}$ respectively. A drawing of the extruder is shown in Fig. 3.2 along with a scale to indicate elevation above the nozzle. Filling to the $6.2 \mathrm{~cm}$ level is barely enough to fill the lower cryostat. Filling to the $13.1 \mathrm{~cm}$ level is enough material to reach the flutes. Typically, these extruders are operated with an unlimited supply of gas so that the upper cryostat will have a pool of liquid available at all times. Similar operation was only approached in the last TPOP-II campaign. Another difference between normal extruder operation and these experiments is that normally the feed gas pressure is quite high (typically 1 bar) whereas the fill pressure here was often below the triple point pressure of $\mathrm{T}_{2}$ (162 torr). Although there was no problem getting the extruder to accept all the gas below the triple point, it is not known what effect the absence of a liquid phase during filling might have on the quality of the ice. However, it was apparent that the quality of the extrusion improved as more material became available for testing.

Typical operating temperatures for the top, middle, and bottom extruder blocks were 23,13 , and $13 \mathrm{~K}$ respectively. Plugs were formed with the punch closed and the heat turned off on the lower block, which reduced its temperature to $<10 \mathrm{~K}$. However, it was found that the lower block could be cycled up in temperature to $\sim 30 \mathrm{~K}$ to evaporate frozen extrusion which was pumped to the top of the extruder for another run without loosing the plug in the extruder. This process required considerable time if the pressure inside the lower block was kept low by pumping on it. However, if the block was kept isolated and allowed to go above the triple point, the extrusion would rapidly liquefy forming rain which could be rapidly removed and recycled.

Figure 3.3 shows a series of pictures of a typical extrusion of pure $\mathrm{T}_{2}$. The pictures were taken with a CCD camera and the frames shown here were taken every two seconds through a $14 \mathrm{~s}$ extrusion. As can be seen the quality of the extrusion, as indicated by the transparency of the extrusion, is best in the middle of the run. The extrusion is $5.5 \mathrm{~mm}$ wide and $9.5 \mathrm{~mm}$ thick (i.e., into the page). This picture is somewhat deceiving because the light is bright enough to saturate the $\mathrm{CCD}$ elements and produce the appearance that the extrusion is necking down. This is not the case, the extrusion is square and straight along the edges. This is illustrated in Fig. 3.4, which shows the picture of an extrusion with less intense illumination. Another thing to note in Fig. 3.3 is that the extrusion hits the bottom of the lower block and wobbles back and forth (buckles) at the end.

Figure 3.5 shows that a fresh transparent extrusions darken (become translucent then opaque) after several tens of seconds presumably due to beta decay. Apparently the pressure in the extruder is high enough to heal these imperfections during at least part of the extrusion process because some transparent material is produced. However, the darkness observed in other parts of the extrusion could either be due to residual beta imperfections, which have not been healed, or to more gross mechanical imperfections such as cracks and holes, which presumably would take more pressure to heal.

The tritium extrusion was found to be quite robust and it would not rapidly melt if the lower block were kept evacuated. The principle source of heat in this situation is the 
tritium decay heat. The time required for the beta decay heat to melt an isolated piece of tritium extrusion can be estimated from

$$
\Delta t=\left(C_{\mathrm{S}} \Delta \mathrm{T}+\Delta \mathrm{H}_{\mathrm{f}}\right) / \mathrm{dH} / \mathrm{dt}
$$

where $\mathrm{C}_{\mathrm{S}}$ is the heat capacity of the solid, $\Delta \mathrm{H}_{\mathrm{f}}$ is the heat of fusion of the solid, and $\mathrm{dH} / \mathrm{dt}$ is the decay heat output of tritium. Using values from Souers ${ }^{12}\left(\mathrm{C}_{\mathrm{S}} \sim 11 \mathrm{~J} / \mathrm{mole}-\mathrm{K}, \Delta \mathrm{H}_{\mathrm{f}}=\right.$ $233 \mathrm{j} / \mathrm{mole}$, and $\mathrm{dH} / \mathrm{dt}=1.95 \mathrm{~W} / \mathrm{mole}$ ), one would expect the $13 \mathrm{~K}$ extrusion to persist about $2.7 \mathrm{~min}$ in a vacuum. It has been observed that the extrusion persists much longer periods of time than this in vacuum and heating of the lower block well above the melting point $(-30 \mathrm{~K})$ is required to flush the solid out of the cryostat for recycling. The persistence of the solid tritium pellet is probably due to heat transfer down the extrusion from colder parts of the extruder and cooling from evaporation.

Figure 3.6 and 3.7 show typical extrusion force as a function of ram position curves for $\mathrm{T}_{2}, \mathrm{D}-\mathrm{T}$, and $\mathrm{D}_{2}$ which were run at comparable conditions. As can be seen there is a definite progression $\mathrm{F}_{\mathrm{T} 2}>\mathrm{F}_{\mathrm{D}-\mathrm{T}}>\mathrm{F}_{\mathrm{D} 2}$ at a given position. Positions here are as measured by the data acquisition system; they run in the opposite direction from that shown in Fig. 3.2 and the entrance to the nozzle (zero in Fig. 3.2) is located at $\sim 10 \mathrm{~cm}$. The relative values of the forces with respect to $D_{2}$ are plotted in Fig. 3.8. As can be seen at the left-hand end of the curve (which is the most important because this is where the highest forces are encountered) forces required for D-T extrusion are about 1.5 that of $\mathrm{D}_{2}$ and that required for $T_{2}$ is $2-2.5$ times that of $D_{2}$.

Figure 3.9 shows a comparison of two consecutive tritium extrusion runs in which very little additional tritium was added to the extruder for the second run. These typical runs show that a much higher force is initially required to start the extrusion than is required to maintain the extrusion at a constant rate. For the purposes of characterizing this data, the two regions will be separated and characterized by a static shear strength, responsible for the high initial force, and a dynamic shear strength, responsible for behavior of the balance of the extrusion. The static shear strengths should be comparable to those determined from pipe gun break-away pressures. Die forces in these experiments were negligible because there was no area reduction of the nozzle. The peak force at the beginning of the extrusion $f(T, L)$ is a function of the temperature $(T)$ and length $(L)$ of the billet contained in the extruder:

$$
f(T, L)=f(\operatorname{Ram})+L P \sigma(T)
$$

where $f(\operatorname{Ram})$ is the force required to overcome ram friction, $P$ is the perimeter of the extruder, and $\sigma(\mathrm{T})$ is the static shear strength of the ice. For the short temperature range involved in these experiments it will be assumed that $\sigma(\mathrm{T})$ follows the linear function:

$$
\sigma(\mathrm{T})=\mathrm{a}+\mathrm{bT}
$$

For this extruder $\mathrm{P}=3.27 \mathrm{~cm}$ and $\mathrm{L}=14.5-\mathrm{z}$ (in $\mathrm{cm}$ ) where $\mathrm{z}$ is the ram position reported by the data acquisition system. Examination of runs in which there was little material extruded (e.g. 1217 in Fig. 3.9) indicates that the ram force always levels off at 
about $100 \mathrm{lb}_{\mathrm{f}}$ prior to encountering material, therefore, it is assumed that $\mathrm{f}(\mathrm{Ram})=$ $100 \mathrm{lb}_{\mathrm{f}}$. TableCurve ${ }^{\circledR} 3 \mathrm{D}^{15}$ was used to determine values of $\mathrm{a}$ and $\mathrm{b}$ from experimental data for the materials studied here; data fits are shown in Figs. 3.10, 3.11, and 3.12 and the parameters are summarized in Table 3.2. Static shear strengths are also plotted as a function of temperature in Fig. 3.13 along with break-away pressures measured in the TPOP-I 10,16 experiment. Agreement with the previously measured data and other literature data $17,18,19$ is good.

Determination of the dynamic shear strength $\sigma_{\mathrm{D}}$ of the material can be made from the extrusion data using an equation similar to Eq. 2:

$$
f(L)=f(R a m)+L P \sigma_{D}
$$

This equation indicates that the extrusion force should become a linear function of ram position after the initial static shear has been overcome. There are several problems that have been encountered in these experiments that severely limit the usefulness of the data for determining this quantity. Firstly, since the apparatus was designed mainly for shooting pellets, the lower cryostat was not designed to be long enough to except the entire length of the extrusion, therefore, the extrusion hits the bottom of the cryostat before the ram is fully inserted. When this occurs, an additional buckling force is added to the measurement that makes Eq. 4 invalid. This is illustrated in Fig. 3.14, which shows the line fitted by the least squares method for the linear portion of the curve. The extrusion should hit the bottom of the cryostat when the ram reaches $8.3 \mathrm{~cm}$ and the end of the nozzle is located at $14.5 \mathrm{~cm}$ on this scale (there is $8 \mathrm{~cm}$ between the end of the nozzle and the bottom of the cryostat). It is clear that the data becomes errant at this point. Another interpretational problem is that the flow must be well developed and not in the transition between static and dynamic behavior. This will occur only when the extruder is relatively full at the start of the run, and even then there is a race between becoming well developed and hitting the bottom of the cryostat. To be consistent with the model the linear extrapolation of the best fit line to the end of the nozzle should have a force of zero or greater; and one might argue that it should be equal to $f(\operatorname{Ram})$. The data in Fig. 3.14 is assumed to be acceptable for this analysis because it shows an extrapolated $21.5 \mathrm{lb}$. force at the end of the nozzle. Figure 3.15 shows a case where the data clearly does not fit this behavior and the fully developed dynamic behavior is totally masked by the additional buckling force. Unfortunately, because of the limited amounts of material available, the latter type of behavior was observed most often. There was sufficient data available for this analysis only at 14 and these results are presented in Table 3.3 and plotted in Fig. 3.13. Note that the ratio of dynamic to static shear strength is about $0.7,0.6$, and 0.5 for $D_{2}, D-T$, and $T_{2}$ respectively. The data showed no dependence of dynamic shear strength on shear rate (ram speed).

It was mentioned previously that effects due to area reduction in the nozzle were small and could be ignored. Now that the dynamic shear strength is known, it is possible to estimate the magnitude of this effect. The extrusion pressure 20 required to overcome the area reduction in the nozzle can be estimated from:

$$
P=\sigma_{D} \ln \left(\mathrm{A}_{1} / \mathrm{A}_{2}\right)
$$


where, $A_{1}$ is the nozzle entrance area, and $A_{2}$ is the nozzle exit area. In this extruder $\mathrm{A}_{1} / \mathrm{A}_{2}=1.63$ and $\mathcal{P} / \sigma_{\mathrm{D}}=0.5$, therefore for dynamic shears in the range of $0.2-0.3 \mathrm{MPa}$ observed at $14 \mathrm{~K}$ the extrusion pressure would be on the order of $0.1-0.15 \mathrm{MPa}$. This translates into a ram force of $2-3 \mathrm{lb}$. Force, a small fraction of the force observed in these experiments. This term becomes larger, but not significantly larger, for smaller extrusions. For example, a one-millimeter diameter extrusion would require about ten times the force of the TPOP extruder $\left(20-30 \mathrm{lb}_{\mathrm{f}}\right)$.

\subsection{HELIUM-3 RESULTS}

Analyses of the $\mathrm{T}_{2}$ gas samples after ${ }^{3} \mathrm{He}$ separation by mass spectrometry are shown in Table 3.4. Helium-3 compositions after separation show a consistent level of about $1 \%$. This is much higher than the best results for the TPOP-I experiment which showed $<0.005 \%$. The reason for this is probably that the same separator is being used for this experiment which involves 5-10 times as much $\mathrm{T}_{2}$ as the former experiments. Increasing the separator size or optimization of the separation procedure could possibly improve its performance; but the few attempts to improve performance tested in these limited experiments proved to be ineffective. Unlike the pipe-gun experiments that showed poor performance with high ${ }^{3} \mathrm{He}$ levels, these experiments proved more positive in that there was no apparent detrimental effect of ${ }^{3} \mathrm{He}$ at these levels on extruder performance.

\subsection{ACCELERATION RESULTS}

During the first run campaign at ORNL, deuterium pellets were produced and accelerated with hydrogen propellant. Figure 3.16 shows one of the early deuterium pellets produced by the gun using a rectangular extrusion nozzle $8 \mathrm{~mm}$ wide and $9.5 \mathrm{~mm}$ thick. After acceleration these pellets were typically $7.5 \mathrm{~mm}$ in diameter by $11 \mathrm{~mm}$ long and traveled at speeds of up to $1.1 \mathrm{~km} / \mathrm{s}$. These pellets would represent about a $10 \%$ density perturbation to ITER. Subsequently, the extruder nozzle was replaced by one $5.5 \mathrm{~mm}$ wide and $9.5 \mathrm{~mm}$ thick, which produced pellets with an accelerated aspect ratio of about one. Figure 3.17 shows a sequence of eleven deuterium pellets fired at a rate of $0.5 \mathrm{~Hz}$. Each of these pellets would represent about a $7 \%$ density perturbation in ITER. Figure 3.18 shows an extrusion of pure tritium and a pure tritium pellet produced at TSTA. Speed results are not of general interest due to the substantial data from TPOP-I for pellet speed as a function of pellet mass and breech pressure ${ }^{16}$. Speed data from this experiment is of little use for two reasons: First, the breech pressure transducer used in TPOP-II has not provided reliable data (and it has not been replaced because this would break a primary tritium boundary). Second, the speeds have generally been lower due to the intentionally conservative use of $\mathrm{D}_{2}$ propellant which mixes with the extruder feed material after a shot and reduces the $T_{2}$ concentration for the next shot. Figure 3.19 shows the general trend of tritium pellet speed as a function of deuterium propellant supply pressure. The fit to $80 \%$ of ideal gun theory is typical for this type of data 16 . 


\section{IMPLICATIONS TO ITER}

The TPOP-II experiment has shown that both $\mathrm{T}_{2}$ and D-T pellets of a size, which is interesting for ITER fueling, can be fabricated and accelerated using methods that have been developed and tested with $D_{2}$. Operating temperatures for fabrication devices like extruders appear to be similar for all isotopes. Extrusion pressures are, however, larger for the heavier isotopes. It has been shown that relatively high ${ }^{3} \mathrm{He}$ levels are acceptable in an extrusion based system, however, a large number of consecutive fills have not been made to simulate accumulation in the extruder and fully establish the maximum acceptable level. The decay heat in tritium does not prevent pellet formation and the pellets, once formed, do not rapidly melt. Although these experiments have been relatively limited and the physical properties of $\mathrm{T}_{2}$ and $\mathrm{D}-\mathrm{T}$ have not yet been fully characterized, no adverse effects have been discovered which would bar their use in a centrifugal or pneumatic pellet fueling system. 
Page Intentionally Blank 


\section{REFERENCES}

1. P. W. Fisher et al., "Tritium Proof-of-Principle Injector Experiment," Fusion Technology, 14, 977 (1988).

2. P. W. Fisher et al., "Tritium Pellet Injector Results," J. Vac. Sci. Technol., 7, 939 (1989).

3. P. W. Fisher, D. T. Fehling, and S. L. Milora, "Tritium Proof-of-Principle Pellet Injector Results," IEEE Proc. of the 13th Symp. on Fusion Engineering, Knoxville, Vol. 2, p. 1236, IEEE 89CH2820-9, Institute of Electrical and Electronics Engineers, New York (1989).

4. S. K. Combs et al., "Repeating Pneumatic Hydrogen Pellet Injector for Plasma Fueling," Rev. Sci. Instrum., 56, 1173 (1985).

5. S. K. Combs et al., "A Three-Barrel Repeating Pneumatic Injector for Plasma Fueling of the Joint European Torus," J. Vac. Sci. Technol. A, 6, 1901 (1988).

6. S. K. Combs et al., "Performance of a Pneumatic Hydrogen-Pellet Injector System on the Joint European Torus," Rev. Sci. Instrum., 60, 2697 (1989).

7. S. K. Combs, C. R. Foust, and S. L. Milora, "Small-bore (1.8-mm), High Firing Rate (10-Hz) Version of a Repeating Pneumatic Hydrogen Pellet Injector," Rev. Sci. Instrum., 66, 2736 (1995).

8. M. J. Gouge et al., "Fuel Source Isotopic Tailoring and Its Impact on ITER Design, Operation, and Safety," Fusion Technology, 28, 1644 (1995).

9. H. Nakamura, et al., "Status of ITER Fueling and Wall Conditioning System Design," Vacuum, 47, 969 (1996).

10. P. W. Fisher, "Properties of Tritium Inferred from Pellet Injector Experiments," Fusion Technology, 21, 794 (1992).

11. S. L. Milora, S. K. Combs, and C. R. Foust, "Fast Opening Magnetic Valve for High-Pressure Gas Injection and Applications to Hydrogen Pellet Fueling Systems," Rev. Sci. Instrum. 57, 2356 (1986).

12. P. C. Souers, Hydrogen Properties for Fusion Energy, University of California Press, Berkeley (1986).

13. P. W. Fisher, "Tritium Proof-of-Principle Pellet Injector - Phase II," Fusion Technology, 28, 603 (1995).

14. P. W. Fisher, "Extrusion of Tritium and D-T Pellets for ITER Fueling," Fusion Technology, 30, 845 (1996).

15. SPSS Inc., 444 N. Michigan Ave., Chicago, IL 60611.

16. P. W. Fisher, “Tritium Proof-of-Principle Pellet Injector," ORNL/TM-11781, July 1991.

17. I. Viniar and A. Lukin, "Screw Extruder Development," Private Communication from LIRAL International Trading, Inc., Saint-Petersburg Russia to Oak Ridge National Lab. (1997).

18. D. N. Bol'shutkin, Y. E. Stetsenko, and L. A. Alekseeva, "Plastic Deformation and Stress Relaxation in Solid Normal Deuterium," Sov. Phys. Solid State 12, 119 (1970).

19. L. A. Alekseeva, O. V. Litvin, and I. N. Krupskii, "Temperature Dependence of the Yield Stress of Solid Hydrogen," Sov. J. Low Temp. Phys. 8, 158 (1982).

20. E. Siebel and E. Fangemeier, "Research on Power Consumption in the Extrusion and Punching of Metals," Mitt. K. W. Inst. fur Eisenforschung 13, 29-43 (1931). 
Page Intentionally Blank 
Table 3.1. TPOP-II tritium utilization at TSTA

\begin{tabular}{|c|c|r|r|r|r|r|r|c|}
\hline Date & PC & Pini, torr & Pfinal, torr & torr- & $\% \mathrm{~T}$ & \multicolumn{1}{c|}{$\mathrm{Ci} \mathrm{T}$} & $\mathrm{g} \mathrm{T}$ & Total $\mathrm{T}, \mathrm{g}$ \\
\hline TPOP-I & & & & & & 100,000 & 10.48 & 10.5 \\
$9 / 26 / 95$ & 986 & 747.6 & 590.0 & 7,880 & 97.4 & 23,486 & 2.46 & 12.9 \\
$9 / 27 / 95$ & 986 & 588.1 & 428.8 & 7,965 & 97.4 & 23,739 & 2.49 & 15.4 \\
$9 / 28 / 95$ & 986 & 427.3 & 268.8 & 7,925 & 97.3 & 23,596 & 2.47 & 17.9 \\
$4 / 22 / 96$ & 986 & 273.3 & 109.9 & 8,170 & 94.3 & 23,575 & 2.47 & 20.4 \\
$4 / 24 / 96$ & 986 & 109.2 & 3.3 & 5,295 & 94.3 & 15,279 & 1.60 & 22.0 \\
$4 / 24 / 96$ & 656 & 411.6 & 311.4 & 5,010 & 94.4 & 14,472 & 1.52 & 23.5 \\
$4 / 25 / 96$ & 656 & 312.9 & 99.0 & 10,695 & 94.3 & 30,861 & 3.23 & 26.7 \\
$8 / 15 / 96$ & ISS & & & 12,238 & 99.1 & 37,111 & 3.89 & 30.6 \\
$8 / 15 / 96$ & ISS & & & 13,412 & 99.1 & 40,671 & 4.26 & 34.9 \\
$9 / 18 / 97$ & 986 & 701.4 & 471.0 & 11,520 & 93.6 & 32,995 & 3.46 & 38.3 \\
\hline
\end{tabular}

Table 3.2. Static shear strength parameters, $\sigma=\mathbf{a}+\mathbf{b T}$

\begin{tabular}{|c|c|c|c|c|c|}
\hline Isotope & $\begin{array}{c}\text { Temperature } \\
\text { range, } \mathrm{K}\end{array}$ & $\mathrm{a}, \mathrm{psi}$ & $\mathrm{b}, \mathrm{psi} / \mathrm{K}$ & $\mathrm{a}, \mathrm{MPa}$ & $\mathrm{b}, \mathrm{psi} / \mathrm{K}$ \\
\hline $\mathrm{D}_{2}$ & $13-15$ & 89.7 & -3.6 & 0.62 & -0.025 \\
\hline $\mathrm{D}-\mathrm{T}$ & $12-15$ & 216 & -10.4 & 1.49 & -0.072 \\
\hline $\mathrm{T}_{2}$ & $12-15$ & 403 & -23.1 & 2.78 & -0.159 \\
\hline
\end{tabular}

Table 3.3. Dynamic shear strength

\begin{tabular}{|c|c|c|c|}
\hline Isotope & Temperature, $\mathrm{K}$ & $\sigma_{\mathrm{D}}, \mathrm{MPa}$ & $\sigma_{\mathrm{D}} / \sigma$ \\
\hline $\mathrm{D}_{2}$ & 14 & 0.194 & 0.72 \\
\hline $\mathrm{D}-\mathrm{T}$ & 14 & 0.259 & 0.56 \\
\hline $\mathrm{T}_{2}$ & 14 & 0.308 & 0.53 \\
\hline
\end{tabular}


Table 3.4. Helium-3 separation data

\begin{tabular}{|c|c|c|c|c|c|}
\hline Date & PC & torr-I & $\%$ T & $\%$ He-3 in feed & $\%$ He-3 after sep. \\
\hline $4 / 24 / 96$ & $986^{*}$ & 5,295 & 94.3 & 5.5 & \\
$4 / 24 / 96$ & $656^{*}$ & 5,010 & 94.4 & 5.5 & 1.2 \\
$4 / 25 / 96$ & 656 & 10,695 & 94.3 & 5.5 & 1.3 \\
9/18/97 & 986 & 11,520 & 93.6 & 5.4 & 1.3 \\
\hline
\end{tabular}

* Combined together prior to separation. 


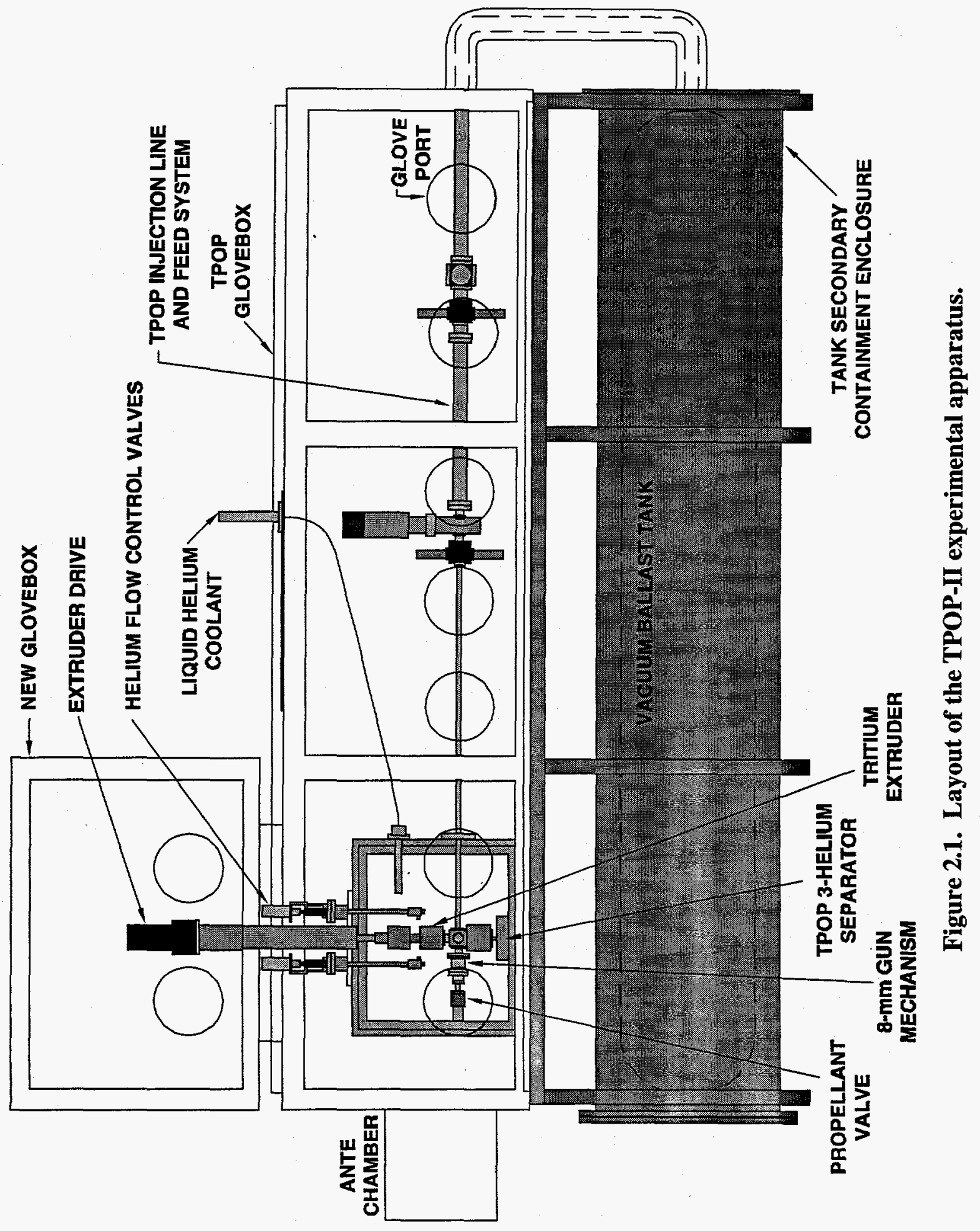




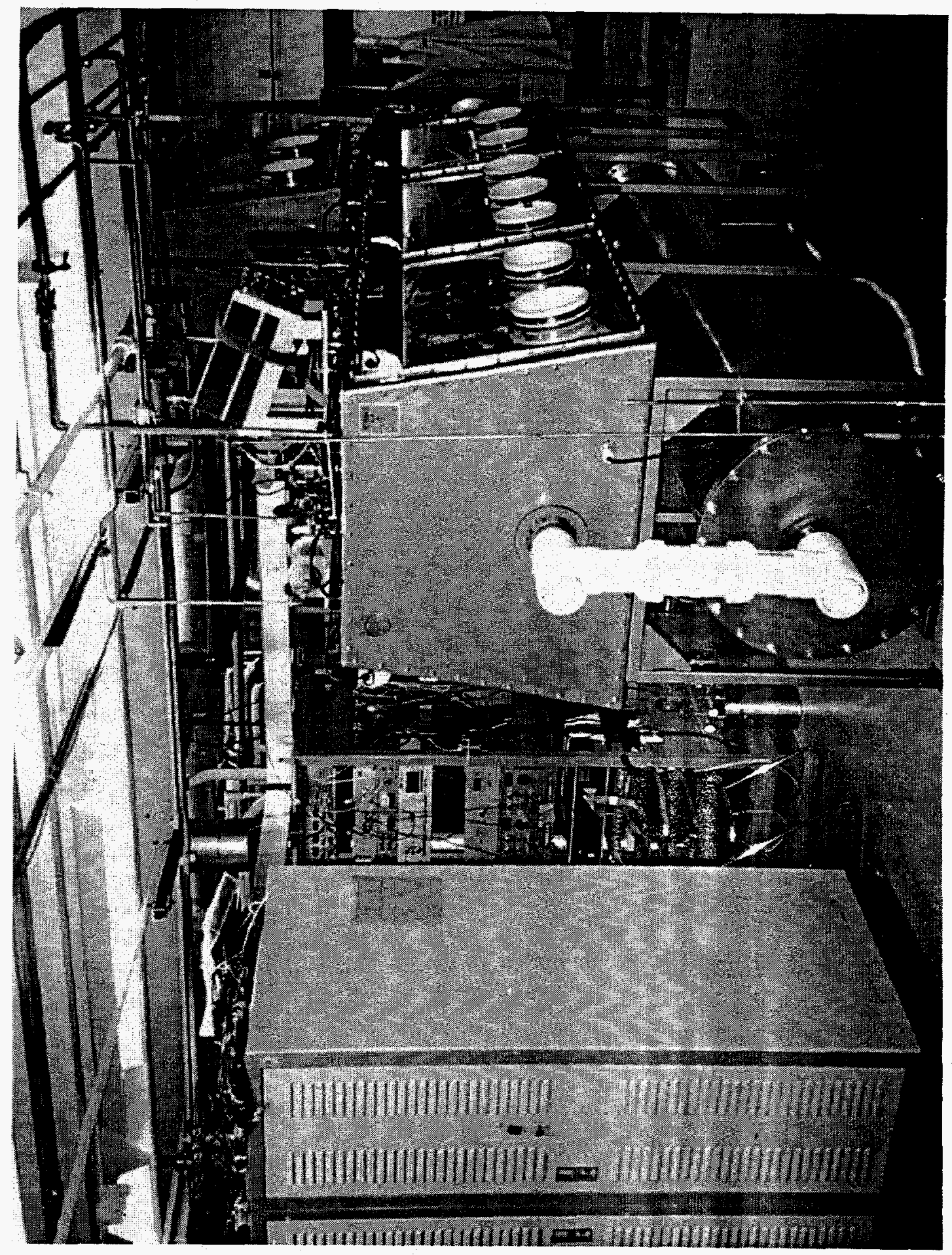

穿 


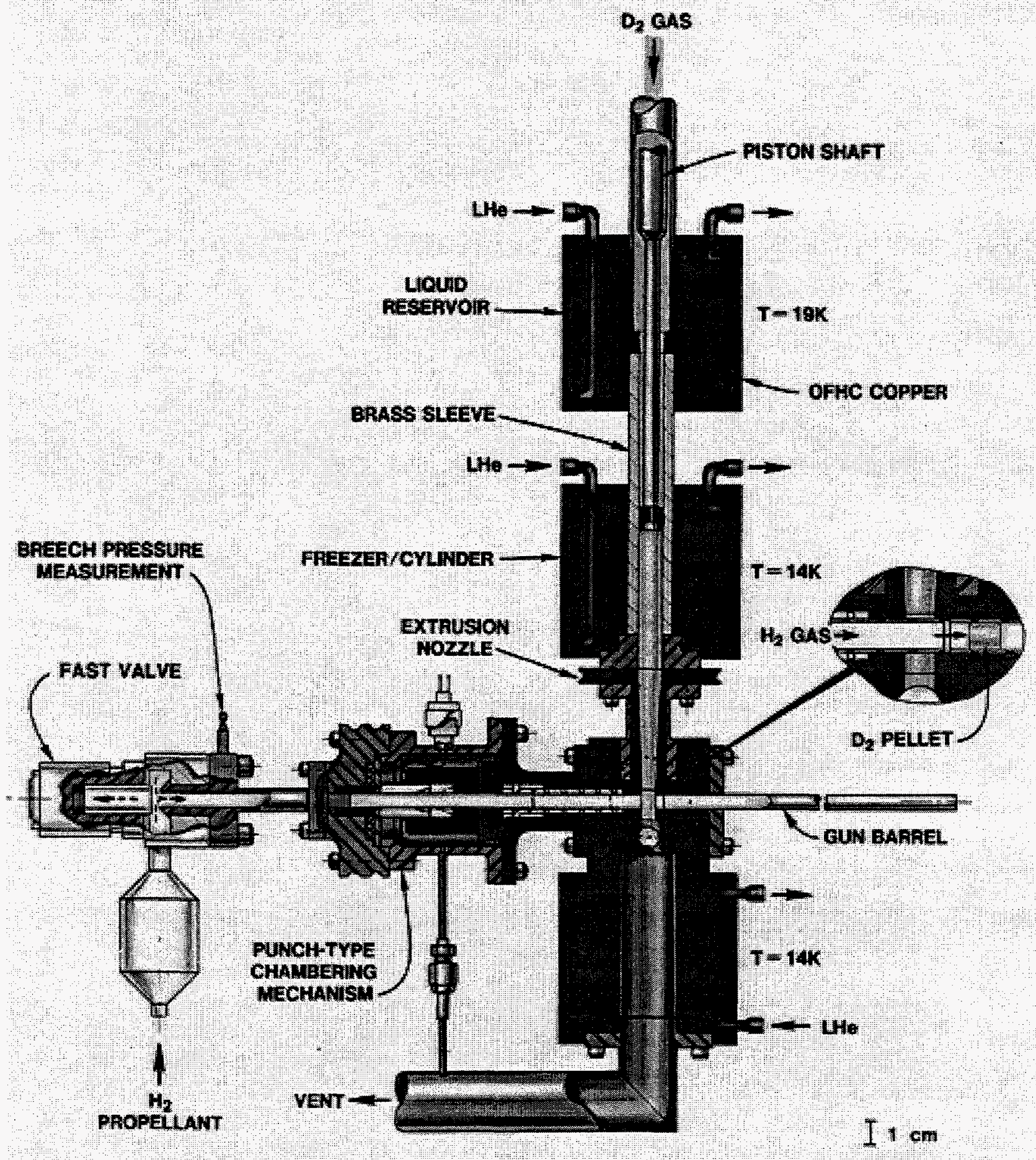

Figure 2.3. Diagram of the repeating pneumatic injector assembly. 


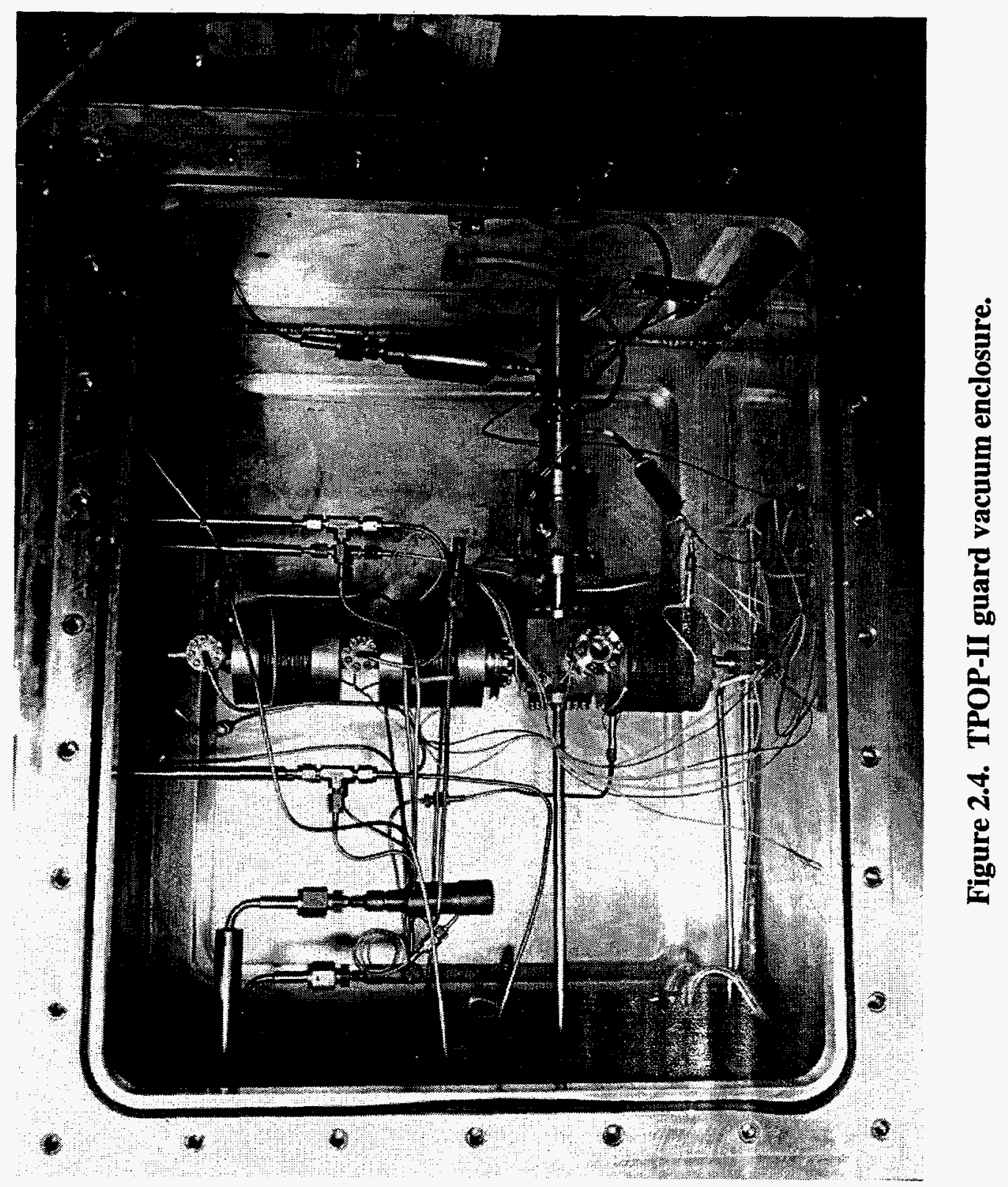




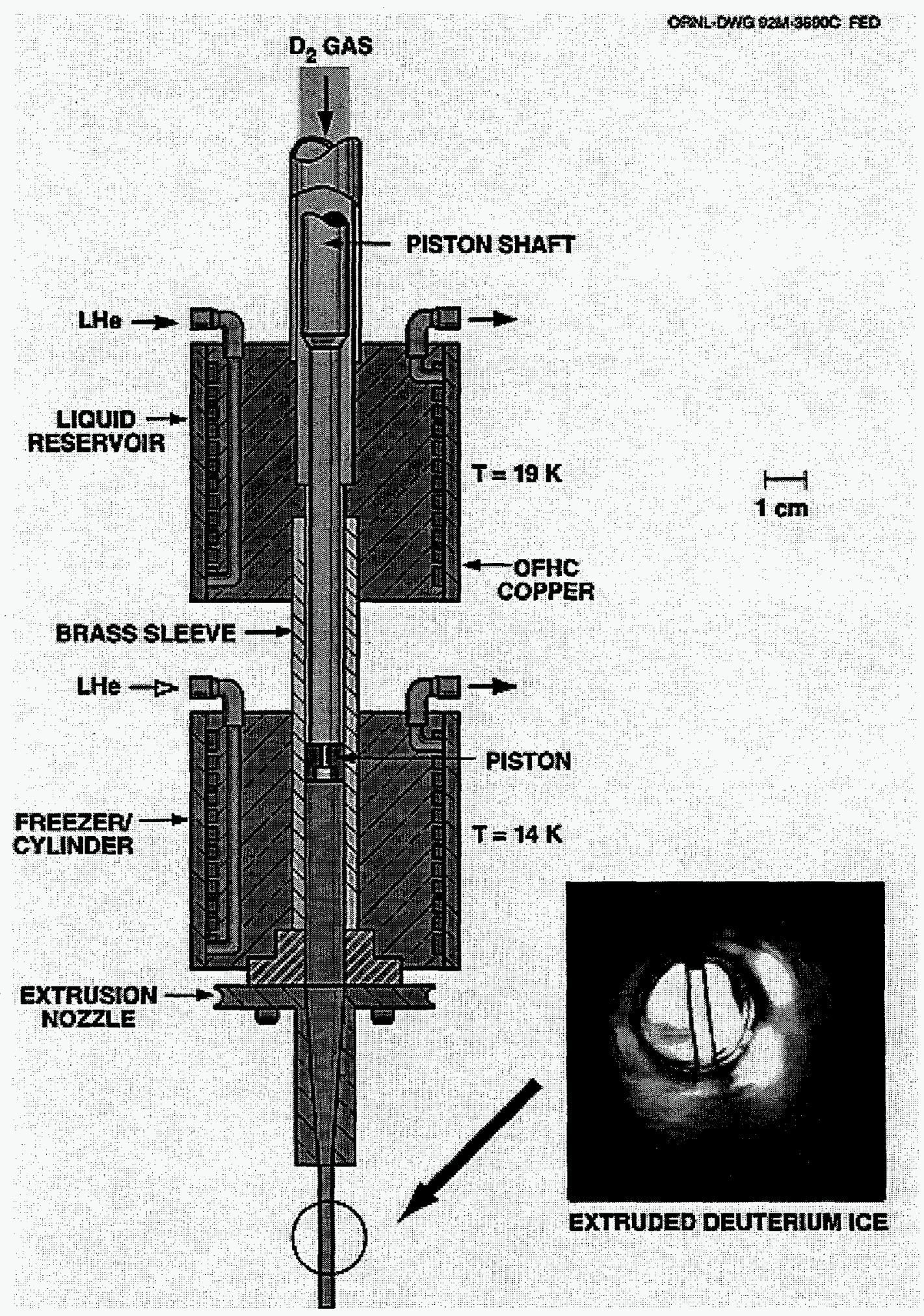

Figure 2.5. Extruder mechanism. 


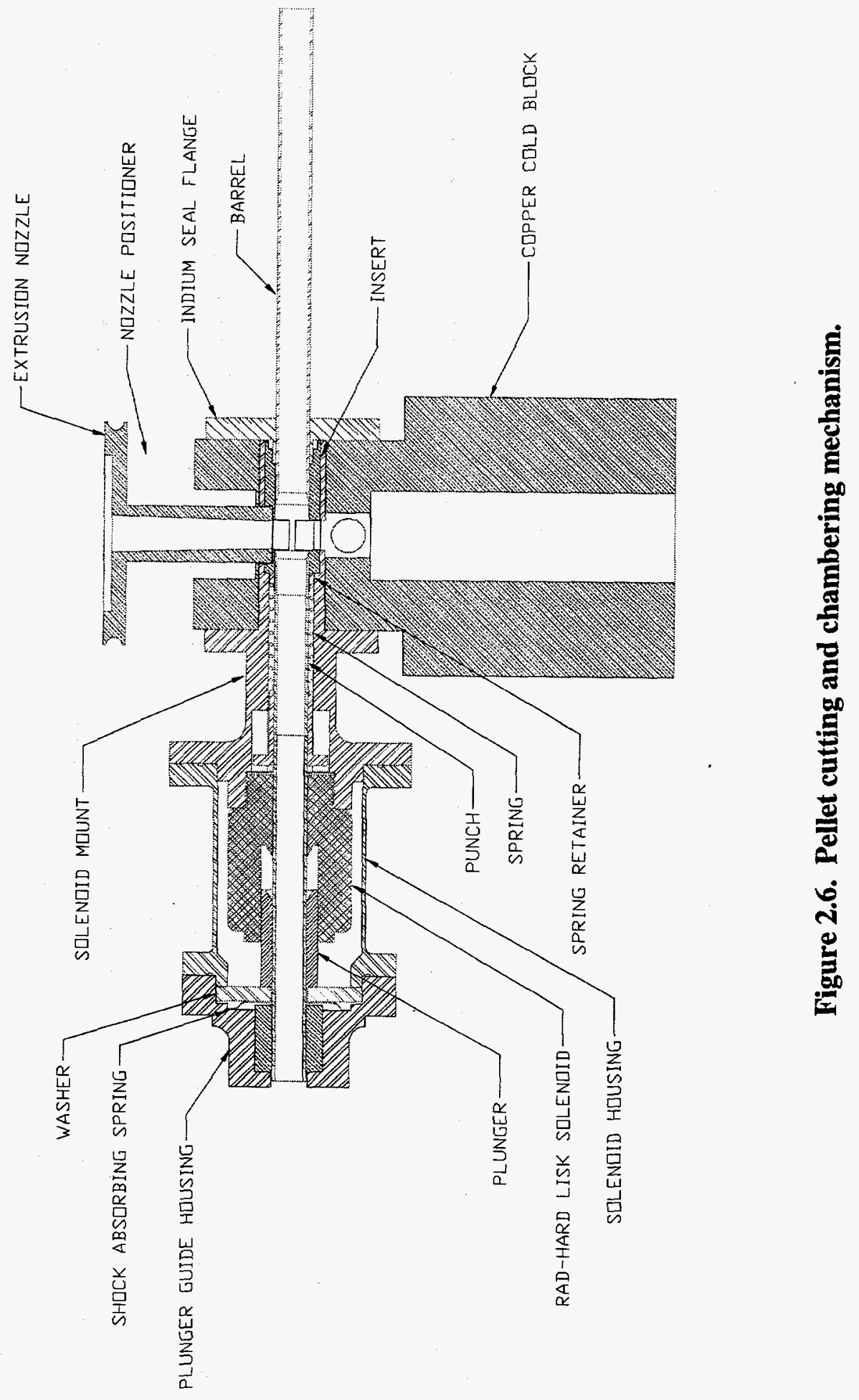




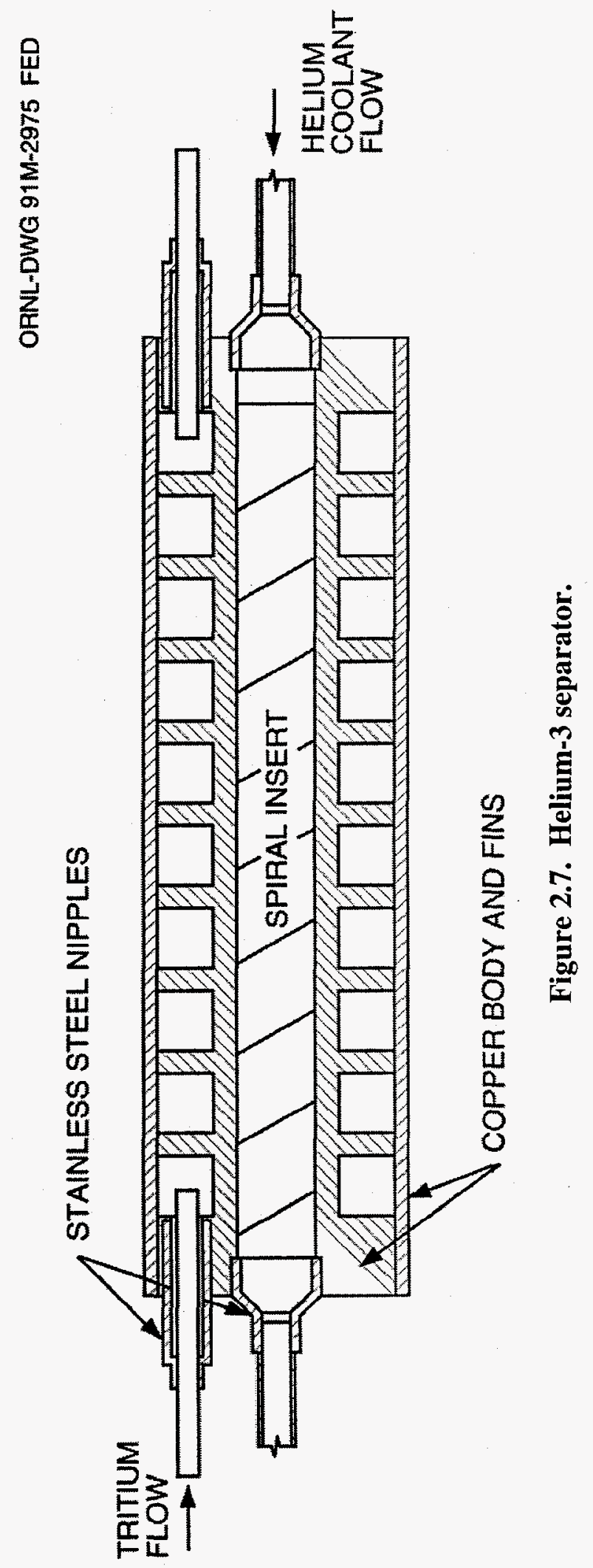




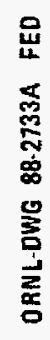
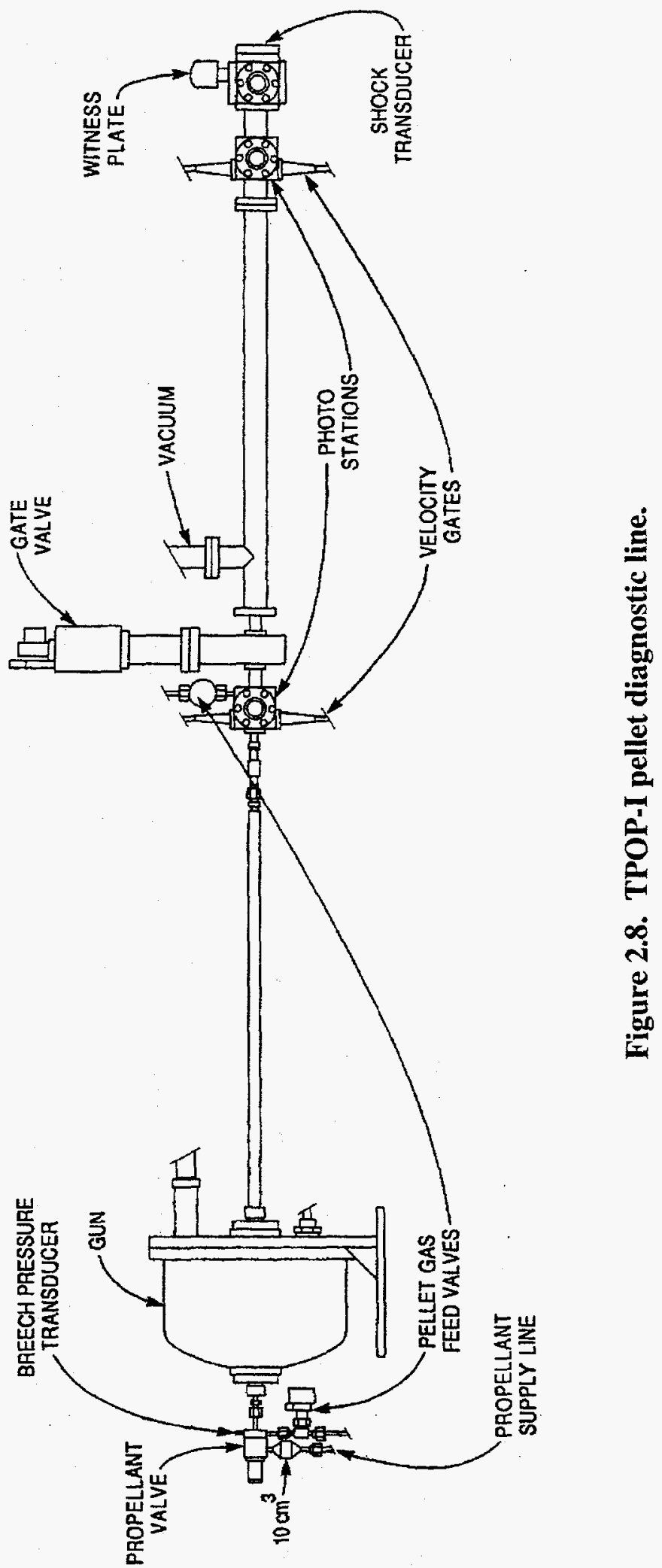


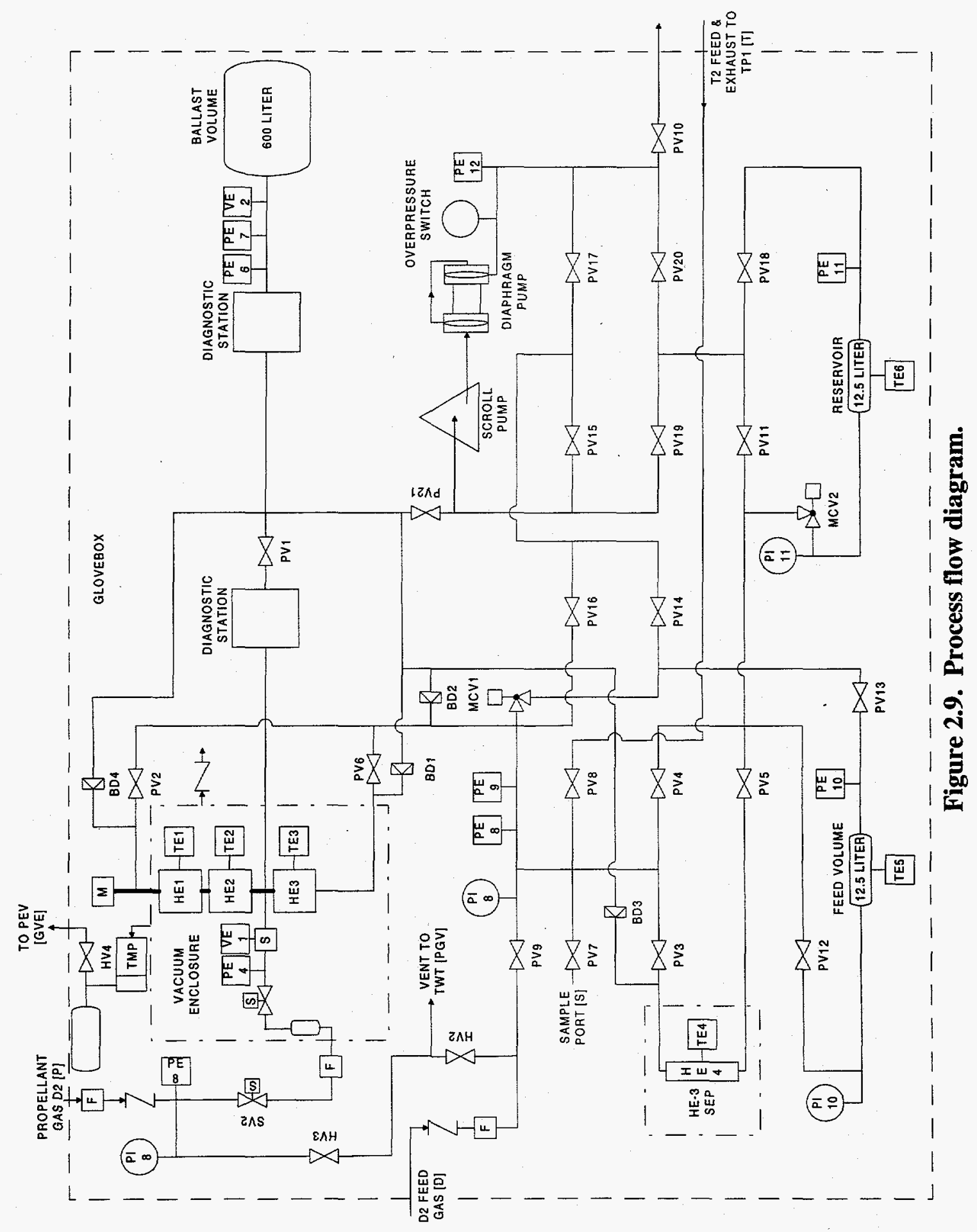




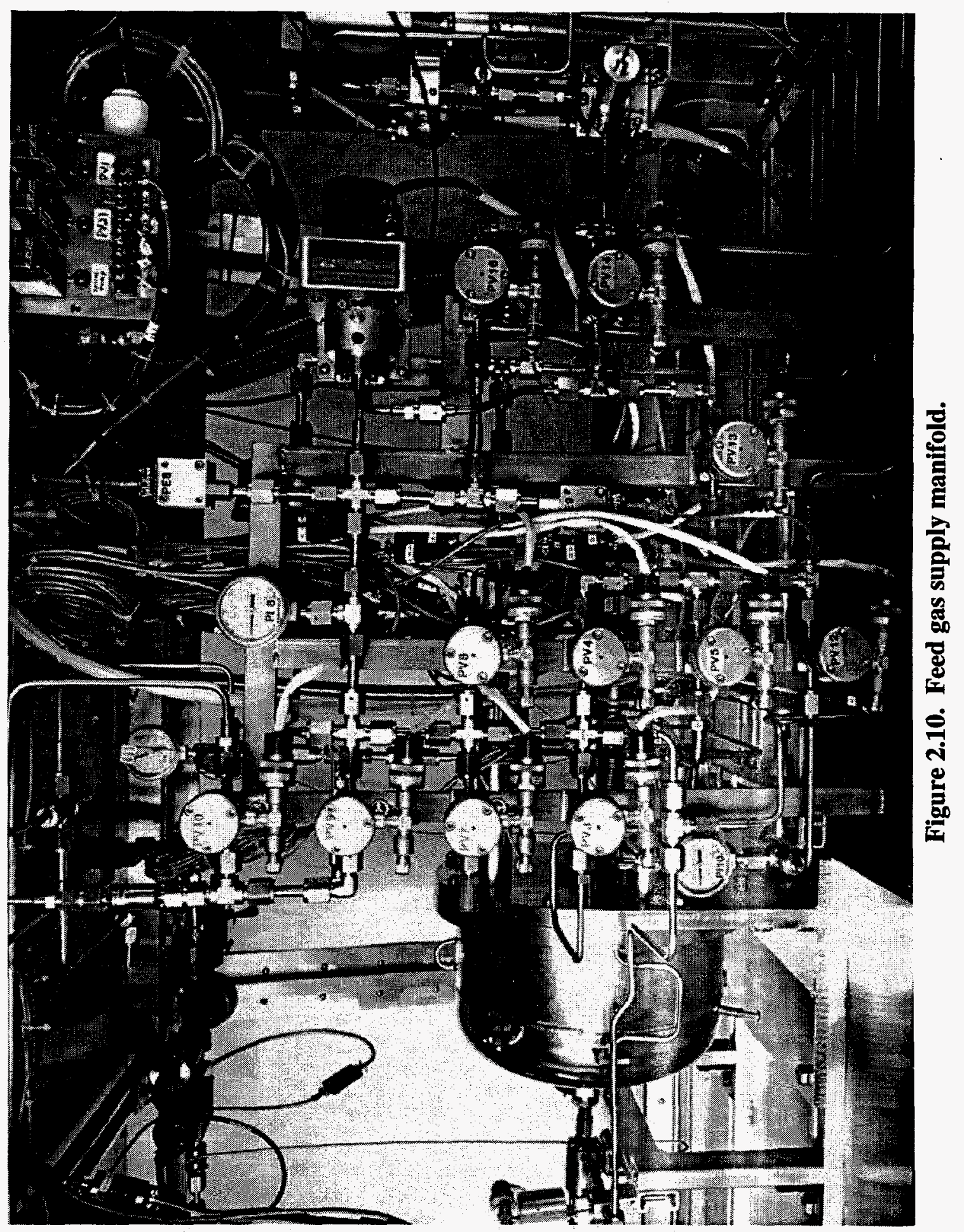




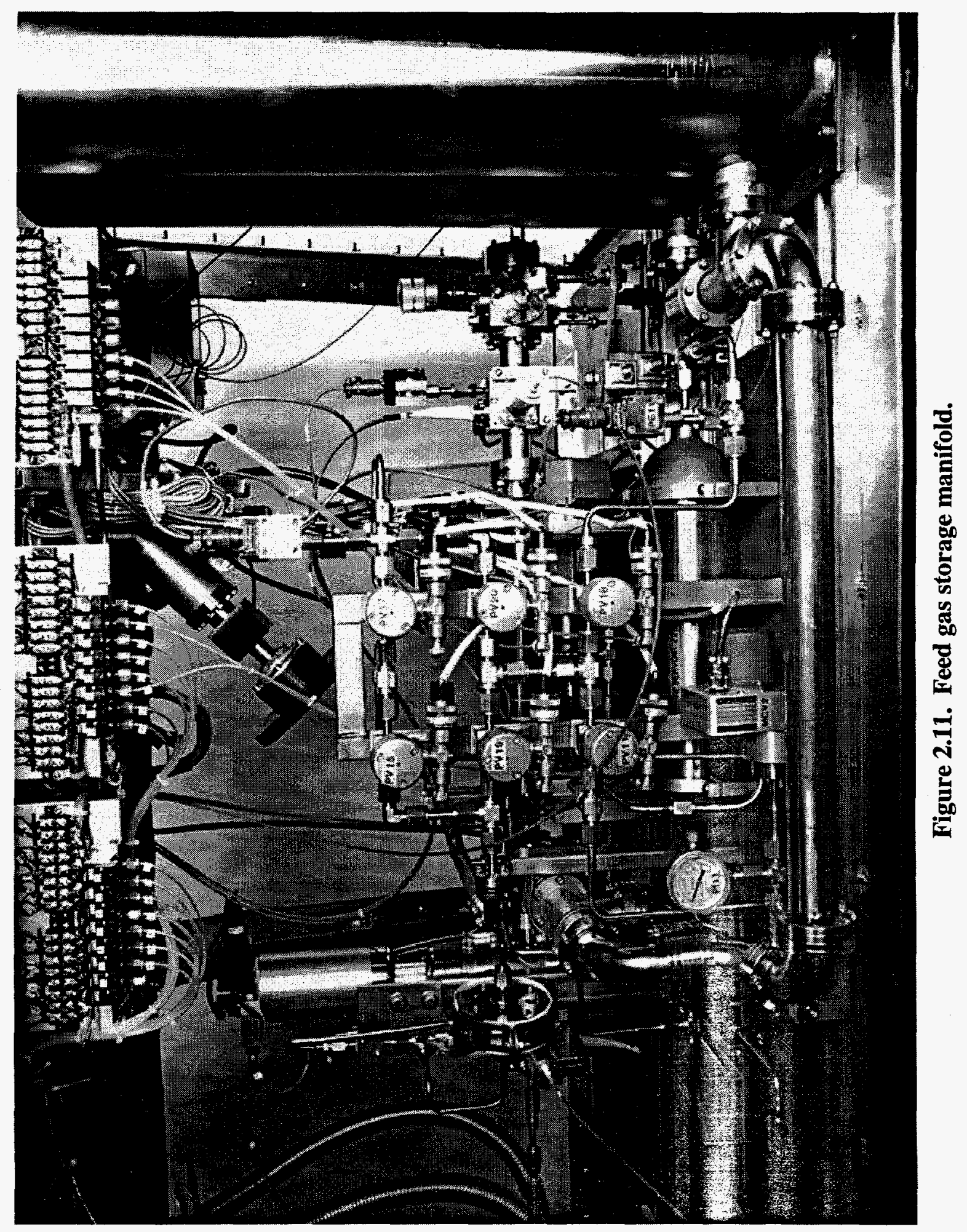











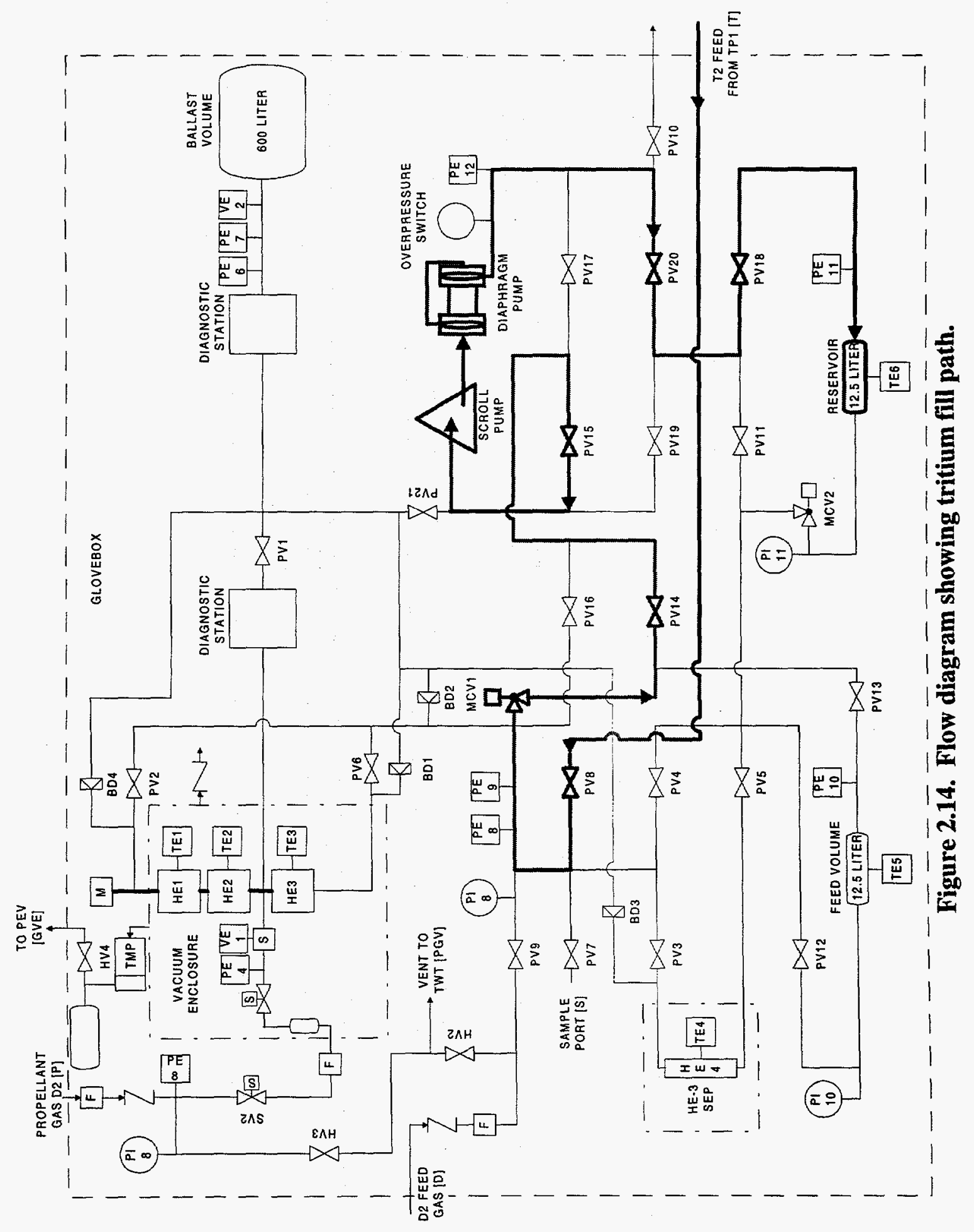




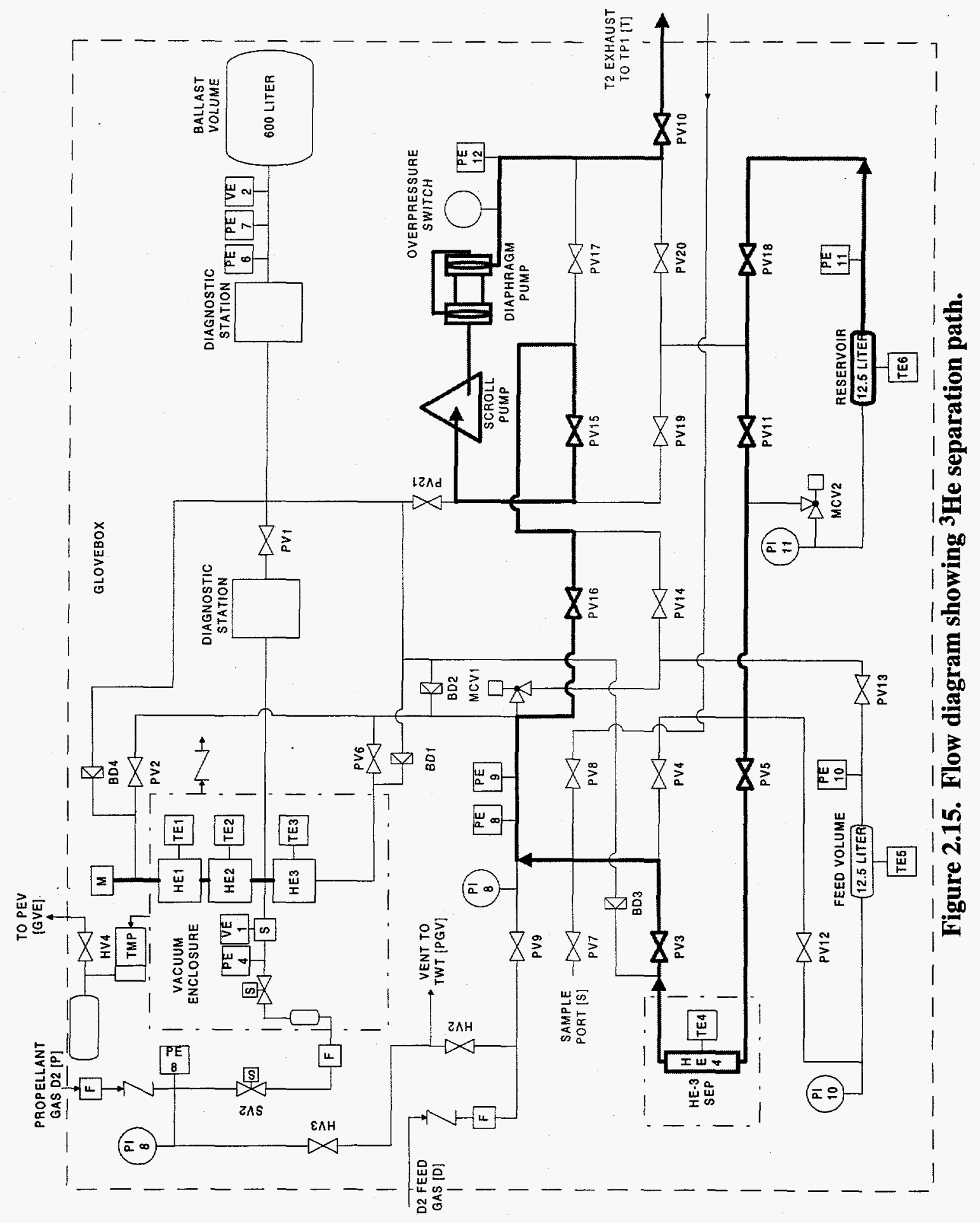




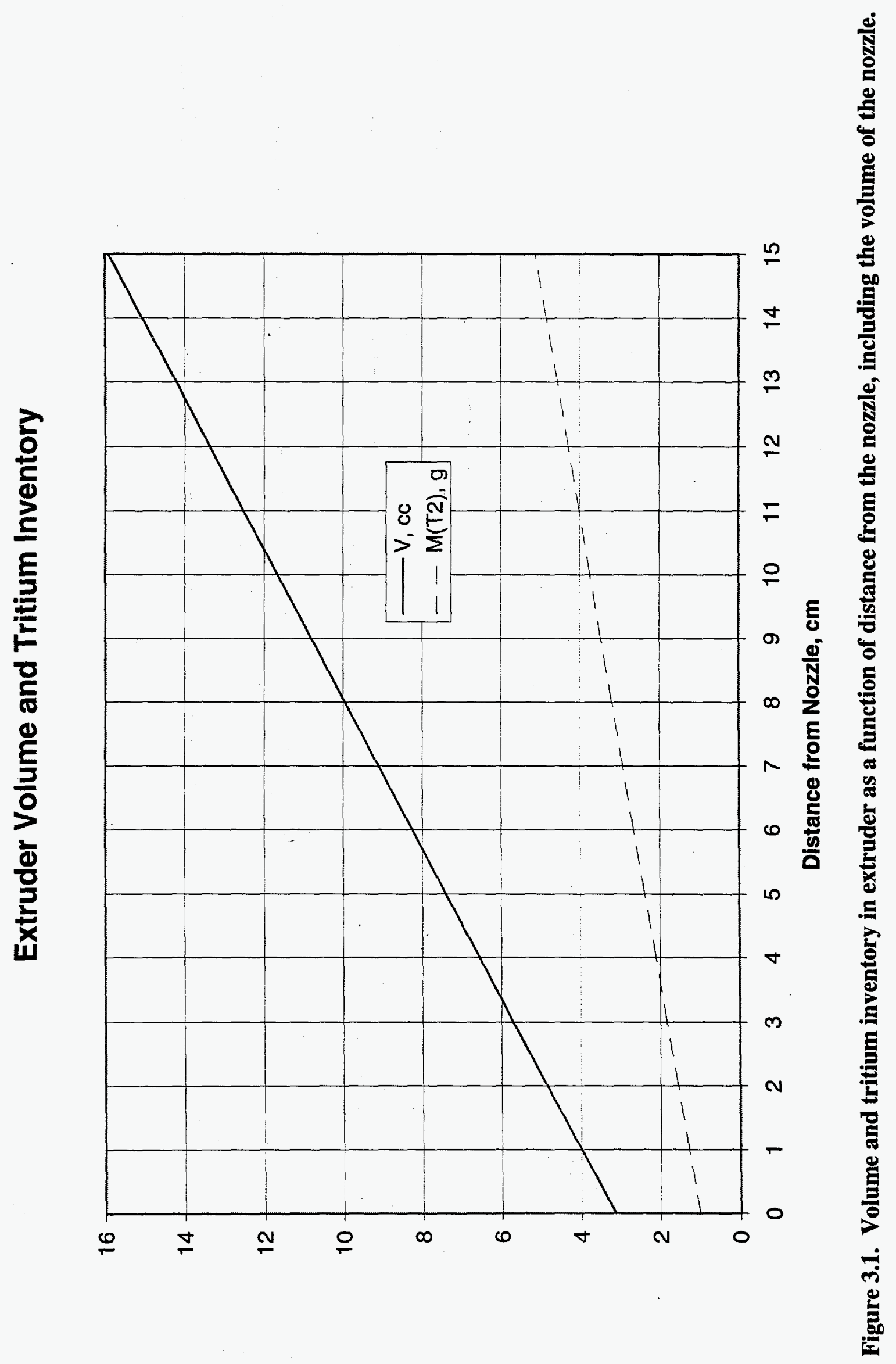




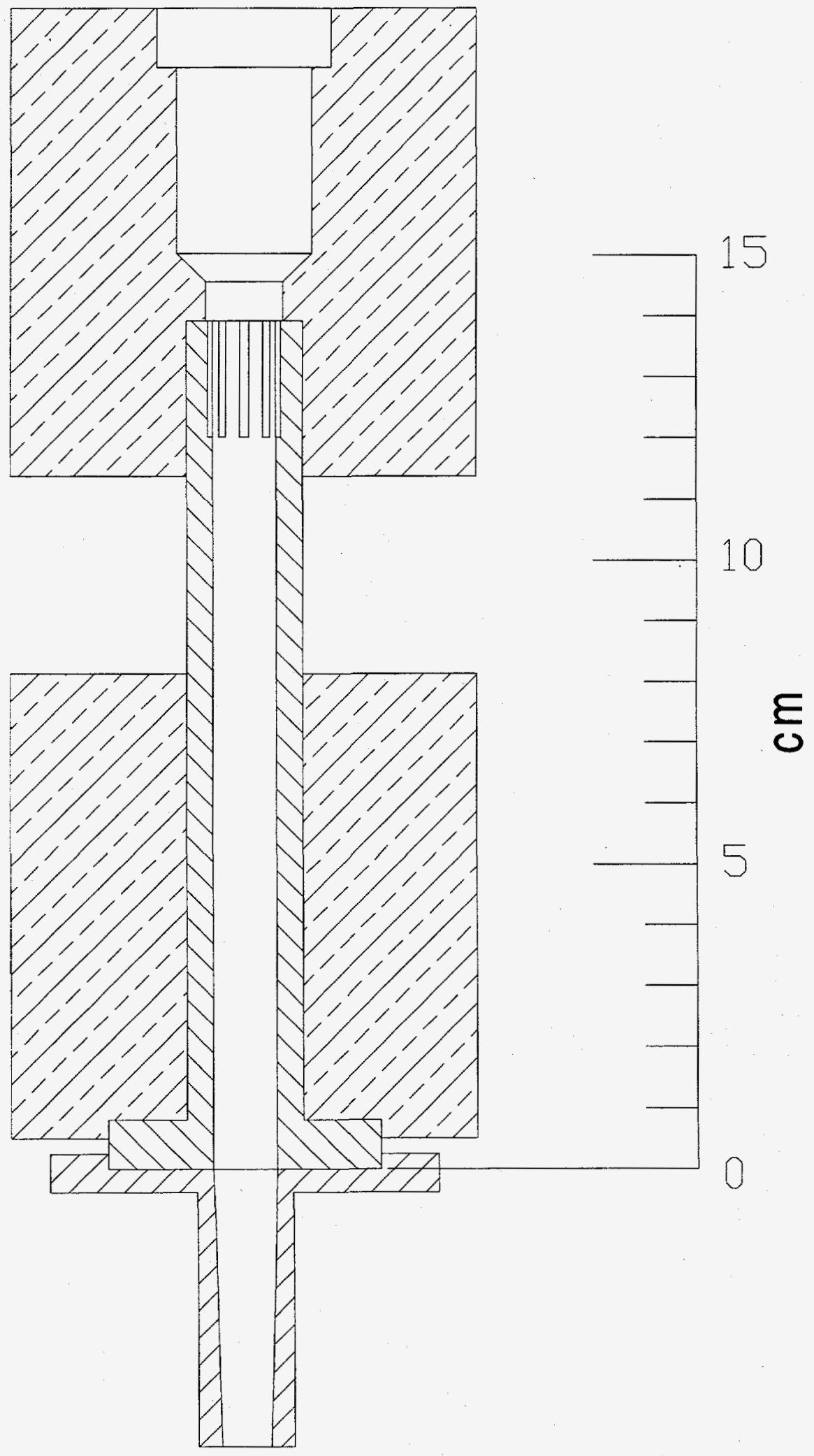

Figure 3.2. Cross section of TPOP-II extruder showing distance above nozzle in centimeters. 

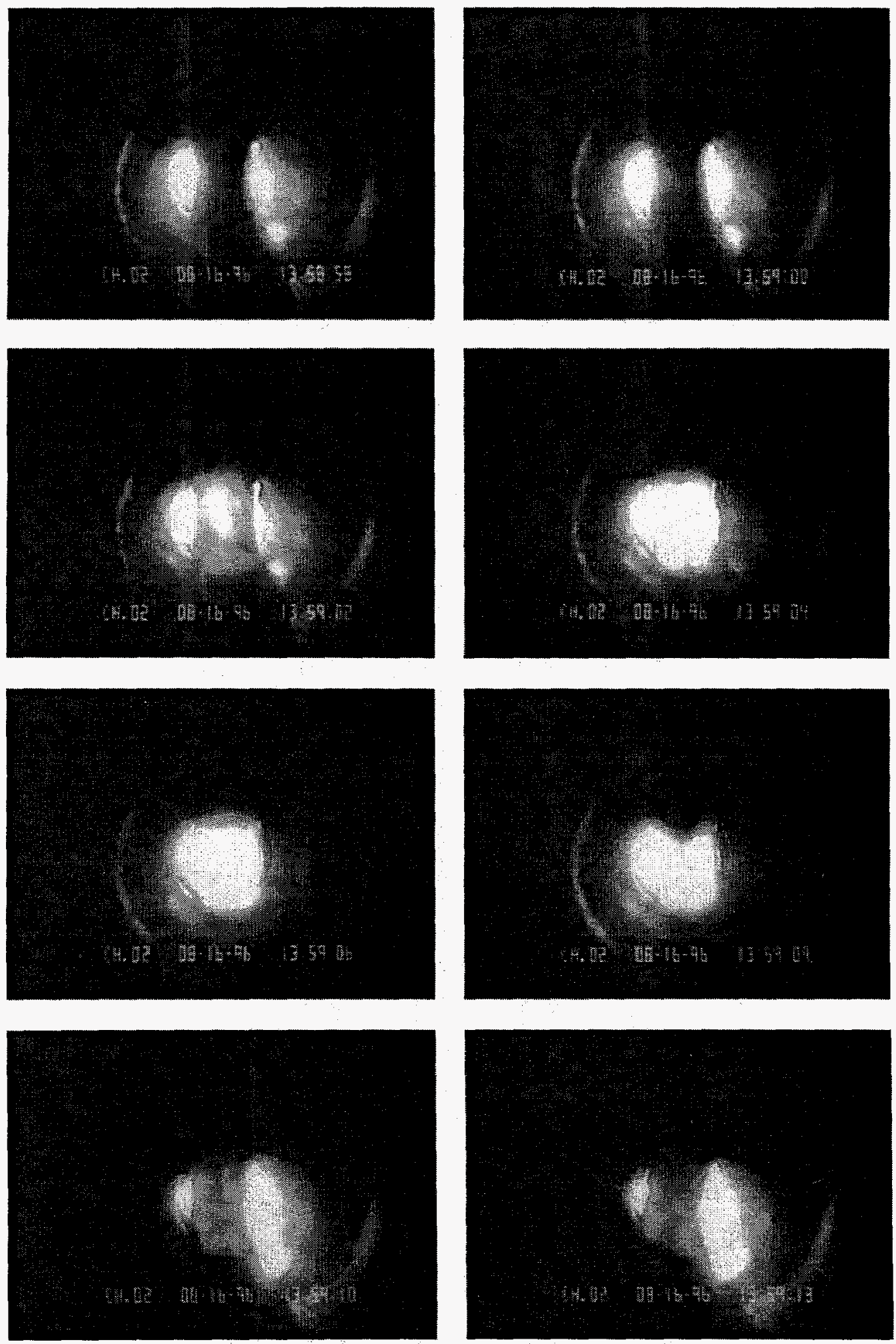

Figure 3.3. A tritium extrusion at various times. 


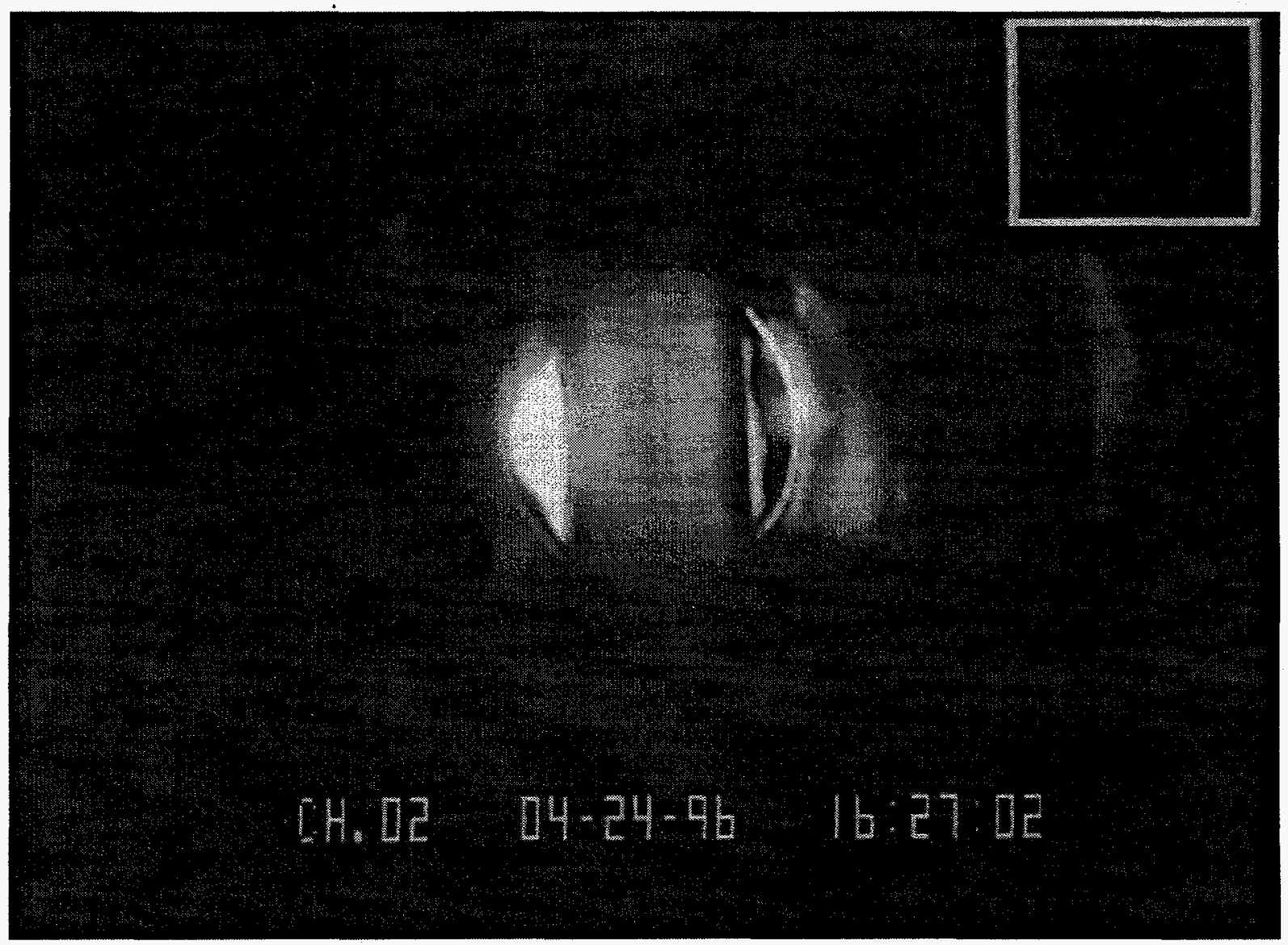

Figure 3.4. A tritium extrusion taken with less illumination. 


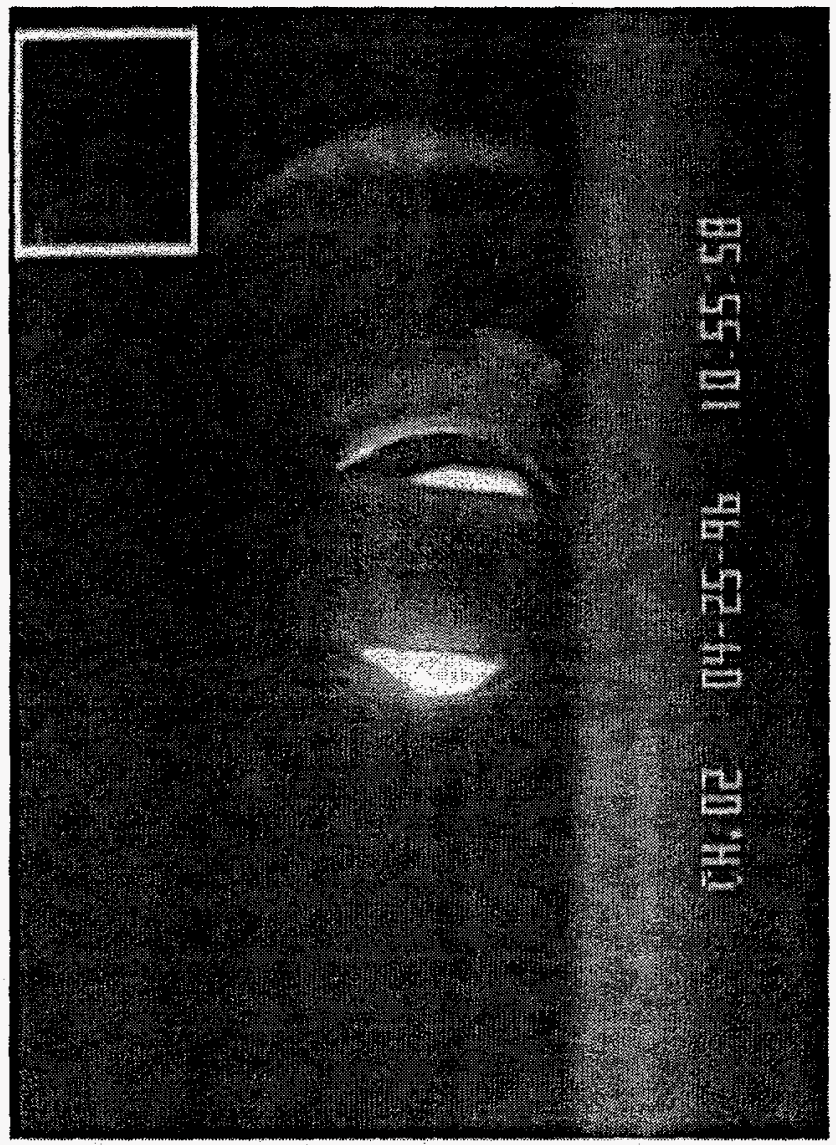

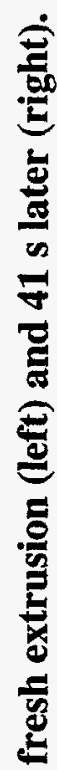

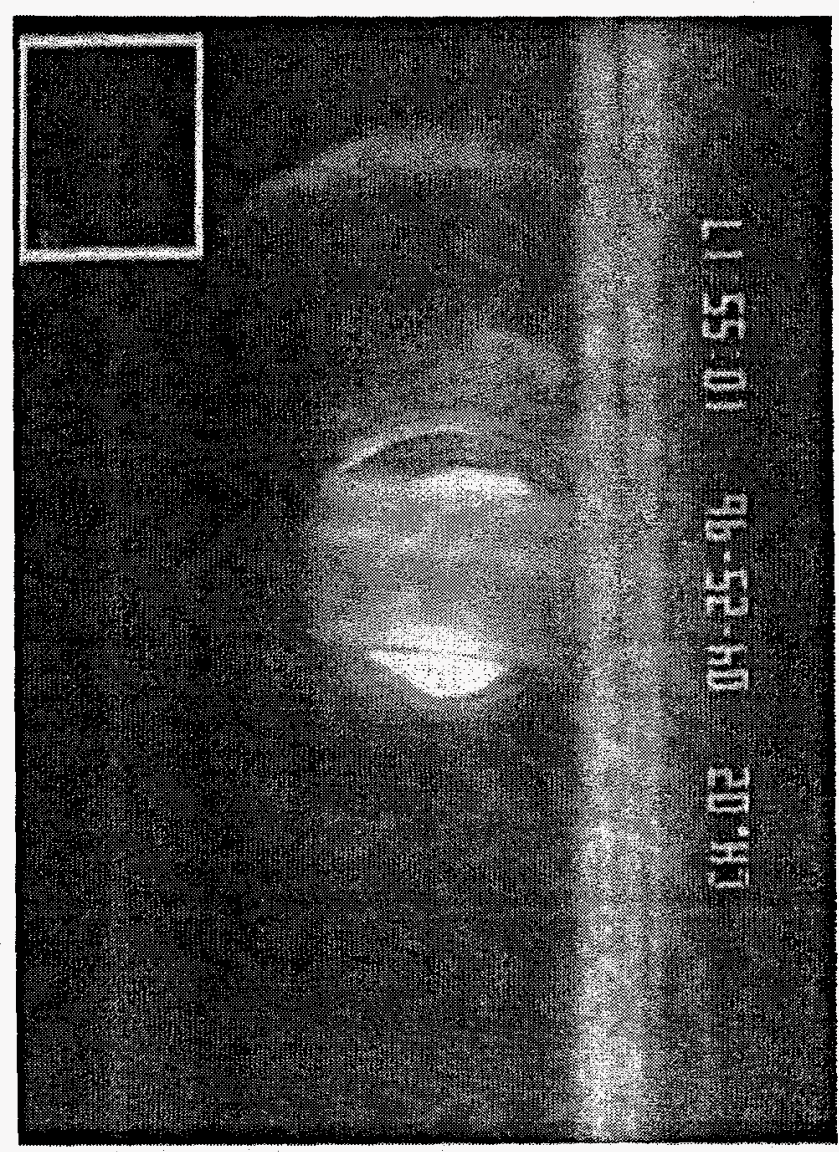

فํ. 


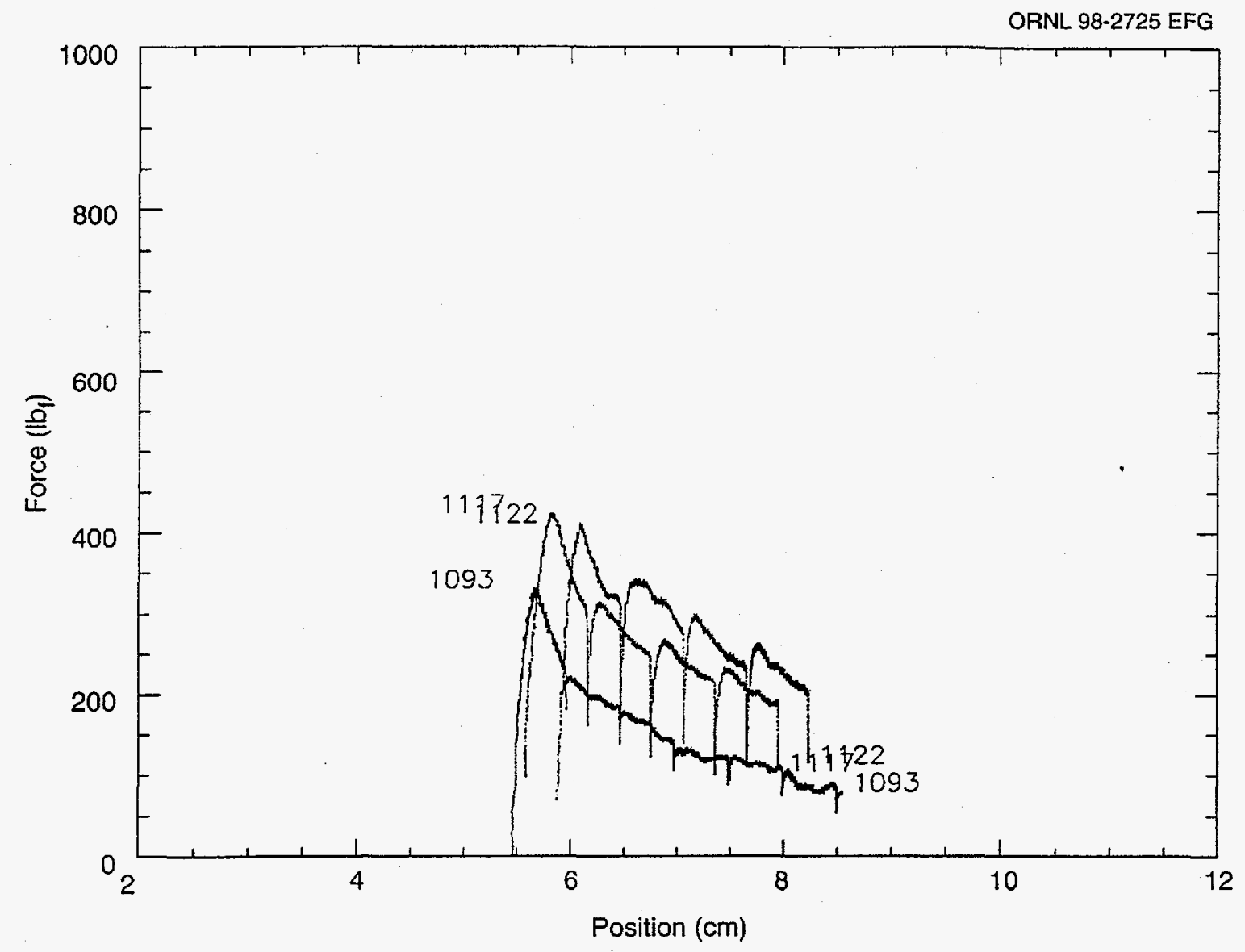

$\begin{array}{llll}\text { Shot } & \text { Material } & \text { Ram Speed, } \mathrm{cm} / \mathrm{s} & \mathrm{TE2}, \mathrm{K} \\ 1093 & \mathrm{D}_{2} & 0.15 & 12.7 \\ 1117 & \mathrm{D}-\mathrm{T} & 0.15 & 13.2 \\ 1122 & \mathrm{~T}_{2} & 0.14 & 13.0\end{array}$

Figure 3.6. Extruder force versus position for $D_{2}, D-T$, and $T_{2}$ at comparable conditions, $0.15 \mathrm{~cm} / \mathrm{s}$ ram speed and $13 \mathrm{~K}$. 


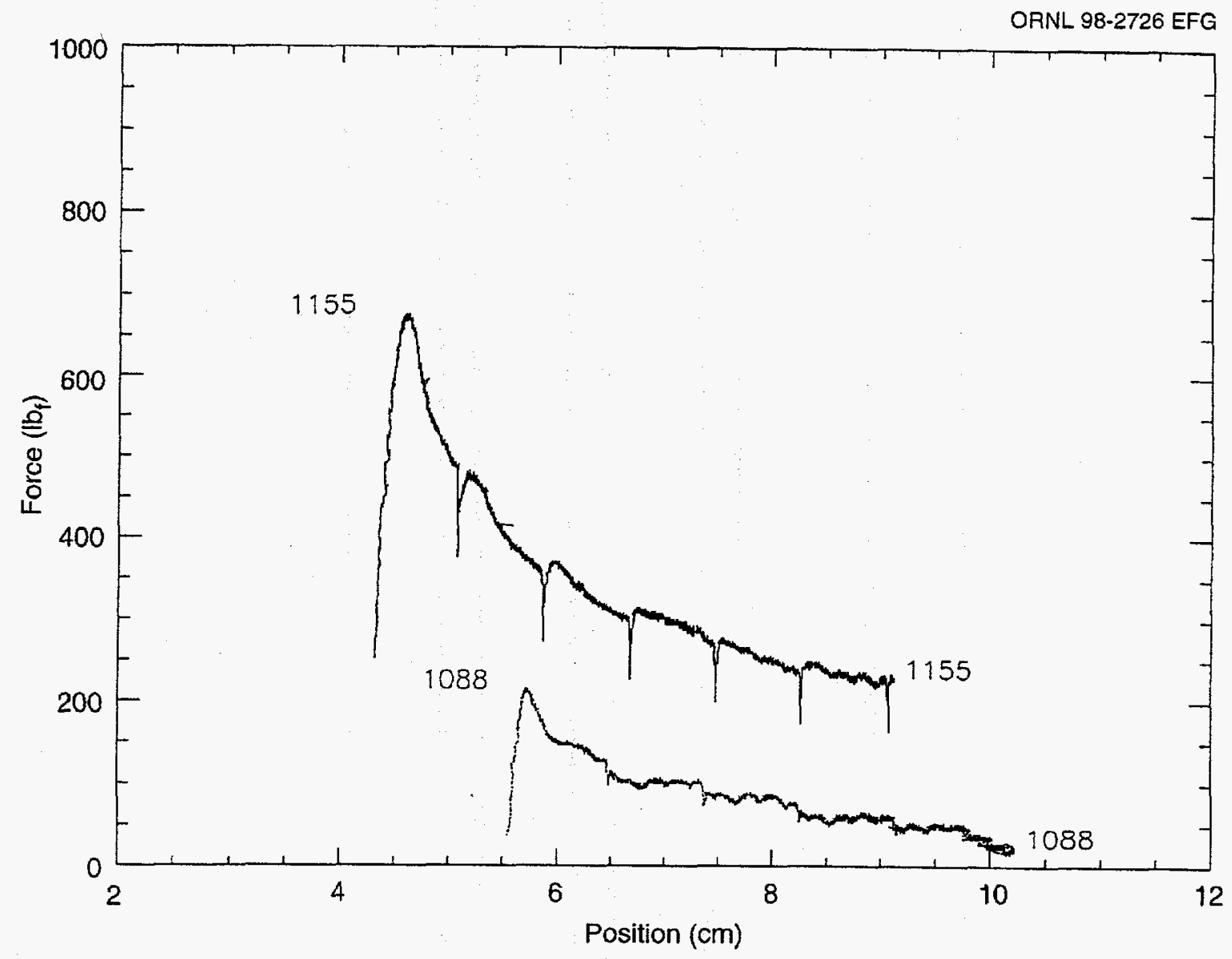

$\begin{array}{llll}\text { Shot } & \text { Material } & \text { Ram Speed, cm/s } & \text { TE2, K } \\ 1088 & \mathrm{D}_{2} & 0.27 & 13.5 \\ 1155 & \mathrm{~T}_{2} & 0.27 & 13.5\end{array}$

Figure 3.7. Extruder force versus position for $D_{2}$ and $T_{2}$ at comparable conditions, $0.27 \mathrm{~cm} / \mathrm{s}$ ram speed and $13.5 \mathrm{~K}$. 


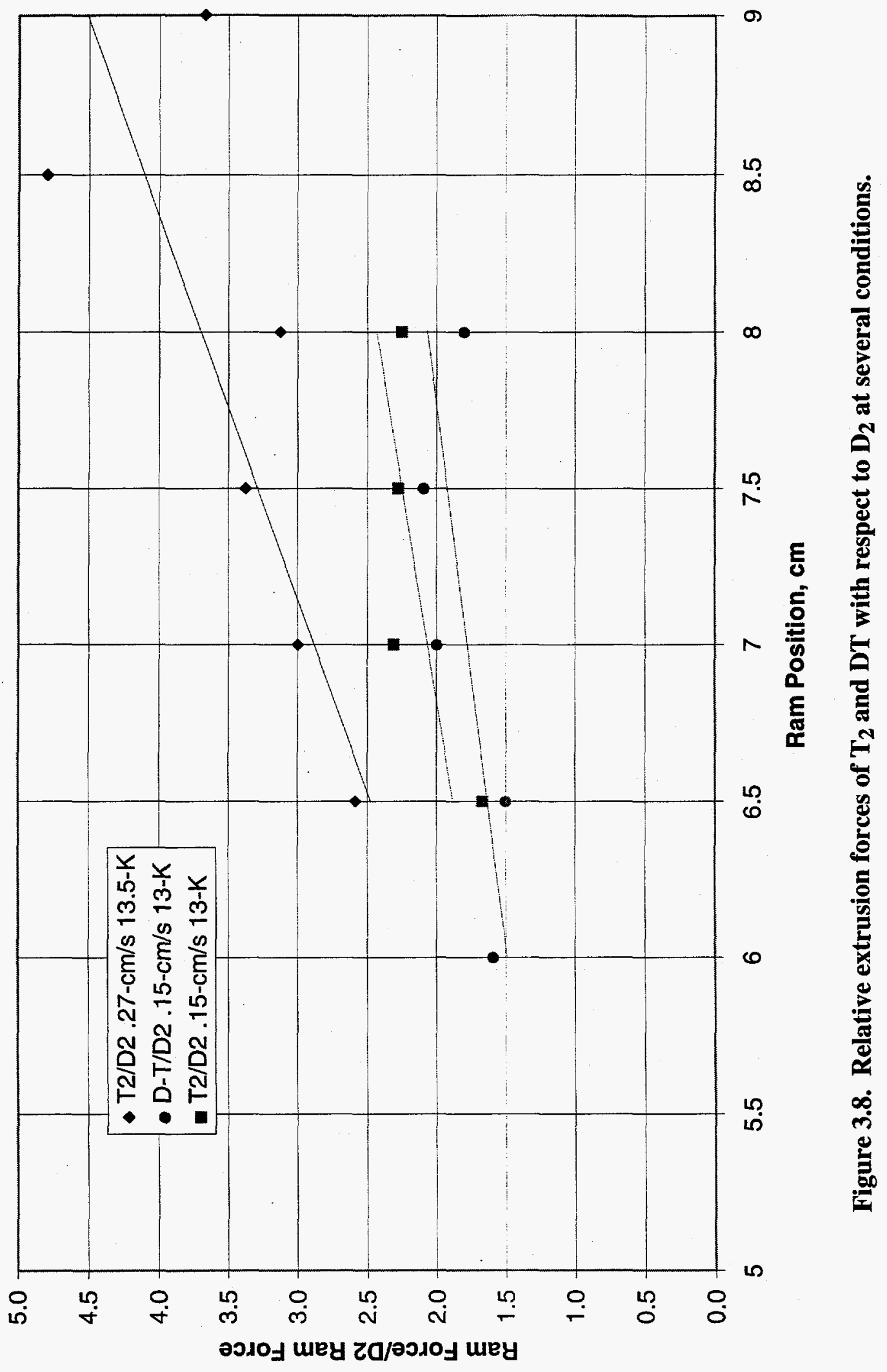




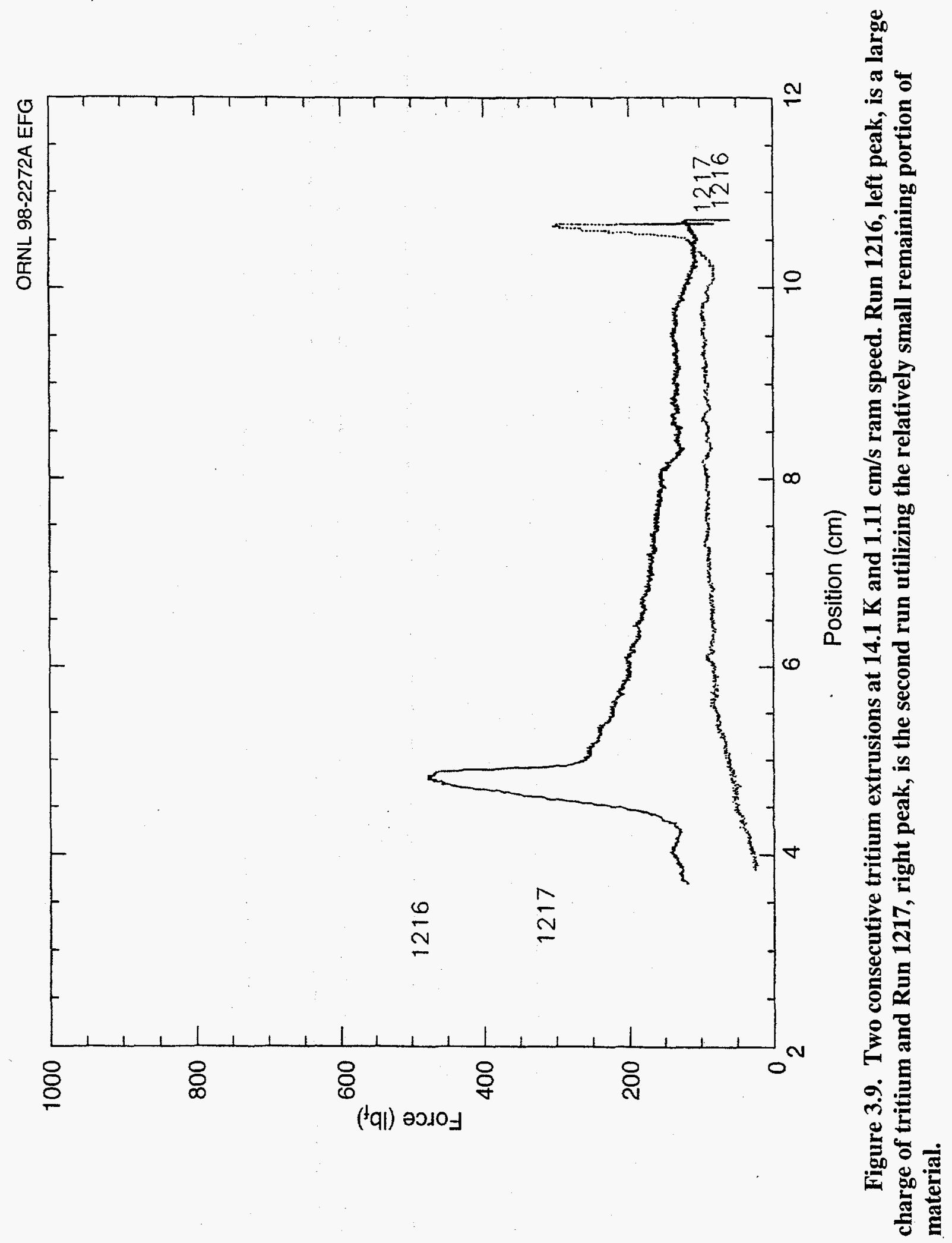




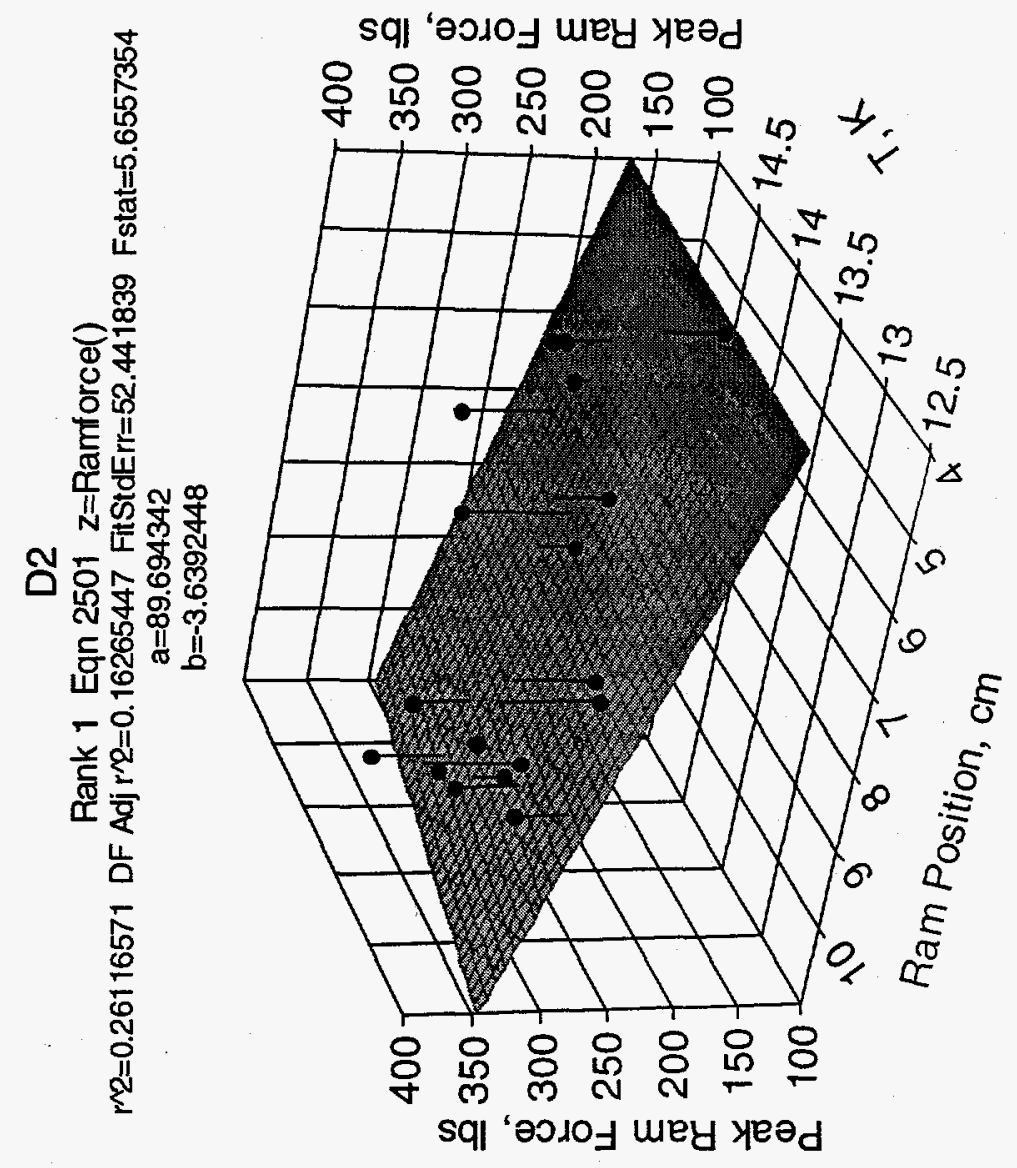

递 


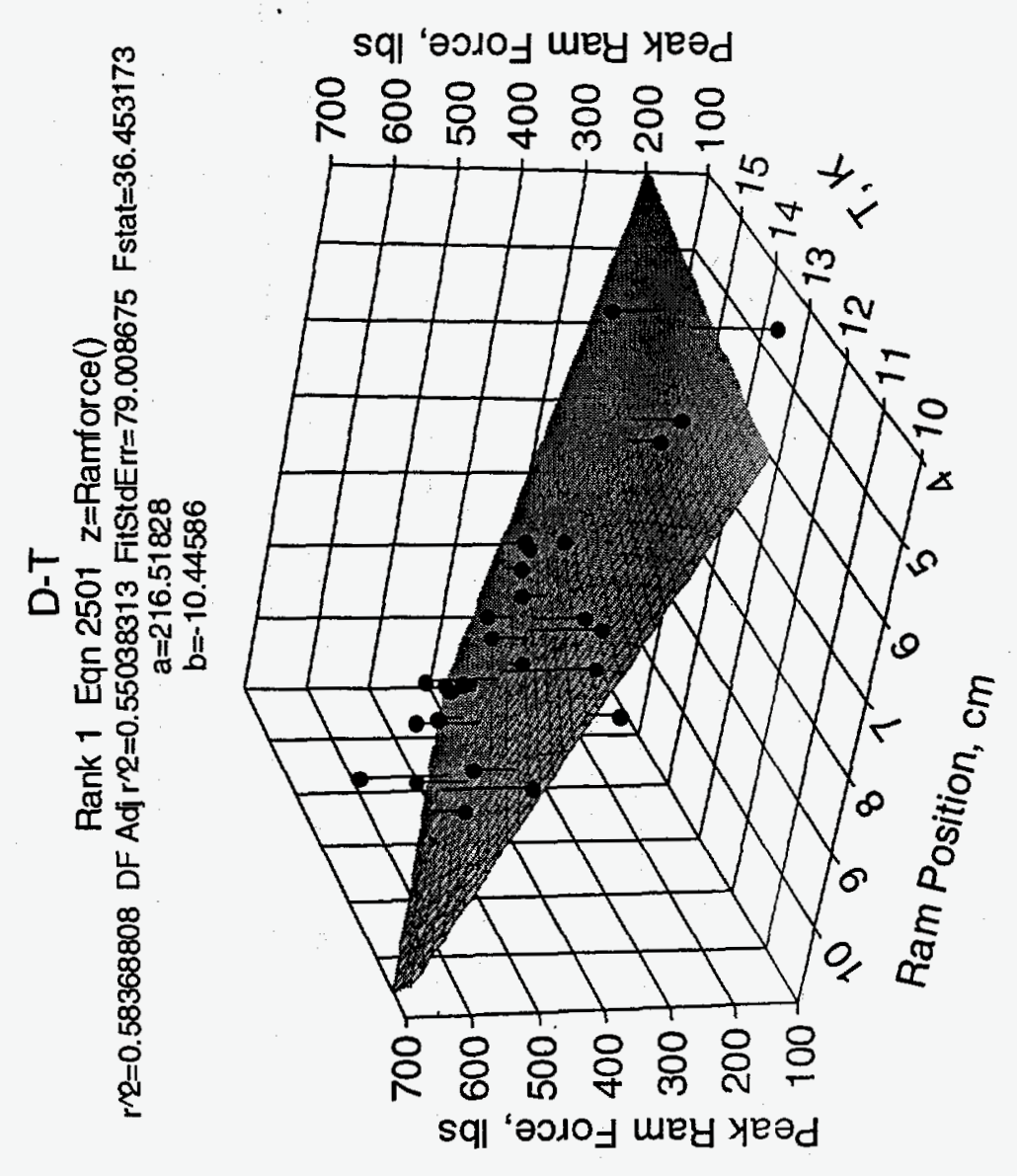

 







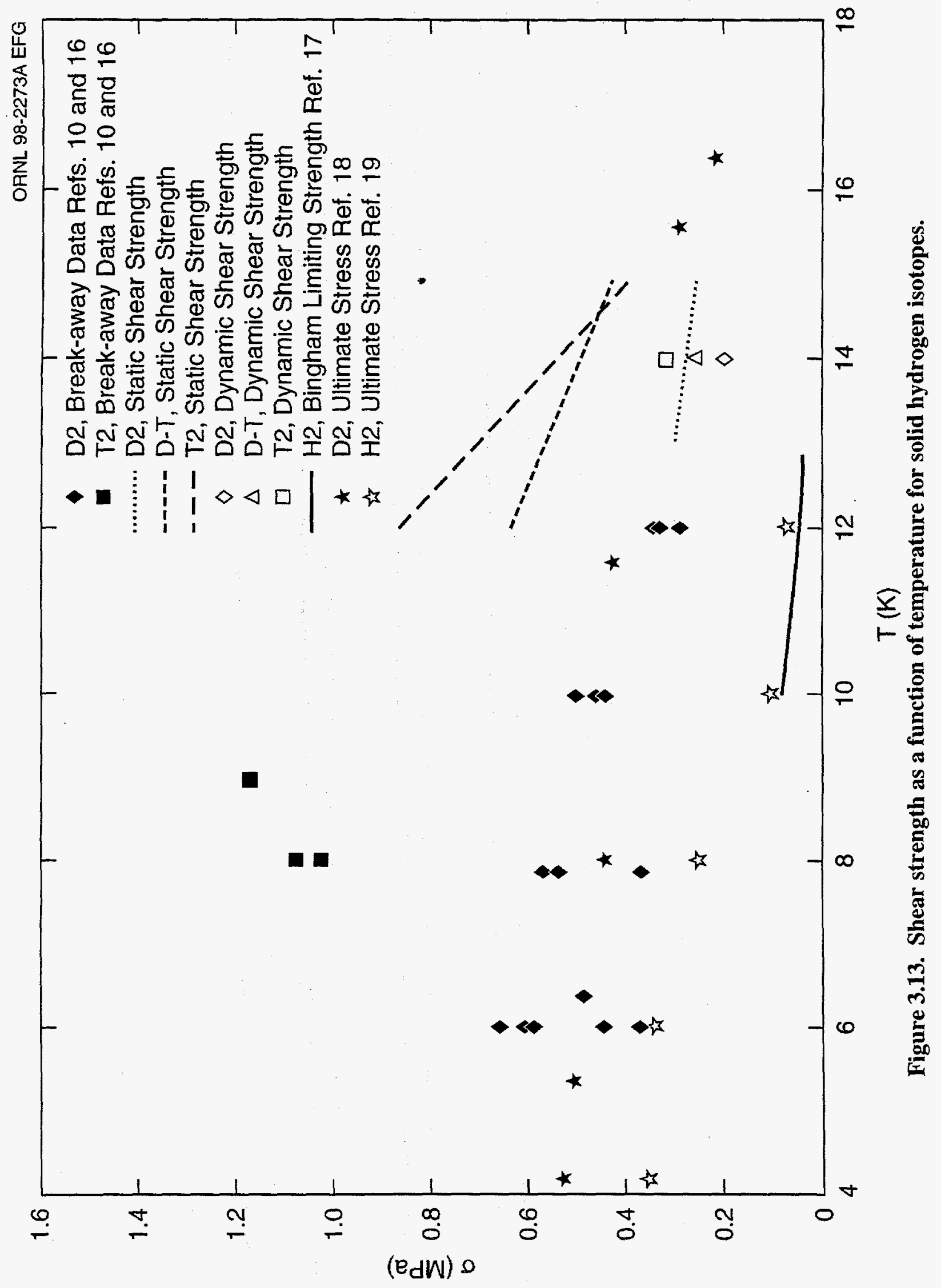




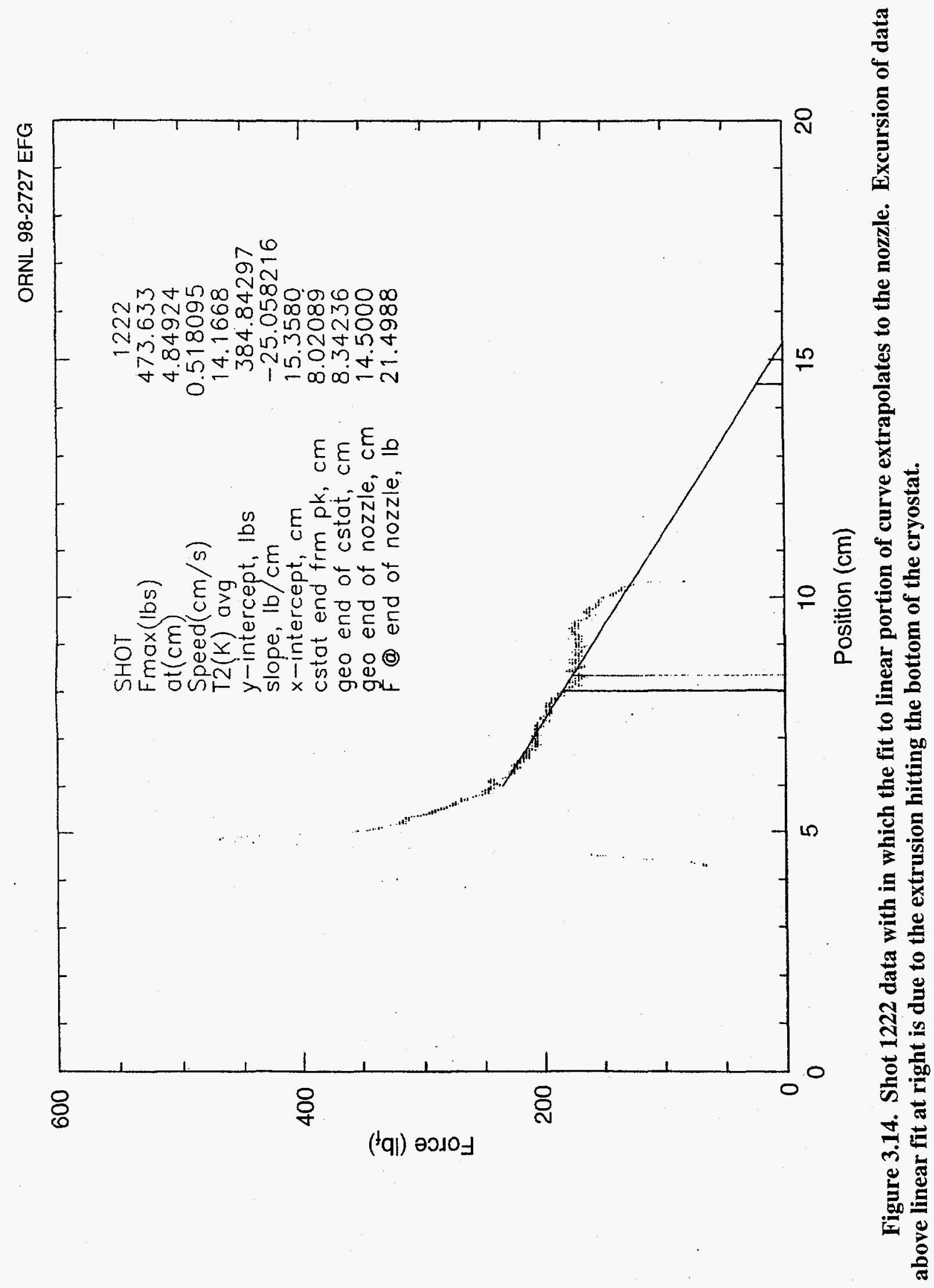




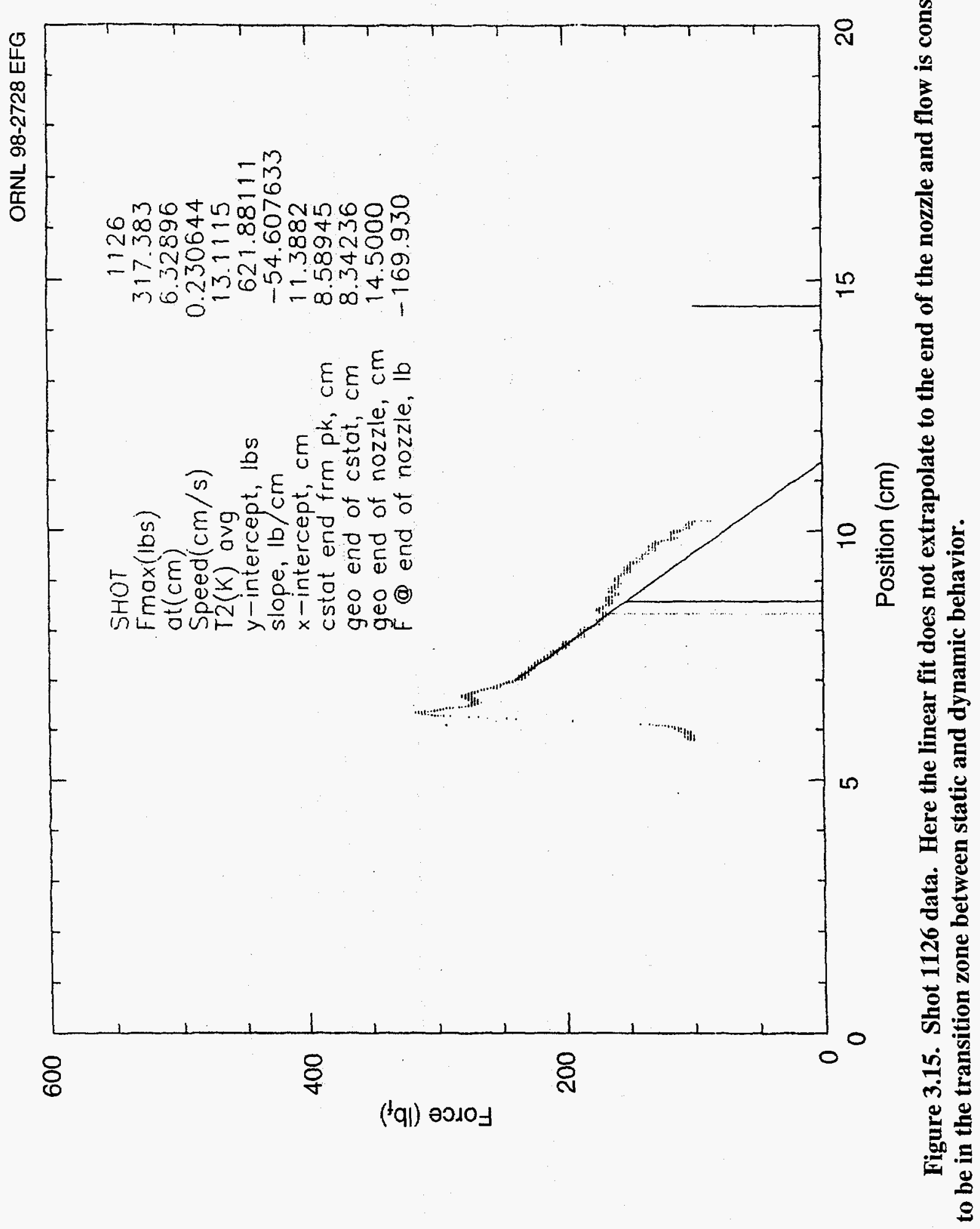




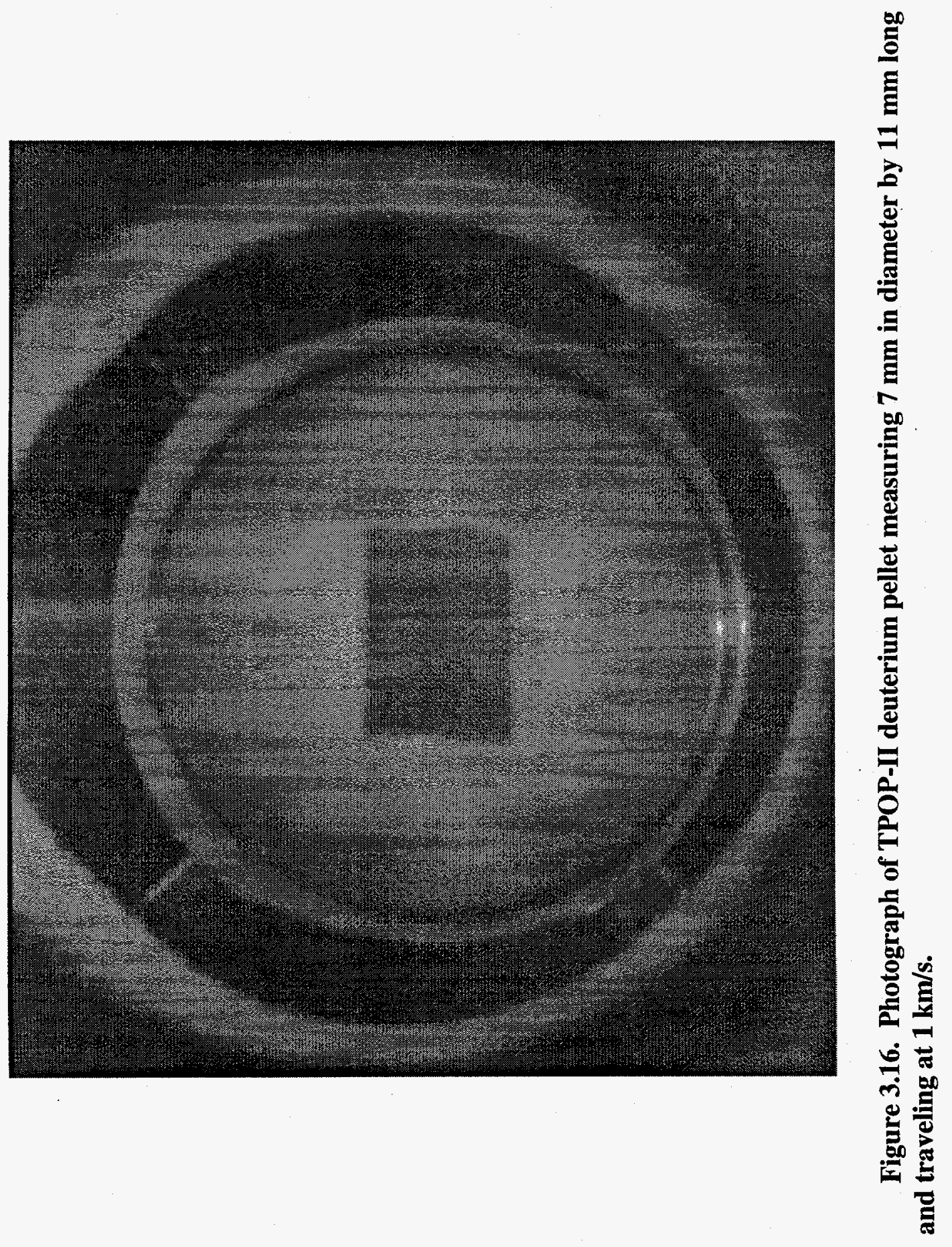






ב⿱艹
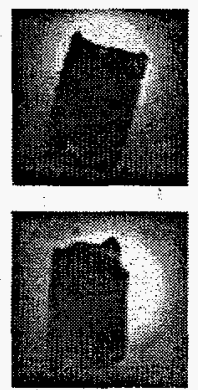

$\stackrel{8}{*}$
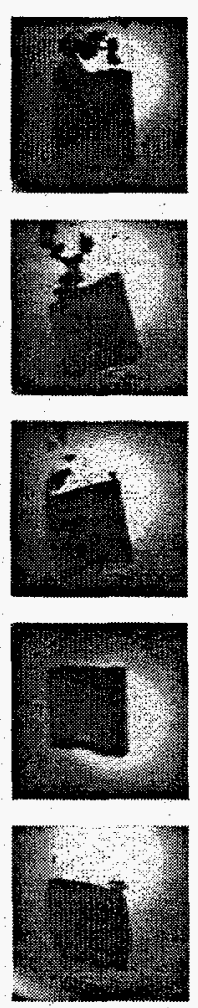



을

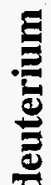

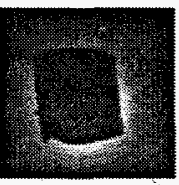

둘 


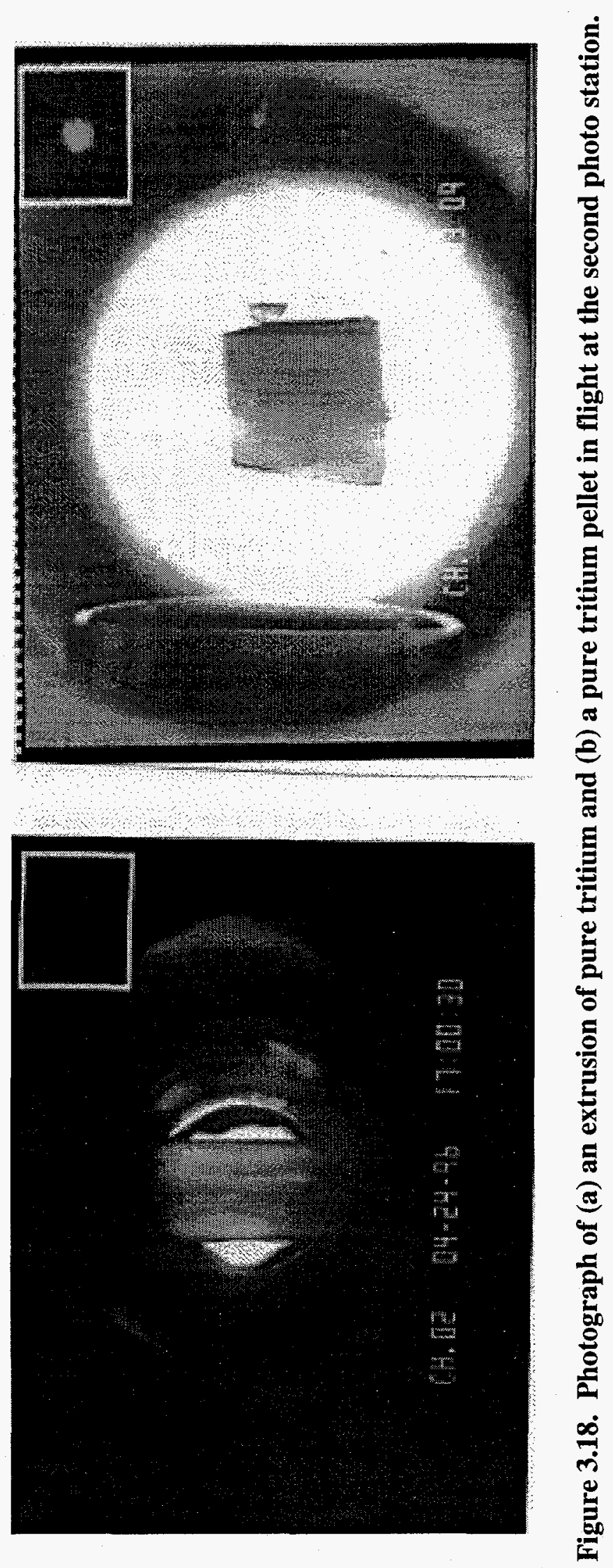




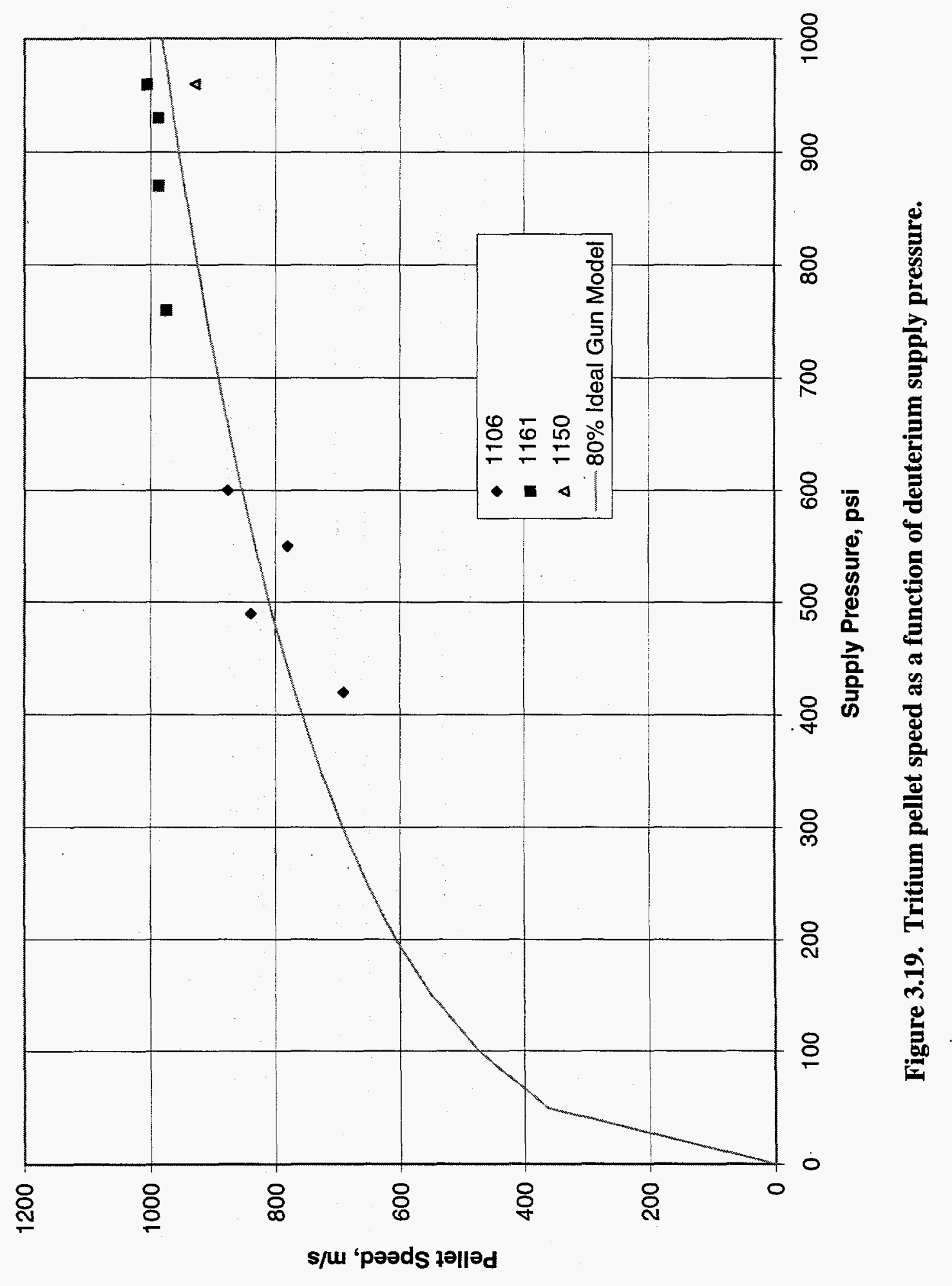


TRITIUM OPERATION OF THE TPOP-II FUEL INJECTION SYSTEM

Document Number

Approval Number

P. W. Fisher

PREPARED BY

PROJECT MANAGEMENT

GROUP MANAGEMENT

QA MANAGEMENT
TTA-TP-TPOP-05, R0

$\underline{5 x x}$
9/5/95

DATE

$\overline{\text { DATE }}$

DATE

DATE 
Page Intentionally Blank 


\section{PURPOSE}

The Tritium Proof-Of-Principle Phase II-Tritium Extruder System (TPOP-II) development program has, as a goal, the first demonstration of tritium extrusion in a pellet injection system sized for the International Thermonuclear Experimental Reactor (ITER) fueling application ( $\sim 8 \mathrm{~mm}$ diameter tritium pellets). It is a continuation of an earlier development program which demonstrated, at the Tritium Systems Test Assembly (TSTA), the formation and acceleration of the world's first tritium pellets for fueling of future fusion reactors. At TSTA the TPOP-II experiment is also known as FIS or Fuel Injection System. The purpose of this test is to produce tritium and deuterium-tritium pellets. Vacuum leak checking, tritium leak checking, deuterium operations, and leak checking of the secondary containment enclosure will all have been performed prior to these tests. The key result of this test will be determination of operating conditions under which ITER relevant pellets can be produced.

\section{CONFIGURATION}

Figure 1 shows a diagram of the TPOP-II experimental apparatus as it is installed at TSTA. All TPOP-II systems, including the pneumatic driver, pellet diagnostic line, vacuum ballast tank, valve manifolds, and pumps, are housed in secondary containment enclosures dedicated to this experiment. The driver is a repeating pneumatic injector (RPI); similar injectors have been used to fuel fusion experiments for the past fifteen

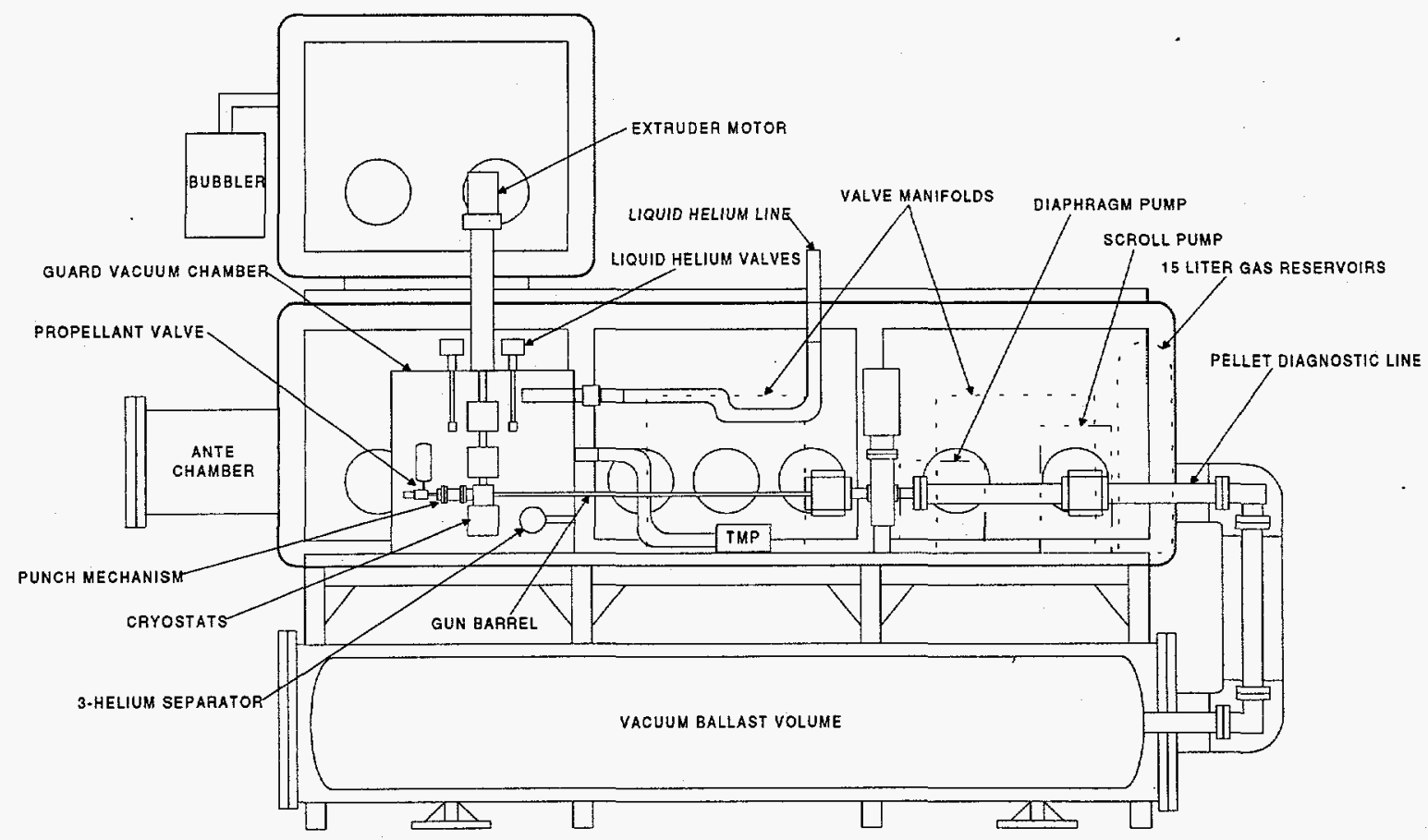

Figure 1. TPOP experiment. 
years. The RPI has three liquid helium cooled cryostats which produce and extrude a solid ribbon of $\mathrm{Q}_{2}$ from gas which is fed to the system. A punch cuts a cylindrical pellet out of the ribbon and high-pressure propellant gas $\left(\mathrm{H}_{2}, \mathrm{D}_{2}\right.$, or $\left.\mathrm{He}\right)$ delivered from a fastacting valve accelerates the pellet down the barrel. The quality and speed of the accelerated pellets is measured in a diagnostic line. When a pellet strikes the end of the diagnostic line it evaporates and the gas from both the pellets and propellant accumulates in the large (600 liter) vacuum ballast volume located underneath the glovebox. The RPI is housed in a guard vacuum enclosure to thermally insulate the cryostats. The enclosure is evacuated with a turbomolecular pump (TMP) which discharges to the process evacuation vacuum (PEV) system. Also housed in the guard vacuum is the cryogenic 3-helium separator which was developed and tested in the original TPOP experiment.

Figure 2 shows the piping and instrumentation schematic diagram for the experiment.

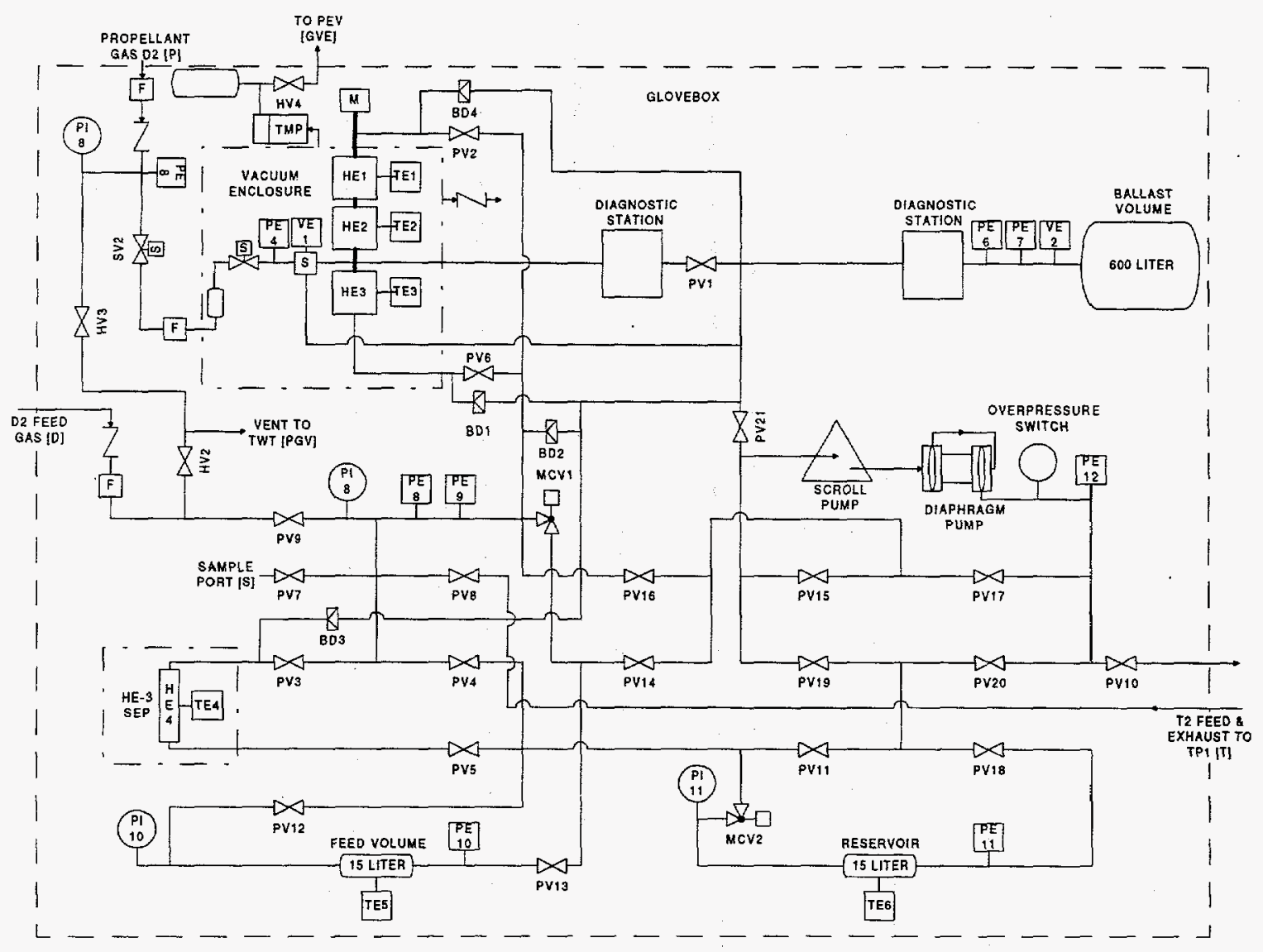

Figure 2. Piping and instrumentation drawing of TPOP experiment.

Parts of the system which constitute primary containment for tritium are of all-metal construction employing Nupro valves, Cajon VCR fittings, ConFlat-type flanges, and indium sealed joints, with the exception of the quartz windows in the injection line and a Vespel seal on the propellant valve upstream of the valve seat which separates the process gas from the high-pressure propellant gas. Tritium is delivered to the system from LIO through TP1 and vacuum exhaust is returned to TP1. Non-tritium gases which enter the 
system are supplied at pressures which are higher than the system pressure. They also pass through check valves and isolation valves to help prevent backflow of tritium from the system. High-pressure propellant gas is batched into the system through a three-way valve which isolates the system from the gas supply so that only a small controlled volume of this gas is available to the system. Parts of the system in which cryogenic materials could become trapped are protected from overpressure by bursting disks which relieve to the large vacuum ballast tank. A Normetex scroll pump and diaphragm pump are used to move gas around the system and to augment reception and return of gaseous $\mathrm{Q}_{2}$ from and to TP1. This pump exhaust line is protected against overpressurization from the pumps by a pressure switch which interrupts power to the pumps.

All instrumentation and control functions shown in Fig. 2 are handled by two computers dedicated to the TPOP-I experiment as shown in Fig. 3. A PC is used for process

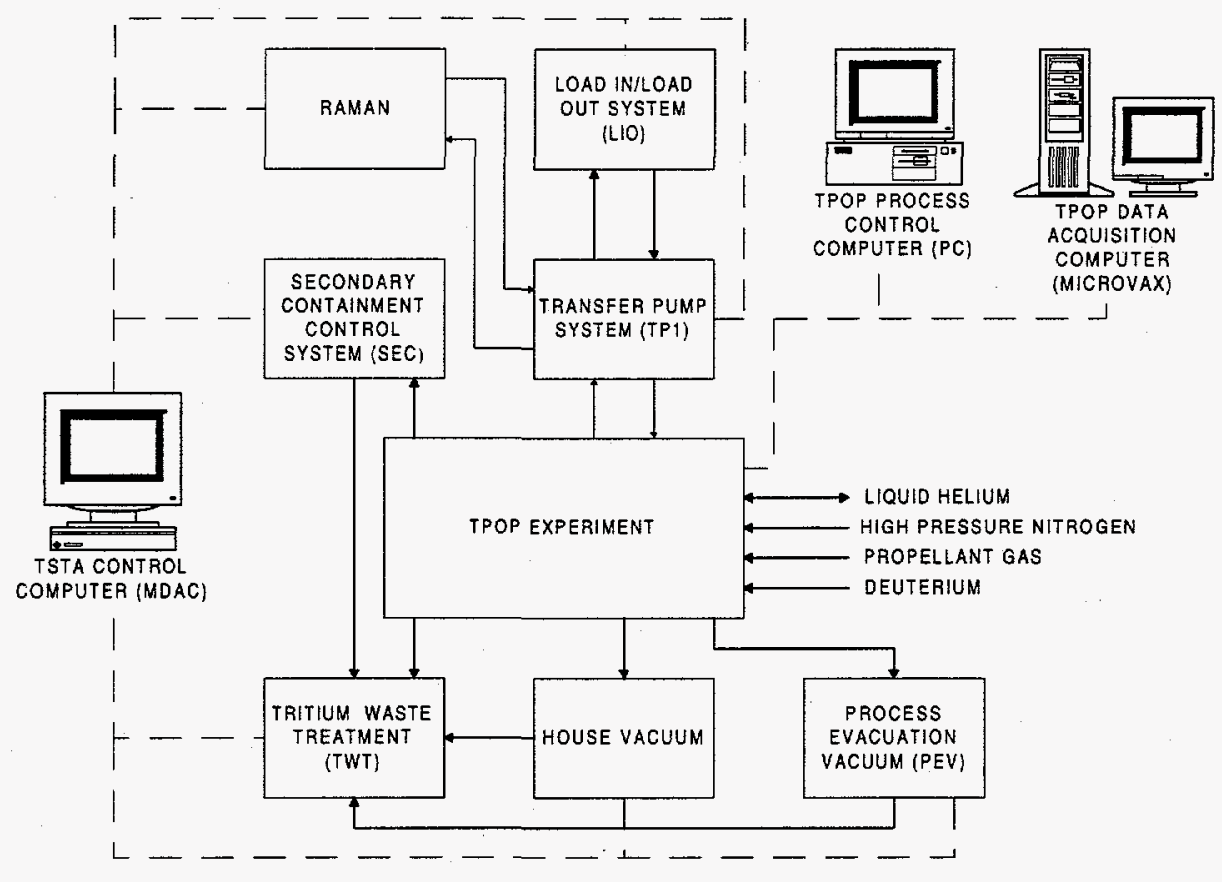

Figure 3. Control block diagram of TPOP experiment.

control and a MicroVAX is used for triggering the driver, fast data acquisition, and archiving data. All system valving and RPI can also be operated manually from the TPOP-II control panel. A program called THE FIX by Intellution is used to operate the system from the PC. This program can be used to operate individual valves or to run programs which automatically sequence the valves to perform particular processes such as tritium transfer, 3-helium separation, etc. All TSTA systems are operated through the MDAC system. There is no interconnection between the TSTA and TPOP-II control systems. Coordination of activities between the two systems is accomplished by verbal communication between the TSTA operator and the TPOP-II test director. 


\section{SUBSYSTEMS AND SPECIAL MATERIALS REQUIRED}

FIS, TP1, PEV, effluent , MDAC, $\mathrm{HPN}_{2}$, house vacuum, SEC, house helium, liquid helium, compressed deuterium, LIO, a PC of pure tritium, three empty PCs, UTB, raman spectrometer, sample cylinder, and mass spectrometer.

\section{PERSONNEL REQUIRED}

The test director for these tests will be Paul Fisher. Mike Gouge will supply further staff direction. Byron Denny will be the operator in charge of running the experiments. Other TSTA personnel will help as needed during the test.

\section{SCHEDULE}

These tests will be conducted between September 25, 1995 and September 30, 1996.

\section{HAZARDS ASSOCIATED WITH THIS TEST}

Hazards associated with this experiment have been evaluated in the TPOP Pellet Injector Phase II system design description TTA-SDD-110-02. The primary hazards associated with this experiment are radiological hazard of tritium, flammability of deuterium, high-pressure gas, and cryogenic fluids. All TSTA standard procedures for dealing with these hazards will be followed.

\section{DATA REQUIREMENTS}

The goals of this experiment are to determine if tritium and DT mixtures can be extruded at cryogenic temperatures, to determine if the extrudate can be punched to form pellets, to determine if the pellets can be pneumatically accelerated to high velocities, and to document the conditions under which this is possible. Key data will include system temperatures, pressures, extrusion speed, extrusion force, punch timing, propellant pressure, pellet speed, pellet composition, and pellet photographs.

\section{OUTLINE OF THE TEST}

\subsection{TEST PREPARATION}

1. Mount PC of pure tritium containing at least 8,000 torr-liters of gas on the LIO manifold. 
2. Have three empty PCs available in test cell. Tritium utilization for a typical series of runs is shown in Table 1. It requires about 8,000 torr-liters of tritium for a series which will produce about 36,000 torr-liters of waste gas; enough to fill an empty PC. Therefore, a full PC of feed ( $-32,000$ torr-liters tritium) will produce four PCs of waste gas and the supply PC becomes a waste container.

Table 1. Gas utilization in a typical series of runs

\begin{tabular}{|l|l|l|l|l|l|l|l|}
\hline \multicolumn{1}{|c|}{ Extrusion No. } & 1 & \multicolumn{1}{c|}{2} & \multicolumn{1}{c|}{3} & \multicolumn{1}{c|}{4} & \multicolumn{1}{c|}{5} & \multicolumn{1}{c|}{6} & \multicolumn{1}{c|}{} \\
\hline Initial gas in system, torr-1 & 8000 & 12000 & 16000 & 16000 & 16000 & 16000 & 16000 \\
Tritium mole fraction & 1 & 0.67 & 0.50 & 0.40 & 0.32 & 0.26 & 0.20 \\
Added deuterium propellant, torr-1 & 4000 & 4000 & 4000 & 4000 & 4000 & 4000 & 4000 \\
Total gas after run, torr-1 & 12000 & 16000 & 20000 & 20000 & 20000 & 20000 & 20000 \\
Final tritium mole fraction & 0.67 & 0.50 & 0.40 & 0.32 & 0.26 & 0.20 & 0.16 \\
Gas removed, torr-l & 0 & 0 & 4000 & 4000 & 4000 & 4000 & 20000 \\
Final tritium in system, torr-1 & 8000 & 8000 & 6400 & 5120 & 4096 & 3277 & 0 \\
\hline Total gas removed from system, torr-1 & 0 & 0 & 4000 & 8000 & 12000 & 16000 & 36000 \\
\hline
\end{tabular}

3. If necessary, prepare TP1 for evacuation of FIS process piping to TWT through PEV and evacuate.

4. If necessary, purge piping with deuterium to clean system and evacuate again.

5. Prepare PEV for evacuation of FIS guard vacuum.

6. Evacuate guard vacuum through PEV.

7. Prepare TWT for reception of gas from FIS vent.

8. Install deuterium bottle to propellant and auxiliary gas feeds.

9. If necessary, fill and vent propellant gas several times to clean system.

10. Prepare for manual and/or computer operation of TPOP-II valving.

11. Prepare pellet data acquisition, light gate, and photography systems.

12. If necessary, test pneumatic driver, data acquisition system, and control system for proper operation and re-evacuate system before cooling system.

13. Test extruder limit switches and interlocks.

14. Connect liquid helium and cool copper cryostats to 6-24K. Suggested operating temperatures for the cryostats are shown in Table 2. 
Table 2. Suggested cryostat temperatures

\begin{tabular}{|c|c|c|c|}
\hline Degrees K & $\mathrm{D}_{2}$ & $\mathrm{DT}$ & $\mathrm{T}_{2}$ \\
\hline Triple point & 18.7 & 19.8 & 20.6 \\
\hline TE1 & 23 & 23 & 23 \\
\hline TE2 & 14 & 13 & 13 \\
\hline TE3 & 14 & 13 & 13 \\
\hline
\end{tabular}

15. Prepare TP1, UTB, and LIO systems for tritium operation.

16. If necessary, prepare raman spectrometer for analysis of TPOP gas mixtures.

17. If ${ }^{3} \mathrm{He}$ concentration of feed gas is unknown, prepare sample bottle and mass spectrometer for analysis of TPOP feed gas.

\subsection{THE EXPERIMENT}

Actual experimental conditions will vary as the test is conducted and results are interpreted, but the following is typical of an experiment.

1. Transfer tritium from LIO to TPOP using TP1 as shown in Fig. 4.



Figure 4. Tritium transfer from LIO to TPOP experiment.

2. Fill 12.5 liter reservoir with adequate $\mathrm{T} 2$ for the run ( -650 torr) through valves $\mathrm{PV} 8$, PV4, PV11, and PV18. If feed pressure is inadequate, use the scroll/diaphragm pump to transfer the tritium as shown in Fig. 5. 


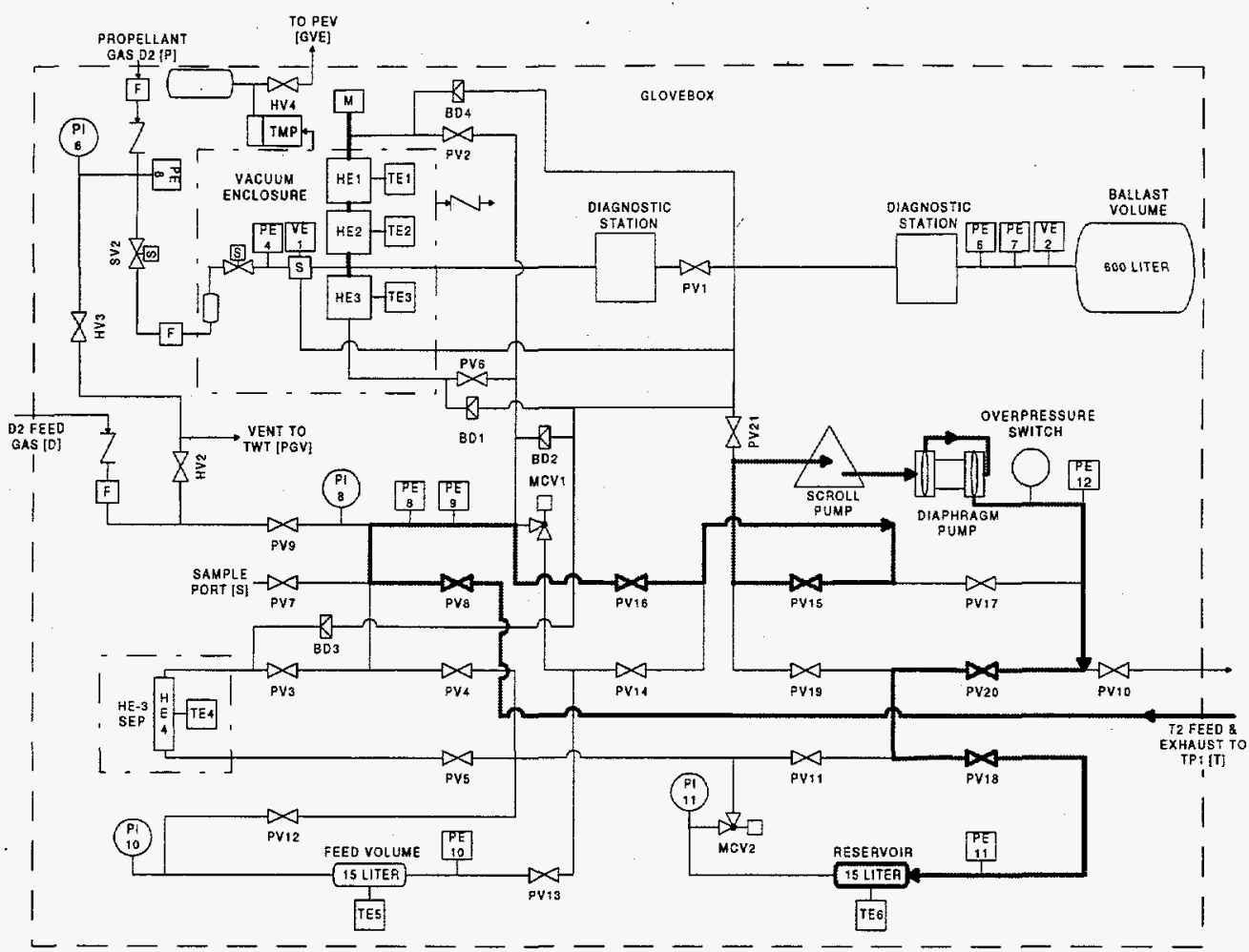

Figure 5. Tritium transfer to TPOP system using scroll/diaphragm pump.

3. To complete transfer, PC may be valved off and lines to TPOP may be drained of tritium by using the TPOP scroll/diaphragm pump as shown in Fig. 5 .

4. If feed gas ${ }^{3} \mathrm{He}$ composition is not known, attach a sample cylinder at PE7. Evacuate the cylinder. Rinse the cylinder twice with sample gas and fill to $\sim 200$ torr for mass spectrometer analysis. Close cylinder, evacuate fitting, remove cylinder, bag, and have RCT monitor transfer from glovebox.

5. Cool ${ }^{3} \mathrm{He}$ separator, perform separation, and return gas to the 15 liter reservoir. Figure 6 shows the flowpath for removal of ${ }^{3} \mathrm{He}$ from the system. Waste gas should be returned to the UTB standard volume during this operation as shown in Fig. 7. 


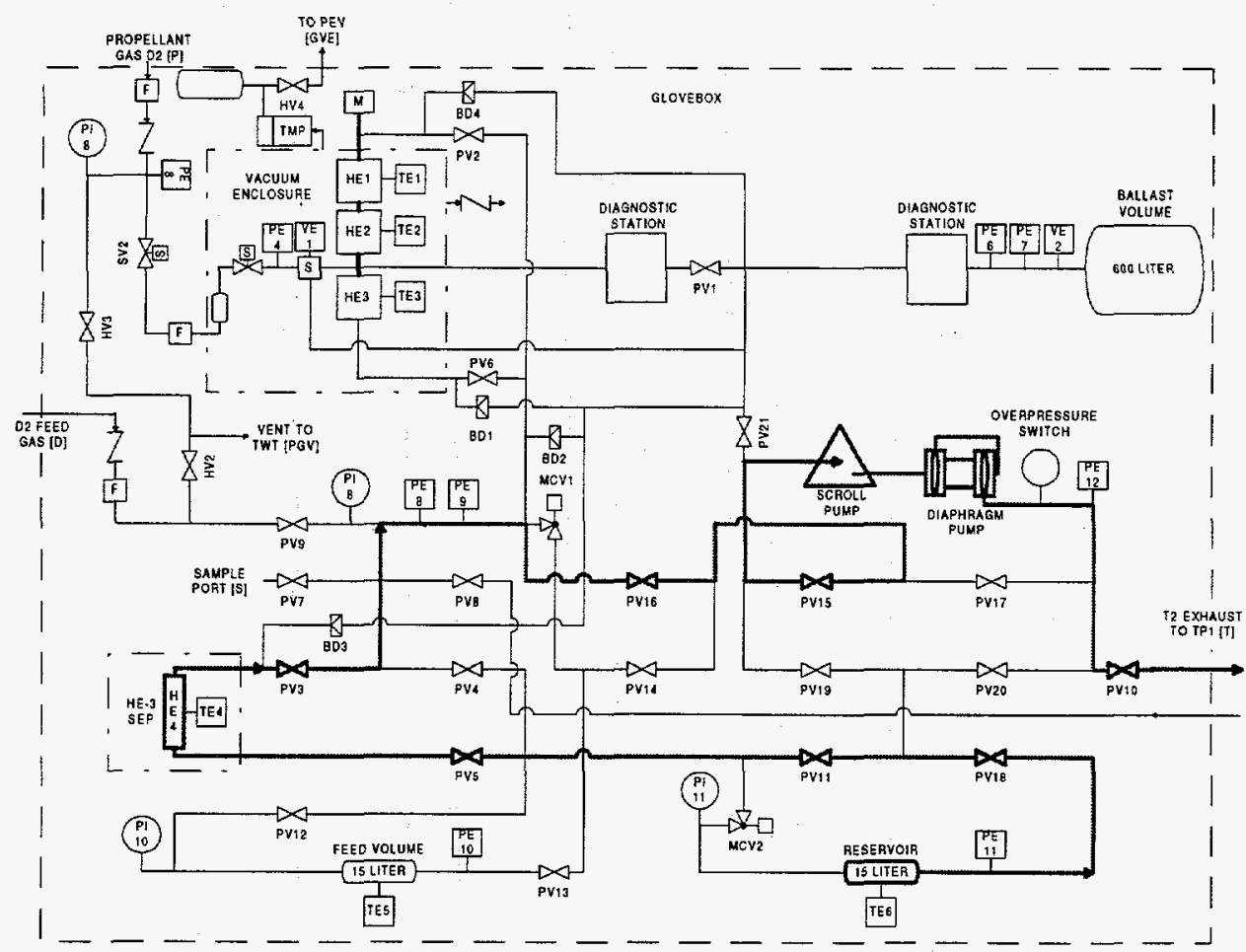

Figure 6. Flowpath for removal of ${ }^{3} \mathrm{He}$ from system.



Figure 7. Removal of waste gas from the TPOP system.

6. Close PV3 and purge system twice with $\mathrm{D}_{2}$ through PV9 to remove traces of ${ }^{3} \mathrm{He}$ from piping.

7. Close PV10 and PV11, and open PV3. Heat ${ }^{3} \mathrm{He}$ separator to $30 \mathrm{~K}$ and transfer tritium from the separator to the reservoir using the scroll/diaphragm pump.

8. A sample of purified gas may be taken for mass spectrometer analysis, if desired.

9. With extruder plunger out, close punch, and subcool lower cooling blocks $(<10 \mathrm{~K})$ in preparation for extruder plug formation.

10. Admit feed gas to the extruder through PV2; pressure may be controlled using MCV1 or MCV2 if desired (e.g. MCV2, PV4, PV2) and the scroll/diaphragm pump may be 
used to increase the pressure if desired (e.g. PV18, PV19, pump, PV17, PV14, MCV1, PV2). Figure 8 shows the flowpath for this operation.

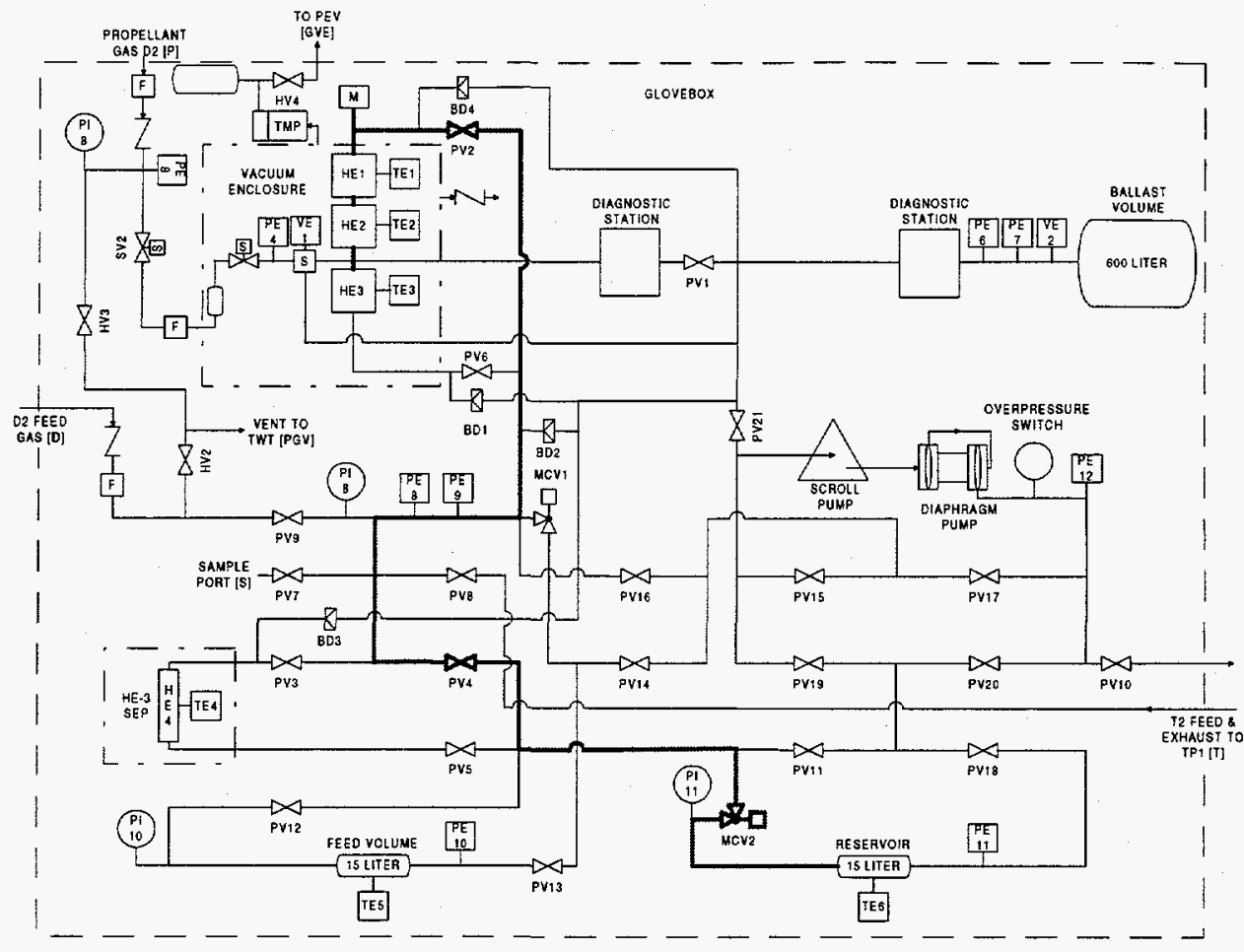

Figure 8. Flowpath for filling extruder.

11. Open PV6 and PV1, release punch, and set cryostats to operating temperature (see Table 2). Gas from PV6 may be returned to the feed reservoir using the scroll/diaphragm pump.

12. Run extruder in (down) until pressure peaks on the force washer.

13. If individual pellets are desired, run extruder in (down), activate punch, and fire propellant valve manually.

14. If continuous pellets are desired, setup the MicroVAX control program to desired conditions and run.

15. Gas may be transferred from the ballast volume to the reservoir, if desired, using the scroll/diaphragm pump (e.g. PV21, pump, PV20, PV18).

16. After the run, gas may be transferred from the ballast volume to TP1 and UTB (Fig. 7) if desired either directly (e.g. PV21, PV19, PV20, PV10) or the transfer can be augmented using the scroll/diaphragm pump (PV21, pump, PV10) as illustrated in Fig. 9. 


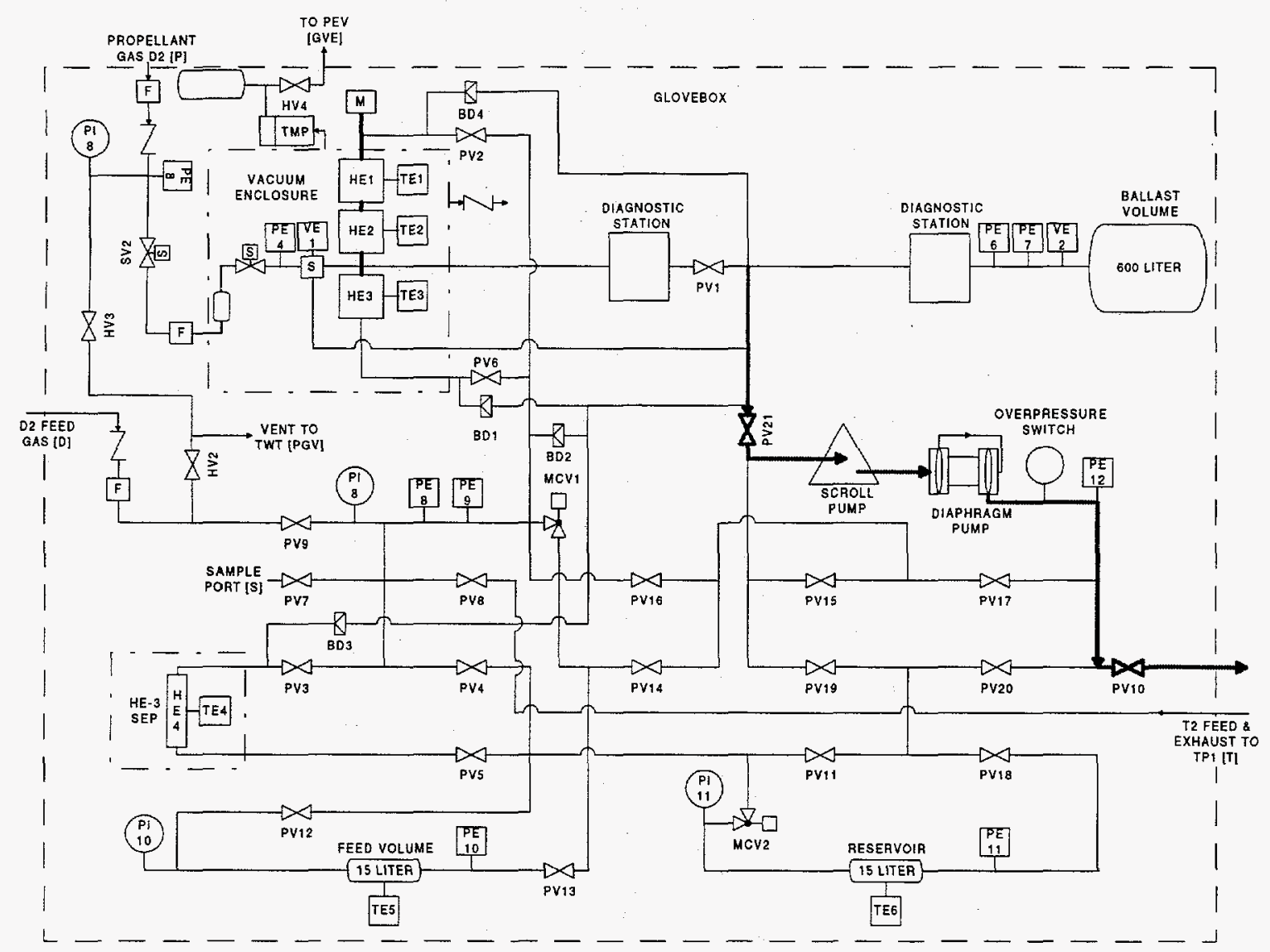

Figure 9. Flowpath for pump assisted transfer of gas from the vacuum ballast volume to TP1.

17. Run extruder out (up) in preparation for refilling.

18. Transfer gas from 600 liter tank to the feed reservoir through PV 21 scroll/diaphragm pump, PV20 and PV18.

19. Refill the extruder through PV2.

20. Repeat extrusion, firing, and evacuation steps as desired.

21. Analysis of gas mixtures with the raman spectrometer may be accomplished by first closing TSTA valves AV4 and MANIN and opening TPOPEX, RAMEX, TPOPIN, and RAMIN as shown in Fig. 10 and circulating gas through the spectrometer using the TPOP scroll/diaphragm pump. After analysis, PV10 should be closed and all gas should be pumped back into the TPOP system before closing the TSTA valves. 


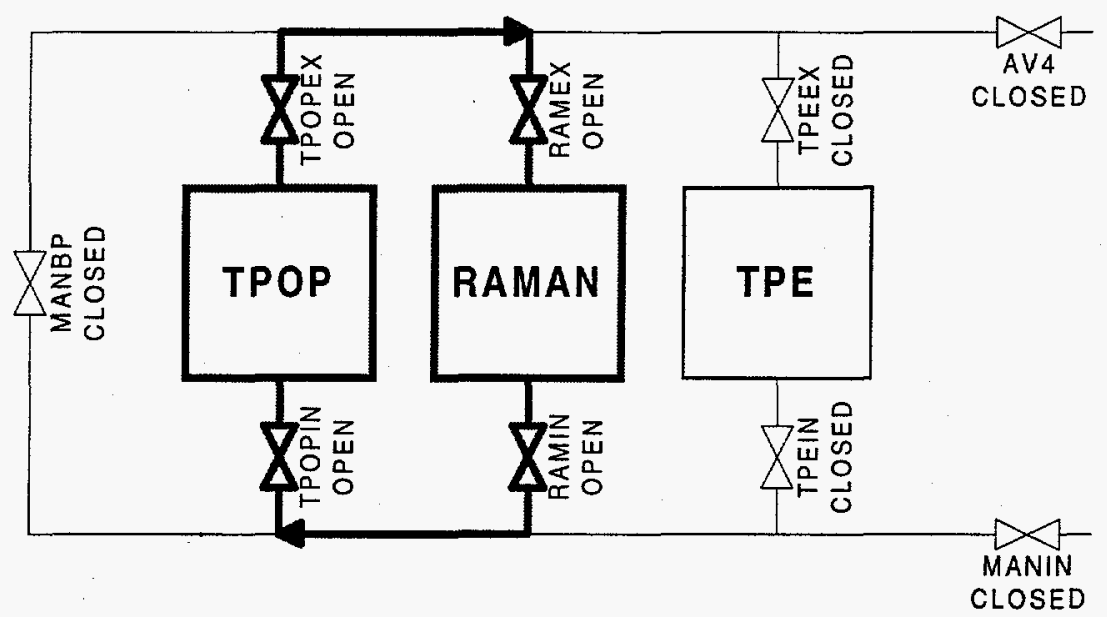

Figure 10. Flowpath for gas between TPOP and RAMAN systems.

22. When system is too lean in tritium ( $<20 \%, \sim 7$ extrusion runs as shown in Table 1$)$ drain entire TPOP gas inventory to the UTB standard volume (Fig. 7). If additional runs are to be made, return to Step 1.

23. After an entire PC of pure tritium has been consumed, transfer the waste gas from the UTB standard volume to empty PCs as illustrated in Fig. 11.

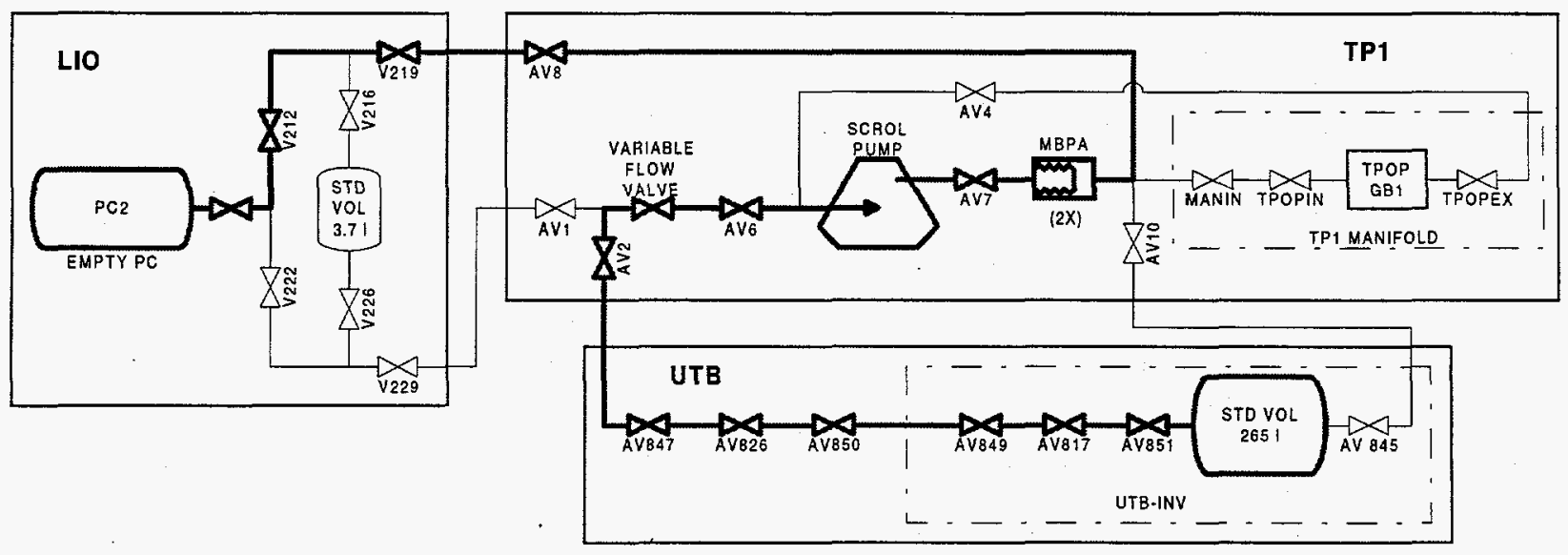

Figure 11. Transfer of waste gas from UTB standard volume to empty PCs.

\subsection{SHUTDOWN}

1. With PV1, PV2, and PV6 open, warm the cryostats to release solidified gas to the ballast volume.

2. Turn off the liquid helium supply and set controllers to warm cryostats to room temperature.

3. Vent the propellant gas to the effluent line.

4. Evacuate all gas from the system to TP1 through PV10 as illustrated in Fig. 7 (the scroll/diaphragm pump may be used to augment this transfer).

5. Transfer waste gas to empty PCs as in Step 23 above. 
6. If system is to be idle for a period of time, it may be backfilled with helium to atmospheric pressure through the auxiliary gas port.

7. Close all system valves.

8. Valve off auxiliary and propellant gas supplies.

9. Place all power supplies, controllers, and computers into their desired standby configurations.

10. Secure TSTA systems as required. 


\section{Appendix II. FAST DATA ACQUISITION}

\section{CONFIGURATION}

The TPOP fast data acquisition system is a CAMAC based system connected to a MicroVAX computer through a data highway. Analog data is inputted through three CAMAC modules an 8210 module with four channels (1-4), an 8210 module with one channel (5), and an 8212 module with eight inputs (7-13). Shot parameter data is recorded through software into the fourteenth channel labeled TPOP_CNF. The module and channel assignments are as follows:

$\begin{array}{llllll}\text { Chan } & \text { Module_Chan } & \text { Windowed } & \text { Input } & \text { Scaling } & \text { Points/Chan } \\ 1 & 8210 \_1 & \text { Yes } & \text { Punch Shock } & 20,000 \mathrm{~g} / \mathrm{V} & 24,576 \\ 2 & 8210 \_2 & \text { Yes } & \text { Breech Pressure } & 200 \mathrm{psi} / \mathrm{V} & 24,576 \\ 3 & 8210 \_3 & \text { Yes } & \text { Target Shock } & 20,000 \mathrm{~g} / \mathrm{V} & 24,576 \\ 4 & 8210 \_4 & \text { Yes } & \text { Not Used } & & 24,576 \\ 5 & 8210 \_5 & \text { Yes } & \text { Light Gates } & 1 \mathrm{~V} / \mathrm{V} & 98,304 \\ 6 & 8212 \_1 & \text { No } & \text { Breech Pressure } & 200 \mathrm{psi} / \mathrm{V} & 4,096 \\ 7 & 8212 \_2 & \text { No } & \text { TE1 (Top Extruder Block) } & 1 \mathrm{~V} / \mathrm{V} & 4,096 \\ 8 & 8212 \_3 & \text { No } & \text { TE2 (Middle Extruder Block) } & 1 \mathrm{~V} / \mathrm{V} & 4,096 \\ 9 & 8212 \_4 & \text { No } & \text { TE3 (Lower Punch Block) } & 1 \mathrm{~V} / \mathrm{V} & 4,096 \\ 10 & 8212 \_5 & \text { No } & \text { Force Washer } & 1000 \mathrm{lb} / \mathrm{V} & 4,096 \\ 11 & 8212 \_6 & \text { No } & \text { Extruder Position } & 2.27 \mathrm{~cm} / \mathrm{V} & 4,096 \\ 12 & 8212 \_7 & \text { No } & \text { PE7 (Injection Line Pressure) } & 100 \mathrm{torr} / \mathrm{V} & 4,096 \\ 13 & 8212 \_8 & \text { No } & \text { PE1 (Propellant Pressure) } & 1000 \mathrm{psi} / \mathrm{V} & 4,096 \\ 14 & \text { TPOP_CNF } & \text { No } & \text { Shot Parameter Data } & & \end{array}$

Channel 14 (TPOP_CNF) is a table of numbers which correspond to the following shot parameters:

$\begin{array}{llll}\begin{array}{l}\text { Number } \\ 1\end{array} & \begin{array}{l}\text { Parameter } \\ \text { Number of Pellets } \\ \text { (Windows) }\end{array} & \begin{array}{l}\text { Designation } \\ \mathrm{n}\end{array} & \begin{array}{l}\text { Typical Value } \\ 8\end{array} \\ 2 & \text { Pellet Frequency, } \mathrm{Hz} & \mathrm{f}_{2} & 0.3 \\ 3 & \text { Propellant Delay, } \mu \mathrm{s} & \mathrm{t}_{3} & 60,000 \\ 4 & \text { Punch Delay, } \mu \mathrm{s} & \mathrm{t}_{4} & 50,000 \\ 5 & \text { Extruder Offset, } \mu \mathrm{s} & \mathrm{t}_{5} & 100,000 \\ 6 & \text { Extruder Voltage, } \mathrm{V} & & 4 \\ 7 & \text { 8210\#1 Sample Rate, } \mathrm{Hz} & \mathrm{f}_{7} & 50,000 \\ 8 & \text { 8210\#2 Sample Rate, } \mathrm{Hz} & \mathrm{f}_{8} & 500,000 \\ 9 & \text { 8212 Sample Rate, Hz } & \mathrm{f}_{9} & 200 \\ 10 & \text { 8210\#1 Delay, } \mu \mathrm{s} & \mathrm{t}_{10} & 55,000 \\ 11 & \text { 8210\#2 Delay, } \mu \mathrm{s} & \mathrm{t}_{11} & 60,000 \\ 12 & \text { 8212 Delay, } \mu \mathrm{s} & \mathrm{t}_{12} & 10 \\ 13 & \text { Extruder Off Time, } \mu \mathrm{s} & \mathrm{t}_{13} & 10 \\ 14 & \text { Extruder Off Length, } \mu \mathrm{s} & \mathrm{t}_{14} & 220,000\end{array}$


Temperature readings can be derived from TE1, TE2, and TE3 voltages by using calibration curve for LakeShore Cryotronics DT470 temperature diodes.

Data acquisition is controlled through the program TPOP which requires entry of the shot number and shot parameters. The CAMAC timing sequence is shown schematically below:


where module duration's are as follows:

$\begin{array}{ll}\text { Module } & \text { Window Duration, } s \\ 8210 \# 1 & 24,576 /\left(\mathrm{f}_{7} \times \mathrm{n}\right) \\ 8210 \# 2 & 98,304 /\left(\mathrm{f}_{8} \times \mathrm{n}\right) \\ 8212 & 4,096 / \mathrm{f}_{9}\end{array}$

\section{CHOICE OF PARAMETERS}

System parameters must be carefully chosen in order to coordinate the timing sequence. The first consideration is setting the extruder ram speed to be commensurate with the pellet frequency. Figures AII.1 and AII.2 show ram speed as a function of voltage settings which can be made either manually or through computer. If set manually, the extruder will not automatically pause when pellets are fired. Figure AII.3 shows the maximum ram speed at which the ribbon length is equal to the punch diameter $(9.5 \mathrm{~mm})$. Higher speeds will produce incomplete pellets and lower speeds will lead to poor tritium utilization. Figure AII.4 shows typical punch dynamics curves for a particular voltage setting. The time required for the punch to engage is relatively independent of the Delay Off setting and can be deduced from Fig. All.5. The Delay Off setting must be large enough to produce a current pulse which slightly exceeds the engagement time and this may be determined from Fig. All.6. The time required for the punch to return after the current pulse ends is shown in Fig. AII.7. The minimum extruder off setting required to 
keep the mechanism from jamming is given by the current on time plus the punch return time.

System parameters may vary with conditions and timing should be checked by observing data from test runs. Data files can be plotted using the program SPLOT. 


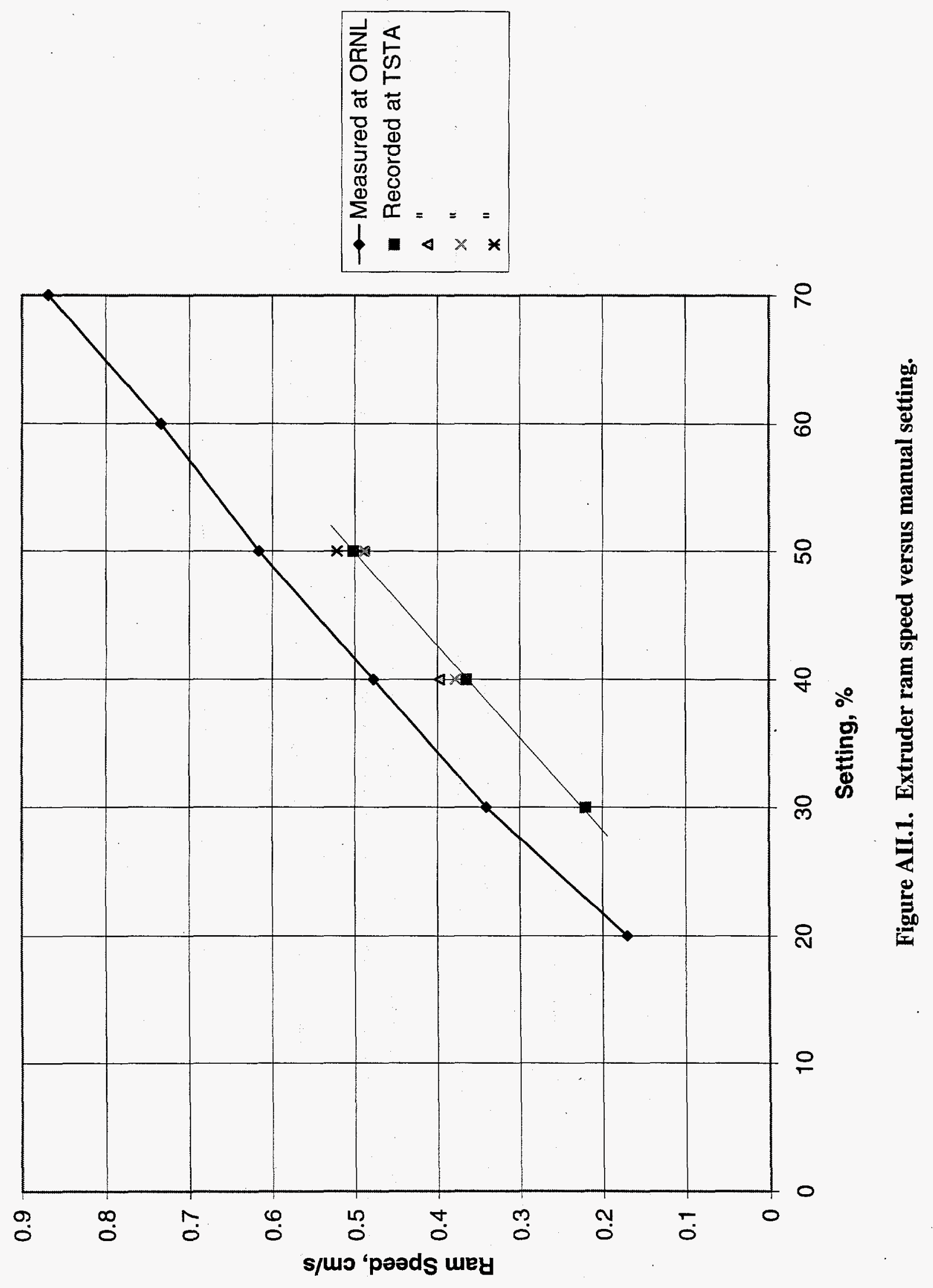



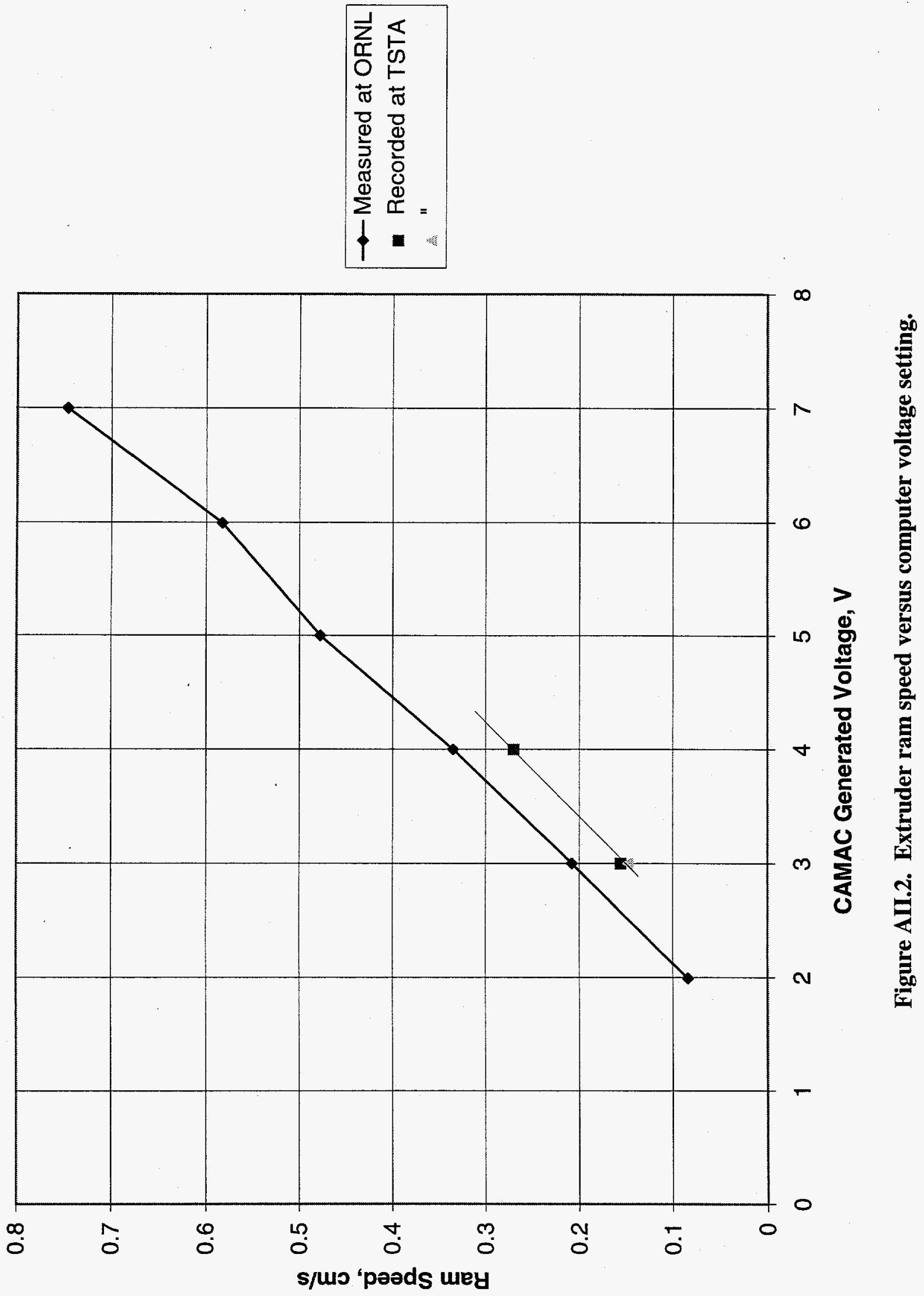


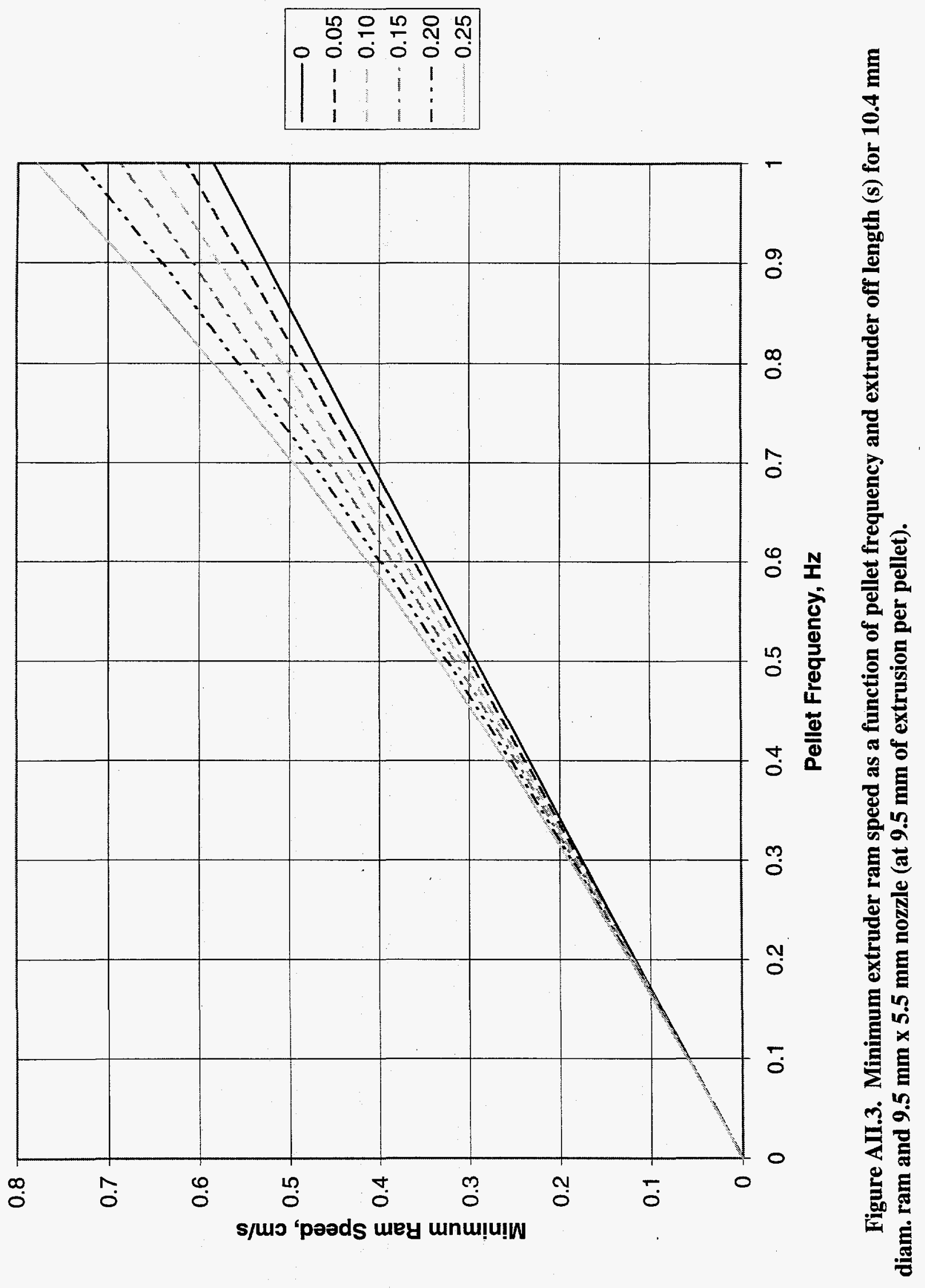




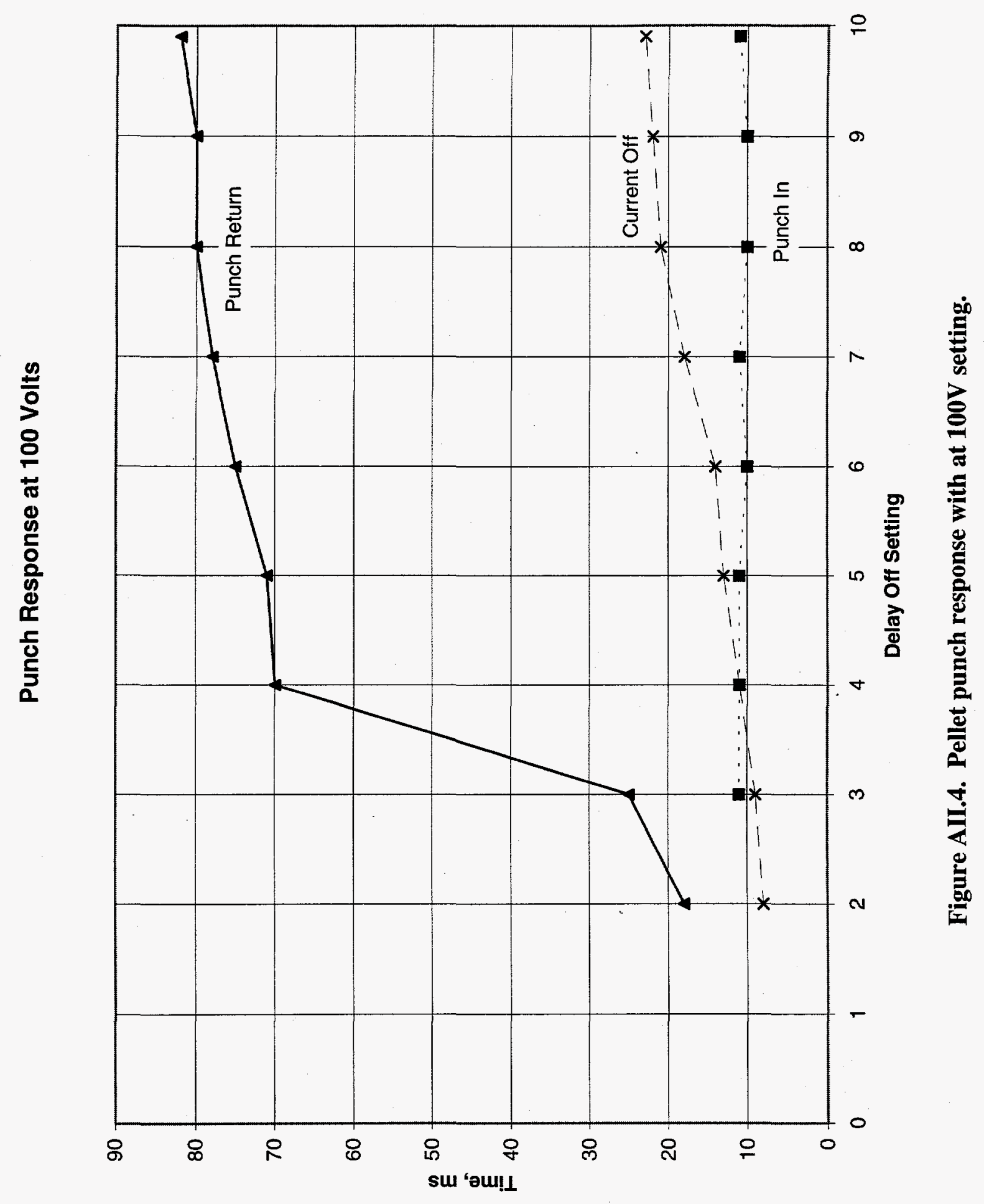




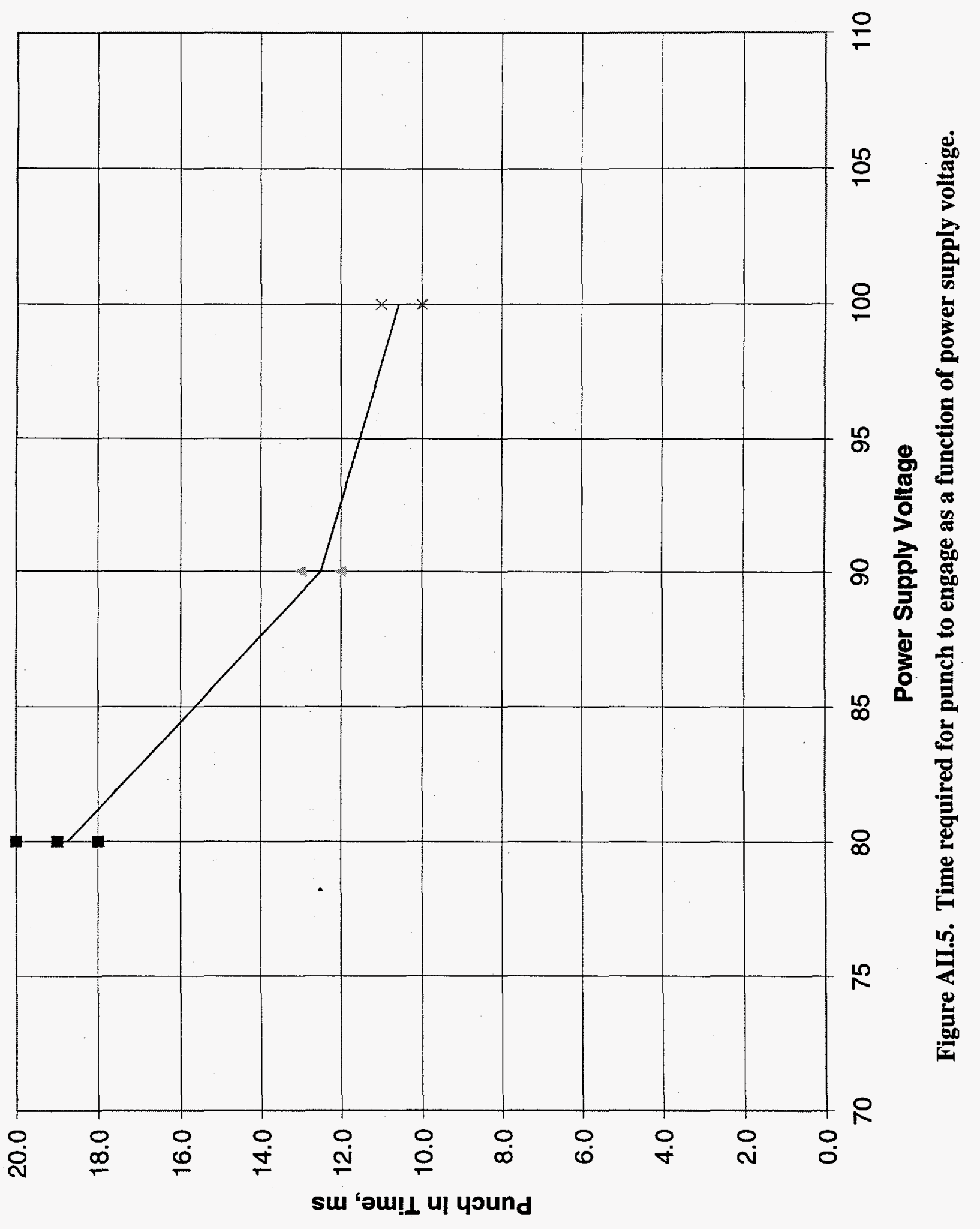









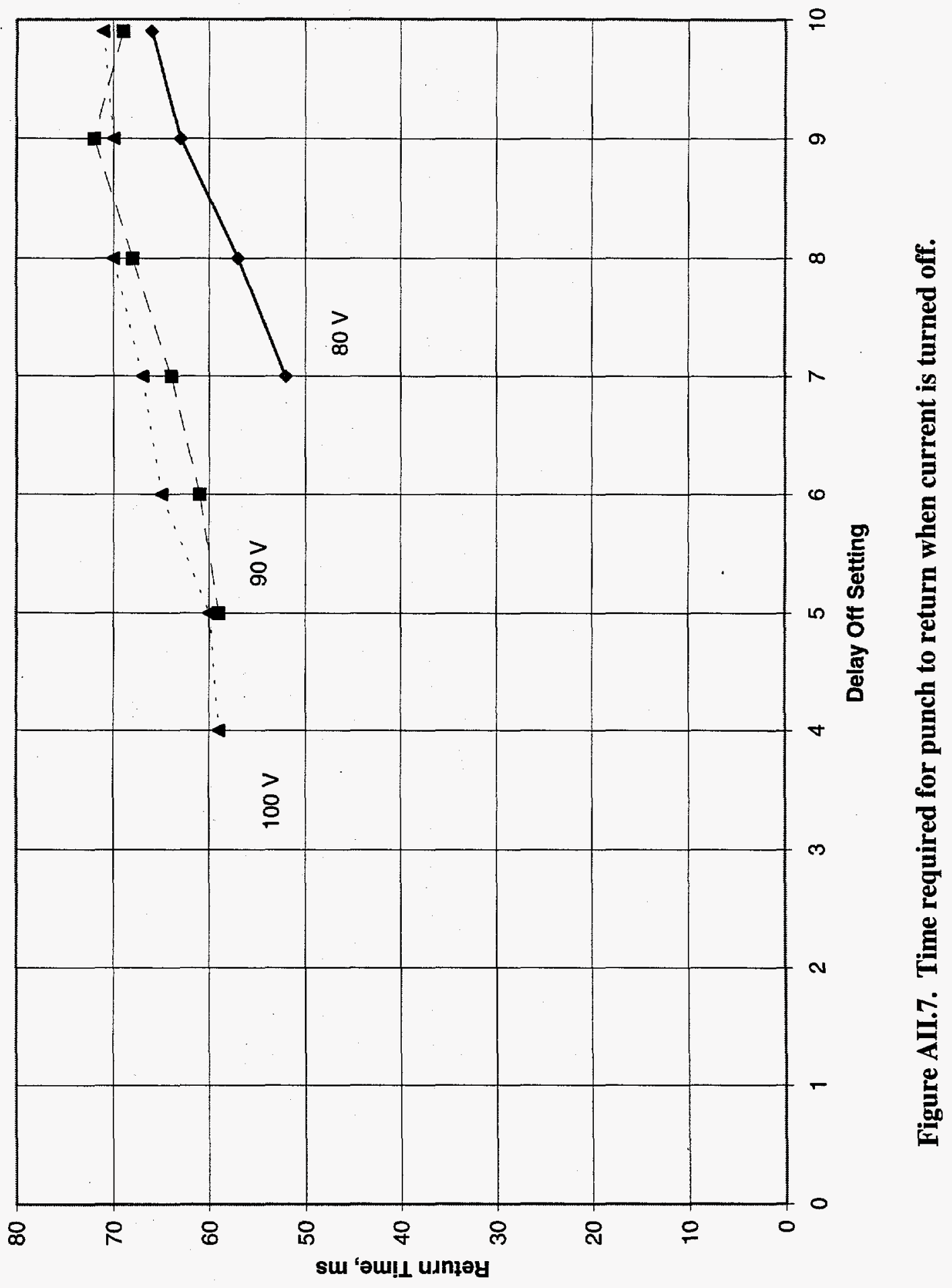




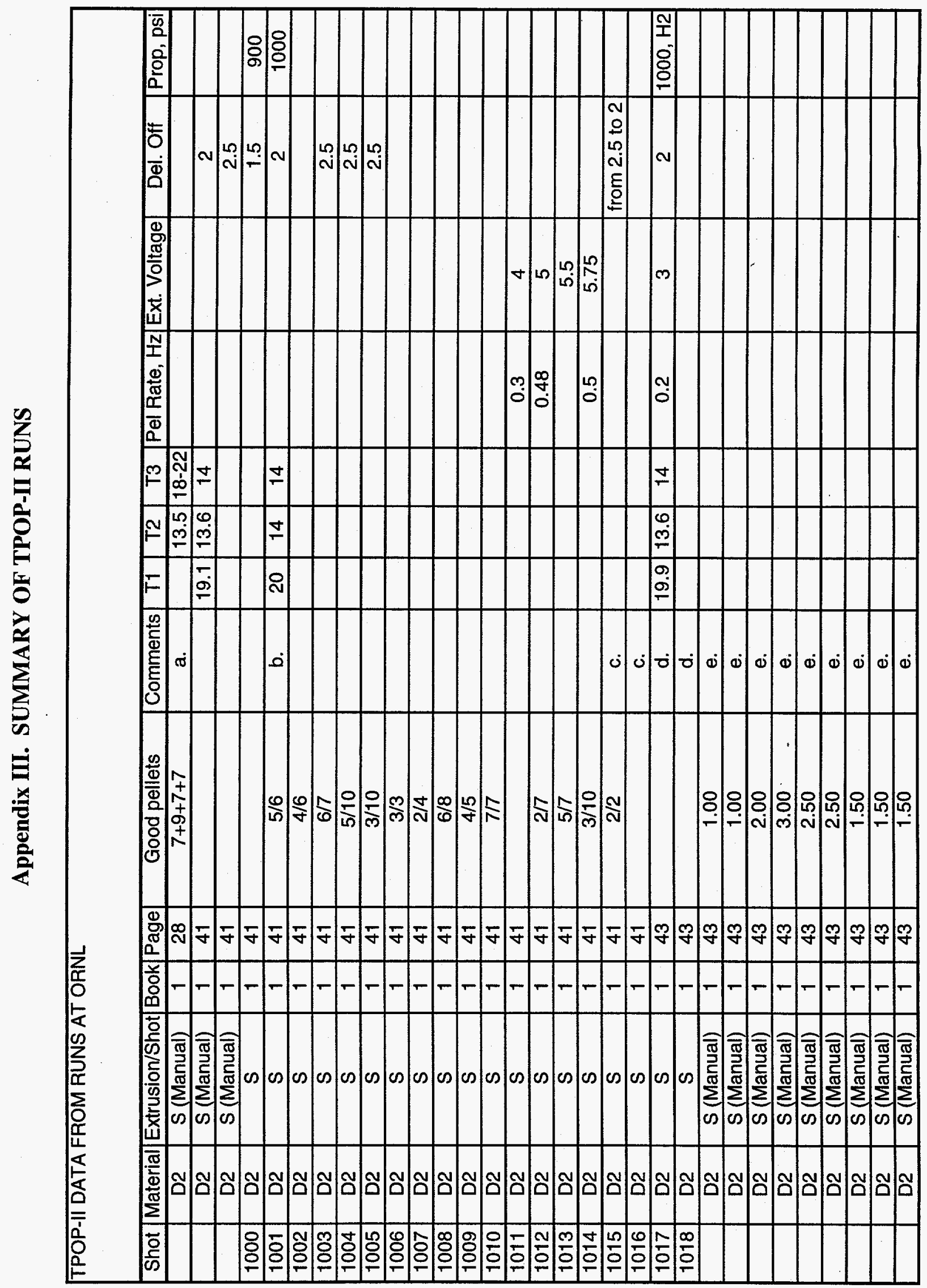




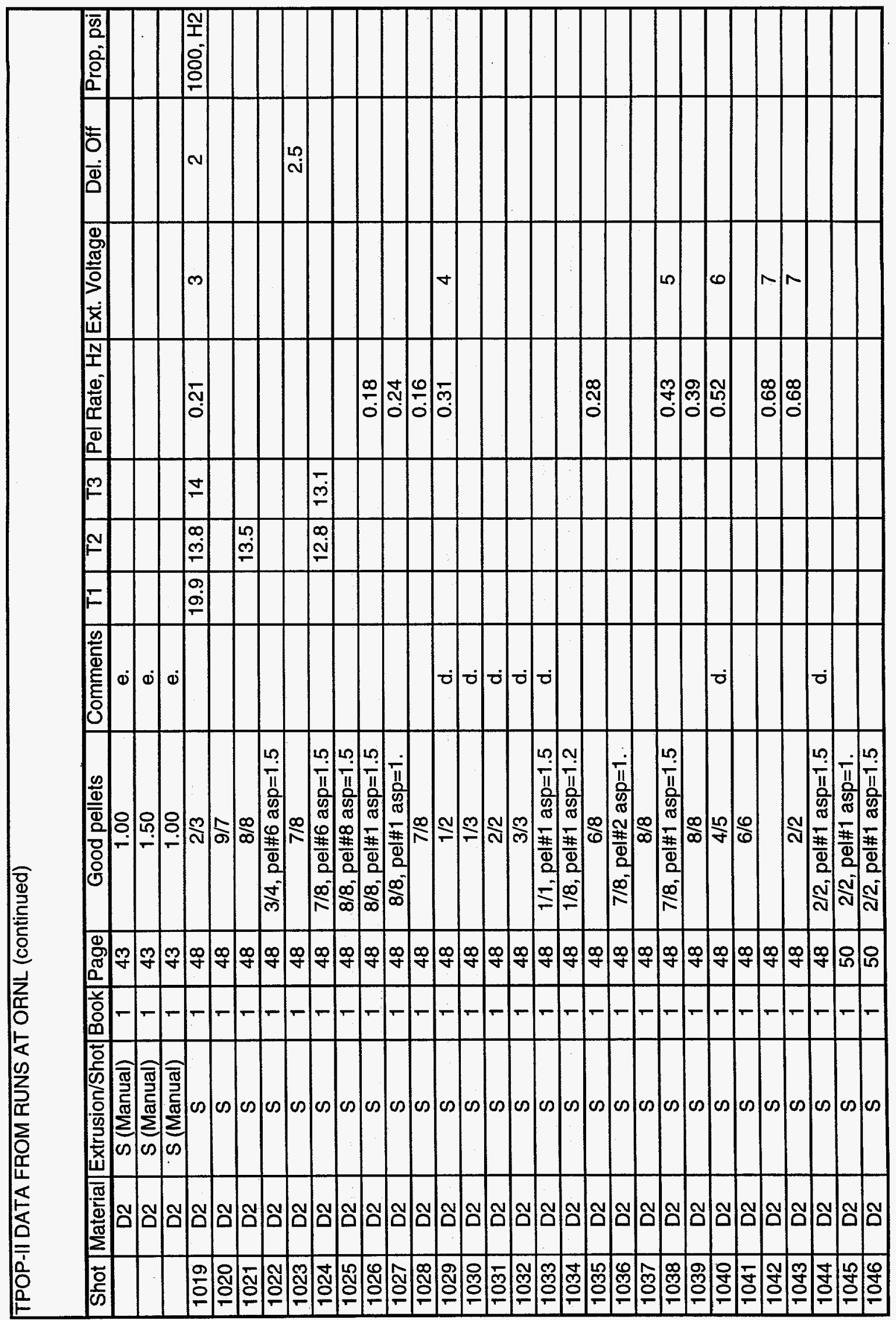




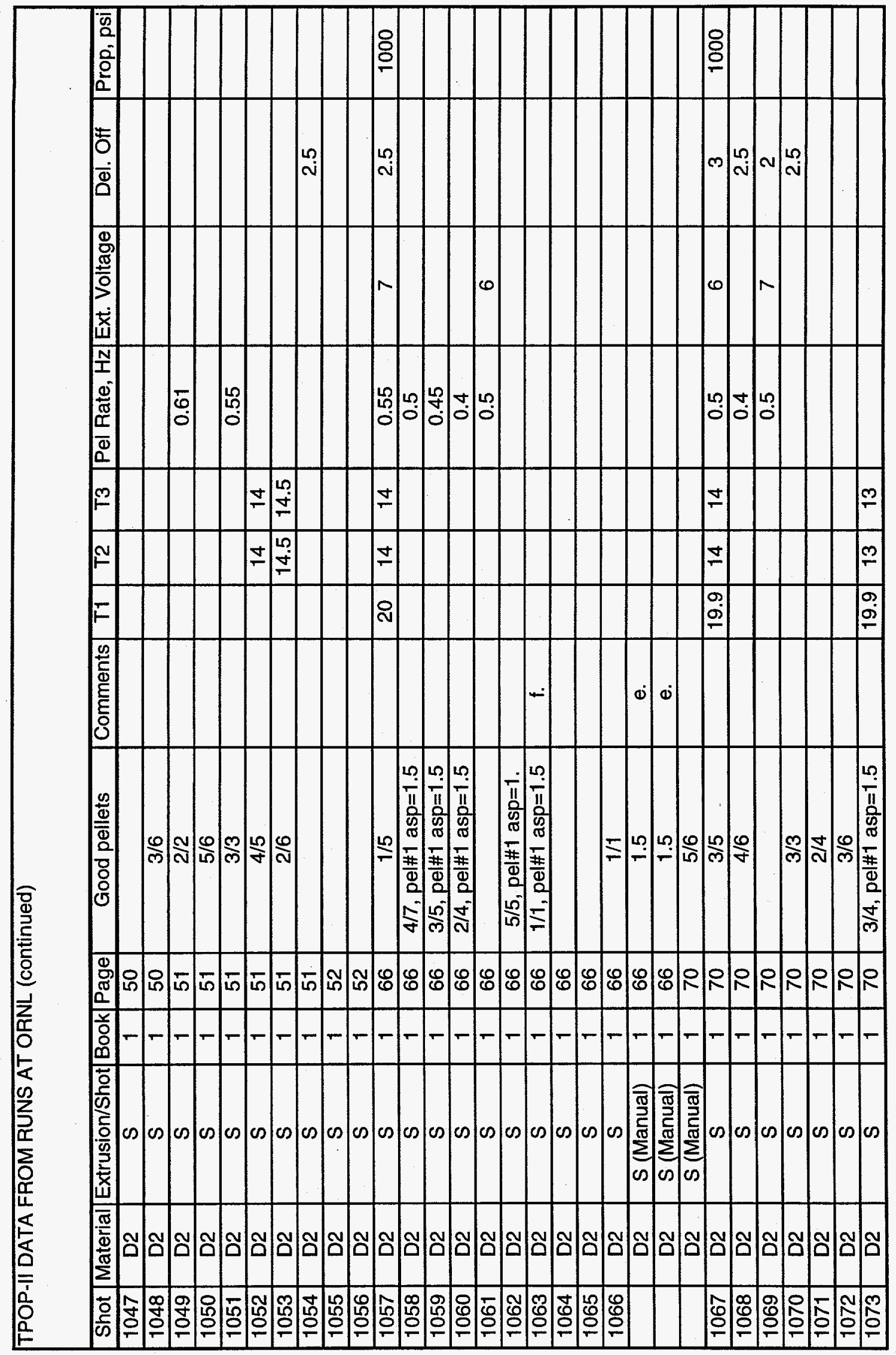




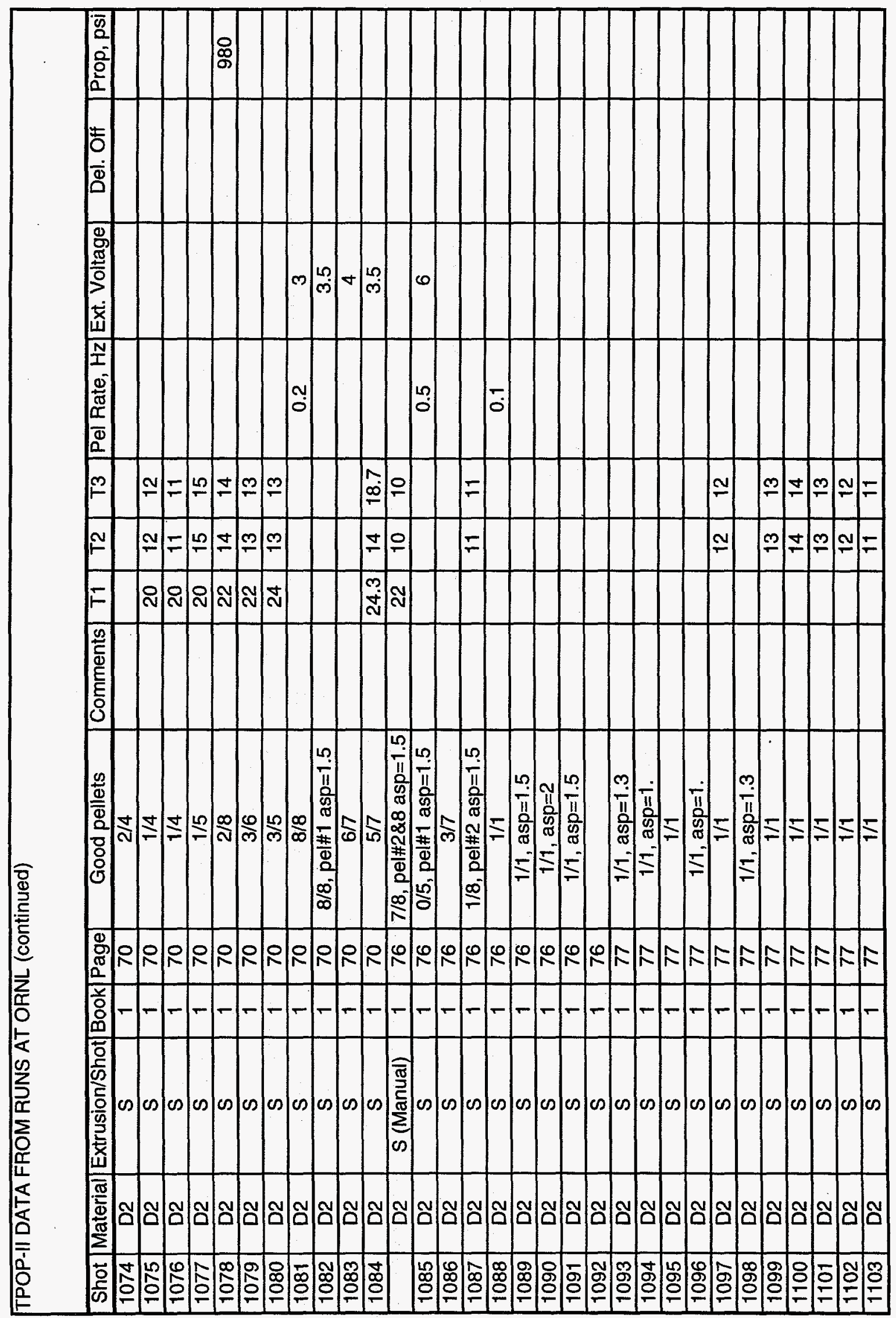




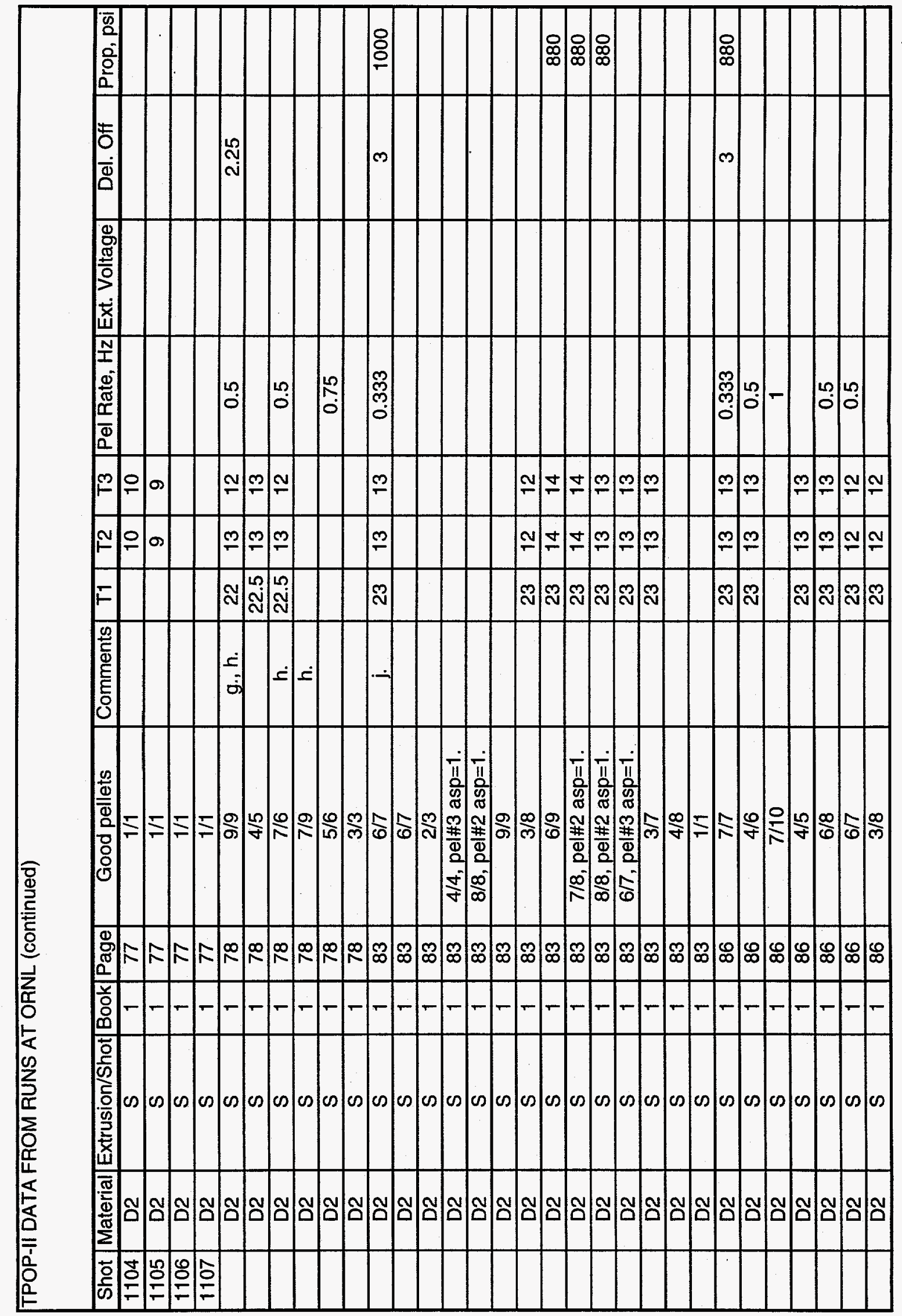




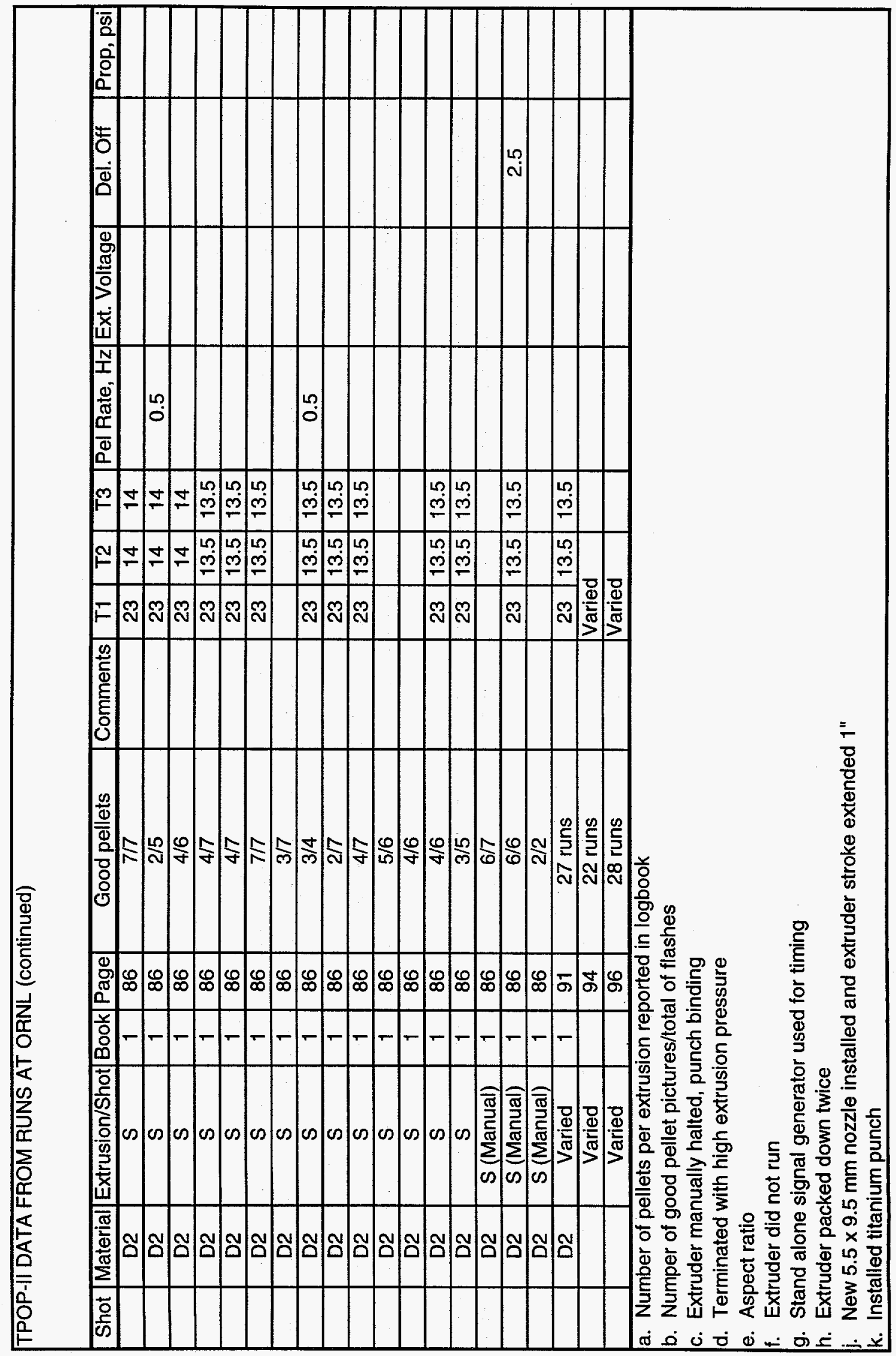




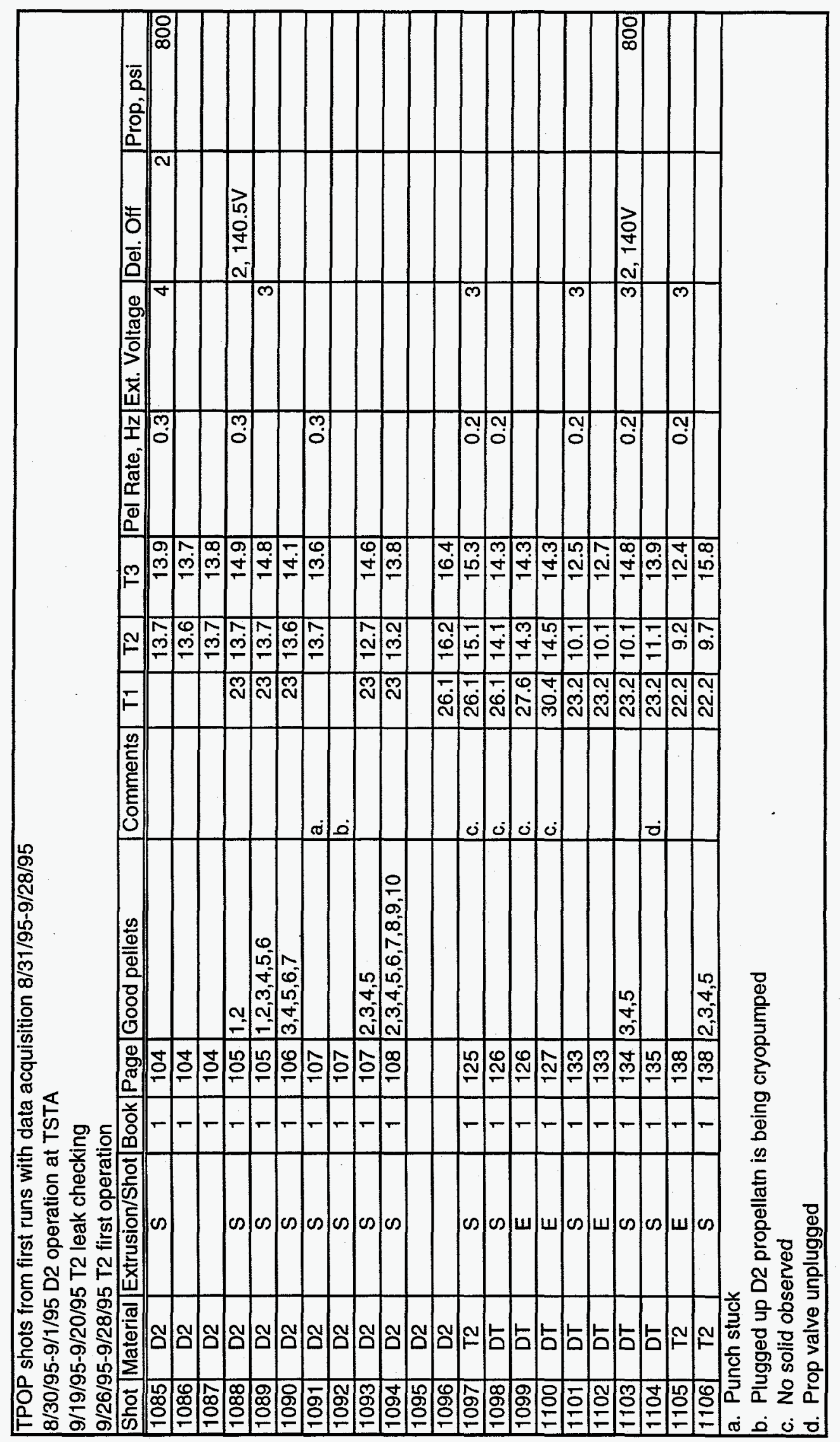




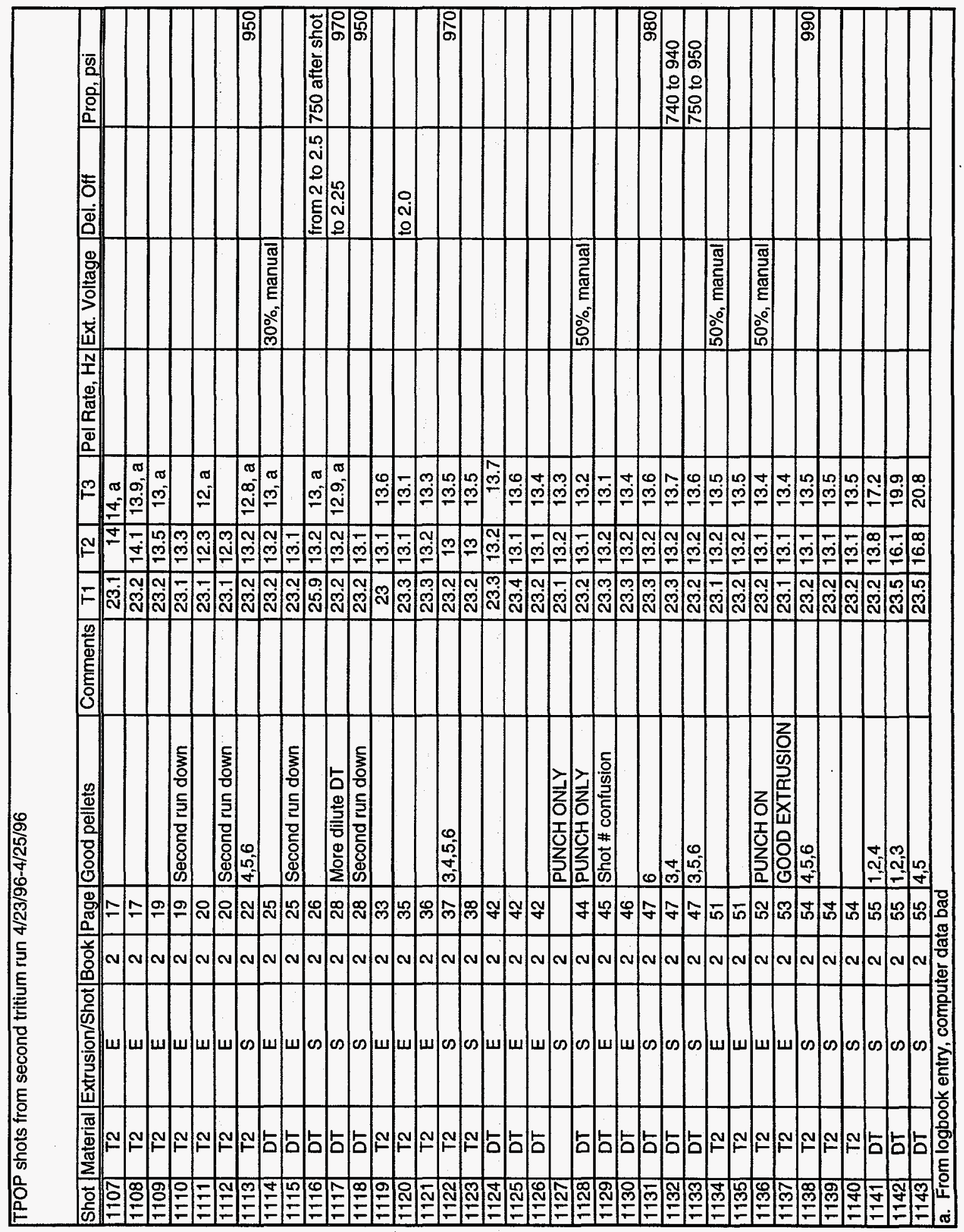




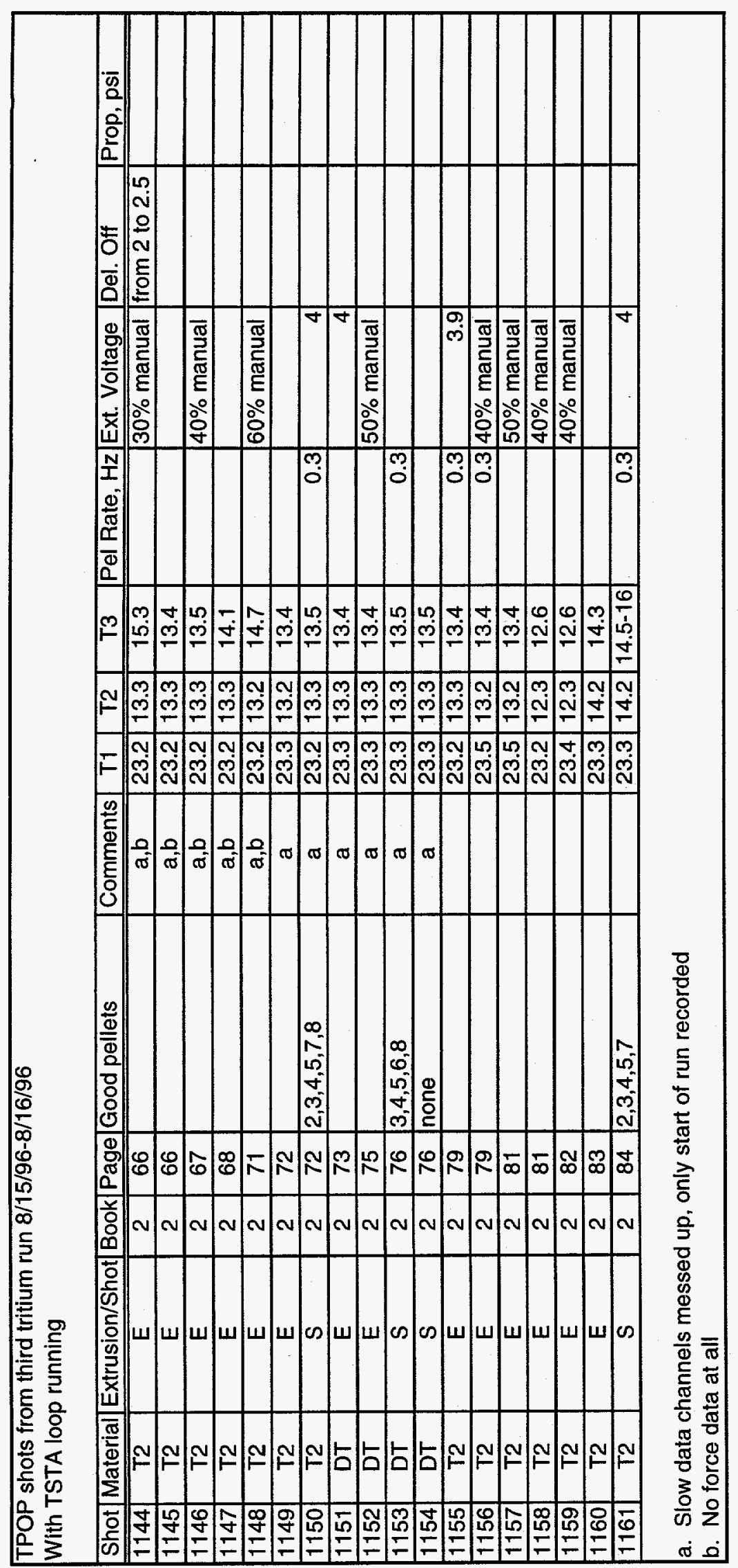




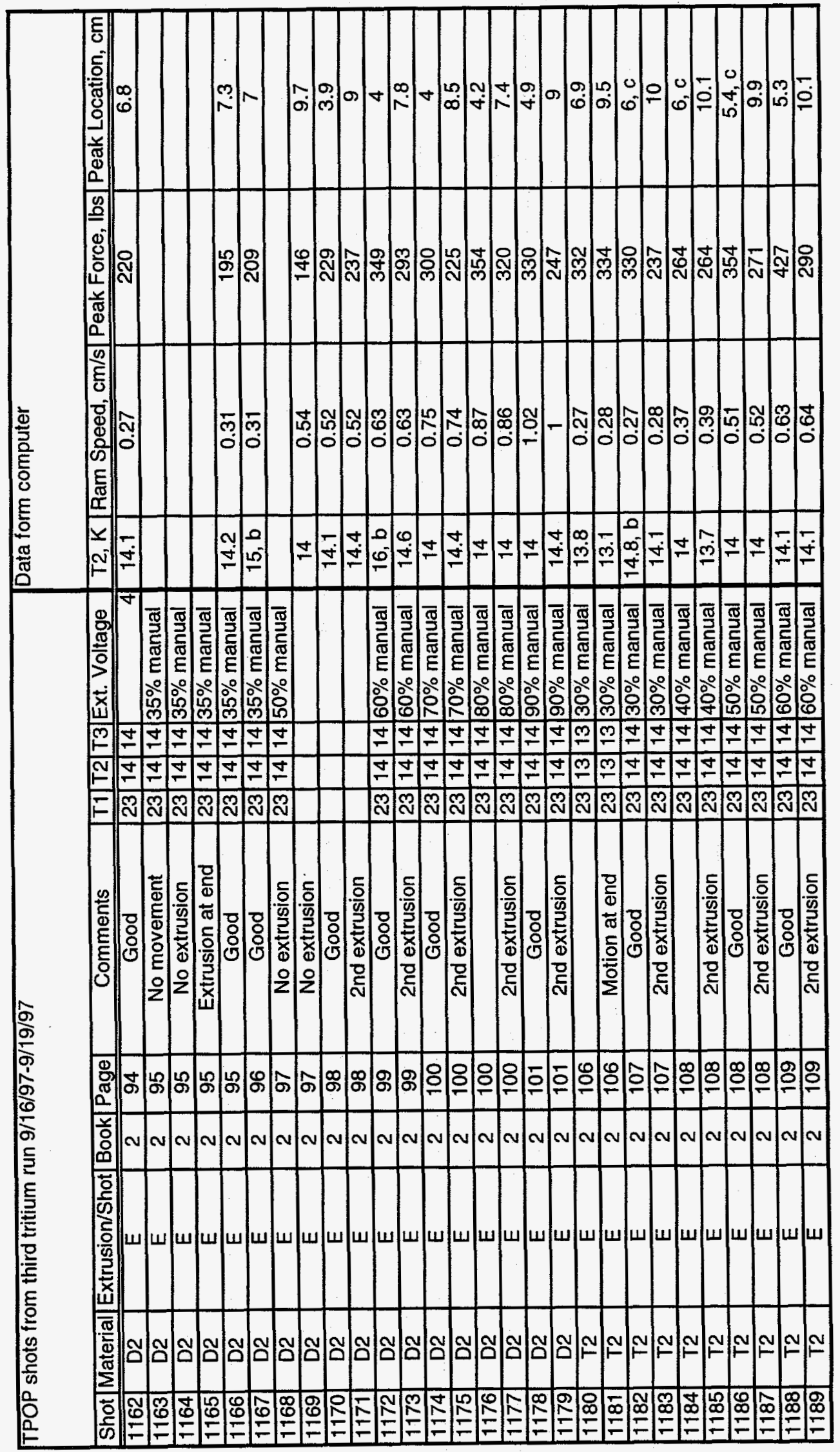




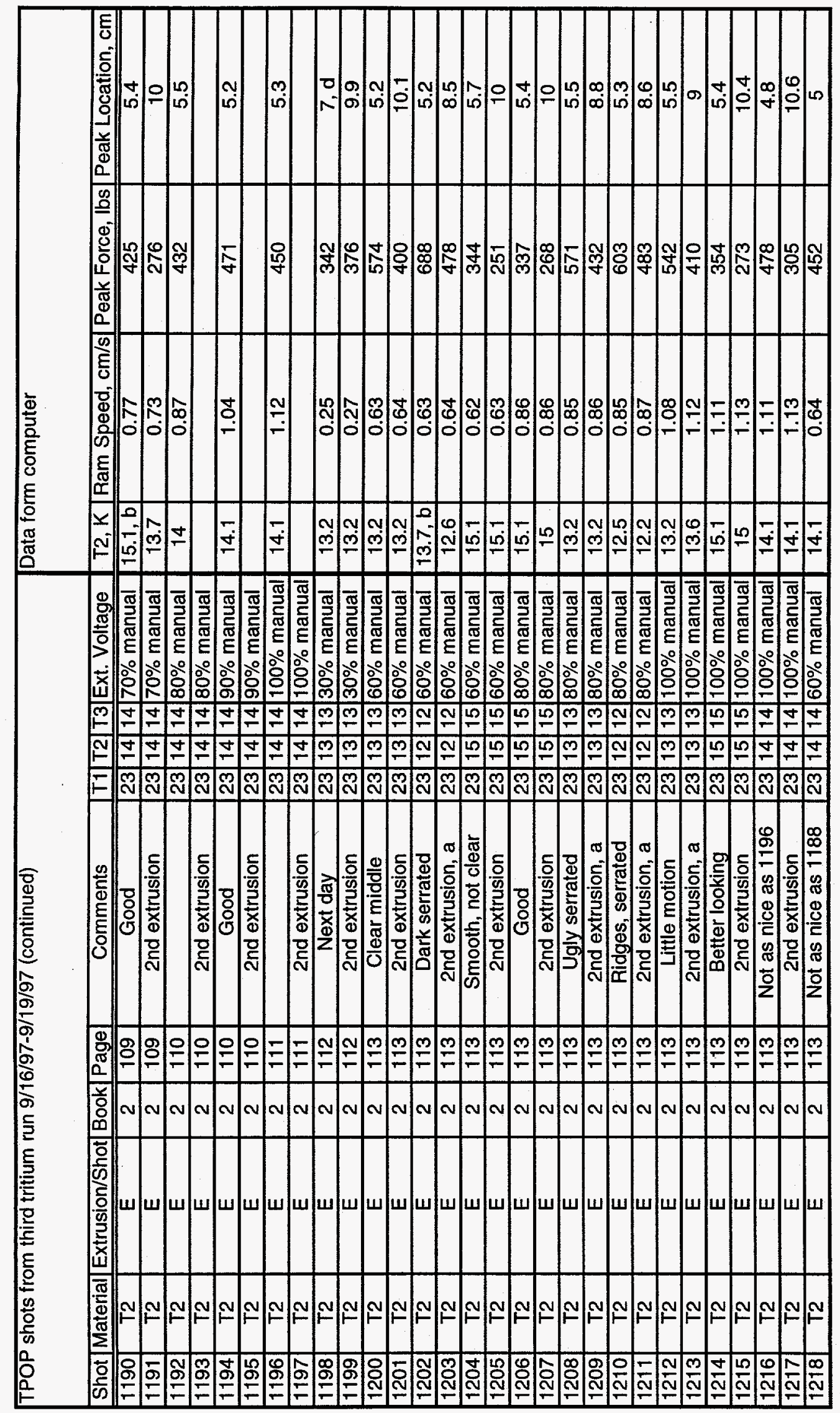




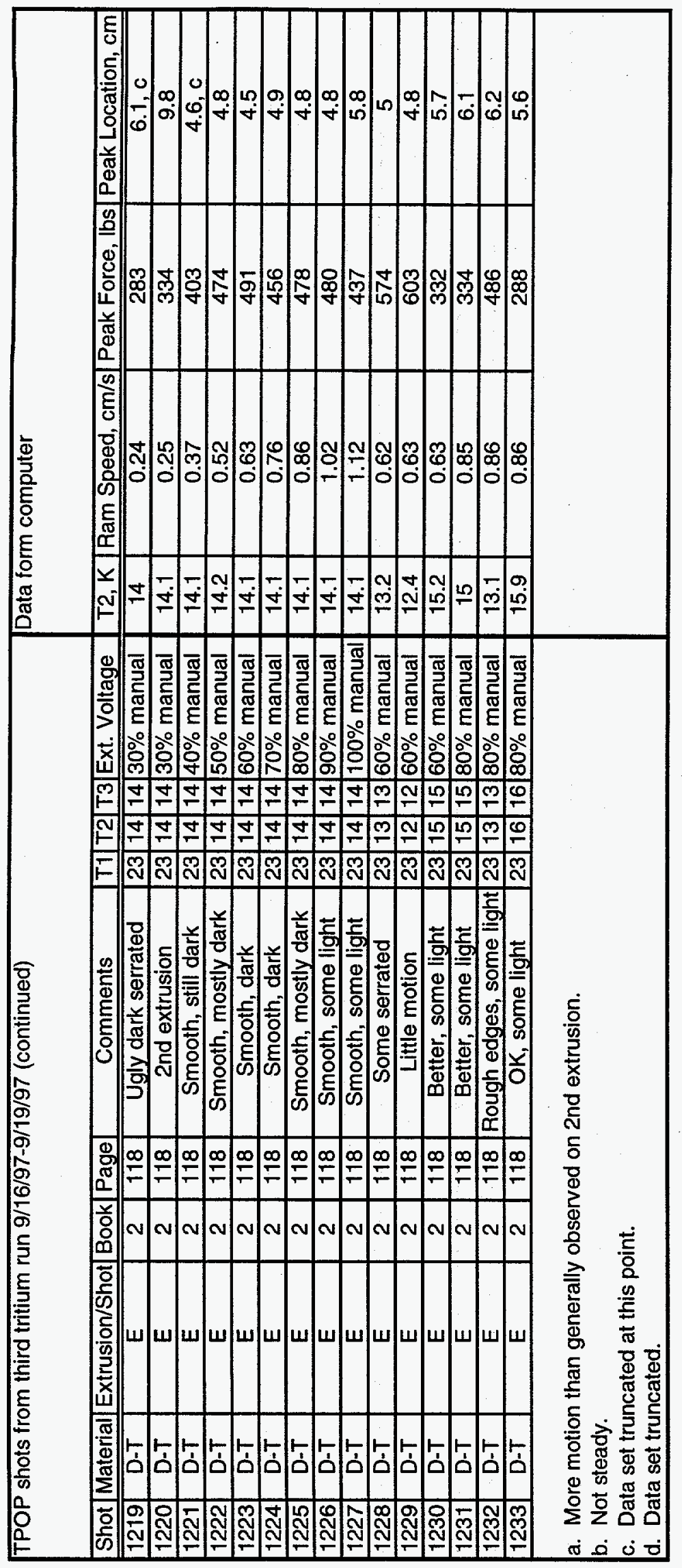

